UNIVERSIDADE DE SÃO PAULO

FACULDADE DE MEDICINA DE RIBEIRÃO DE PRETO

DEPARTAMENTO DE PUERICULTURA E PEDIATRIA

PRISCILA BEATRIZ DE SOUZA MEDEIROS

Avaliação de aterosclerose subclínica em pacientes com lúpus eritematoso sistêmico juvenil

Ribeirão Preto

2019 


\section{Avaliação de aterosclerose subclínica em pacientes com lúpus eritematoso sistêmico juvenil}

\section{Versão Corrigida}

A versão original encontra-se disponível tanto na Biblioteca e Documentação da Faculdade de Medicina de Ribeirão Preto da Universidade de São, quanto na Biblioteca Digital de Teses e Dissertações da USP (BDTD)

Dissertação apresentada à Faculdade
de Medicina de Ribeirão Preto da
Universidade de São Paulo,
Departamento de Puericultura e
Pediatria, para obtenção do título de
Mestre em Ciências.

Área de Concentração: Saúde da Criança e do Adolescente

Orientadora: Profa. Dra. Luciana Martins de Carvalho 
Autorizo a reprodução e divulgação total ou parcial deste trabalho, por qualquer meio convencional ou eletrônico, para fins de estudo e pesquisa, desde que citada a fonte.

Catalogação na publicação

Serviço de Biblioteca e Documentação

Faculdade de Medicina de Ribeirão Preto da Universidade de São Paulo

Medeiros, Priscila Beatriz de Souza

Avaliação de aterosclerose subclínica em pacientes com lúpus

eritematoso sistêmico juvenil. Ribeirão Preto, 2019

109p.: il; $30 \mathrm{~cm}$

Dissertação apresentada à Faculdade de Medicina de Ribeirão Preto/ USP. Área de Concentração: Saúde da Criança e do Adolescente

Versão corrigida

Orientadora: Carvalho, Luciana Martins Carvalho

Co-orientadora: Ferriani, Virgínia Paes Leme

1.Lúpus eritematoso sistêmico juvenil. 2.Risco cardiovascular.

3.Aterosclerose subclínica 4.Espessamento médio-intimal carotídeo

5.Dislipidemia 6.Fatores de risco cardiovascular não tradicionais 7.Dieta 
Nome: Medeiros, Priscila Beatriz de Souza

Título: Avaliação de aterosclerose subclínica em pacientes com lúpus eritematoso sistêmico juvenil

Dissertação apresentada à Faculdade de Medicina de Ribeirão Preto da Universidade de São Paulo para obtenção do título de Mestre em Ciências.

Aprovado em:

Banca Examinadora

Prof. Dr.

Instituição:

Julgamento:

Prof. Dr.

Instituição:

Julgamento:

Prof. Dr.

Instituição:

Julgamento

Prof. Dr.

Instituição:

Julgamento 
A minha família, aos admiráveis professores que tive ao longo da minha formação e em especial aos pacientes, que me lembram a cada dia os motivos de minha escolha profissional 


\section{Agradecimentos}

A minha orientadora Professora Doutora Luciana Martins de Carvalho meus sinceros agradecimentos pela oportunidade de trabalhar com pesquisa clíni ca, por sua disponibilidade e paciência sempre, desde o projeto até a versão final dessa dissertação. Agradeço por acreditar no meu potencial e me estimular a fazer sempre o meu melhor, a admiro muito. Aprendi com ela que mesmo vendo pacientes graves diariamente, tendo que se despedir de alguns ainda tão crianças, cada pequena vitória deve ser comemorada deixando seu dia mais leve para procurar novas formas de ajudá-los. Seu exemplo como pessoa e profissional me acompanharão por toda vida.

Agradeço a minha co-orientadora Professora Doutora Virgínia Paes Leme Ferriani, que conheci ainda criança, inicialmente só por nome, como a médica do "reumatismo" da minha amiga Cláudia, há 30 anos. Ela precisava tomar muitos remédios, pois o "sistema imune não gostava dela e comia suas juntas", fenômeno que muito tempo depois descobri se chamar autoimunidade e que acabou por nortear toda minha formação. Há 5 anos, seu nome ganhou um rosto, um sorriso de bom dia e a certeza de que é possível ser ética, ter rigor científico e mesmo assim ser gentil, olhar o paciente além da doença, enxergando detalhes escondidos que não são possíveis de se acessar, nem pelo mais detalhado exame físico, pois só se vêem com o coração. Descobri então, um exemplo da profissional que gostaria de ser um dia.

A toda equipe envolvida no projeto: Profa. Dra. Jaqueline, Priscila, Roberta, Dra. Sara, Profa. Dra. Rita, Diane e Luciana, meu muito obrigada! Sem a colaboração de vocês esse projeto não teria acontecido.

Agradeço à equipe de nutrição a Profa. Dra. Jaqueline, a Priscila, e especialmente a Roberta que me ajudou muito além da avaliação nutricional. Auxiliou-me em outros detalhes do projeto, orientou a ter sempre muitos "backups" e a manter as pastas do projeto no computador nomeadas e organizadas. Obrigada pela amizade e por ser a melhor consultora em nutrição infantil.

Agradeço à Dra Sara Reis Teixeira que conduziu a realização

das ultrassonografias do estudo e contribuiu com a elaboração do planeja mento e desenvolvimento do trabalho. 
Agradeço à Profa. Dra. Rita Tostes, por disponibilizar o laboratório de Aterosclerose da Farmacologia e à Diane por seu trabalho no processamento e armazenamento de amostras, além da realização das análises de citocinas e moléculas de adesão. Obrigada pelo apoio constante nesta trajetória.

Agradeço também à Luciana Roberti que auxiliou na compra de materiais, trabalhou na coleta e no transporte das amostras até o laboratório. Obrigada pelo suporte ao longo dos meses de coleta.

Obrigada ao Dr. Hugo e a Dra. Paola que me acolheram e muito me ensinaram desde o primeiro dia na Reumatologia Pediátrica, agradeço nossa equipe multidisciplinar à psicóloga Flávia, à fisioterapeuta Adriana e à assistente social Carmen pela boa convivência e pelos desafios enfrentados diariamente, juntos somos mais fortes.

Um agradecimento especial ao "ACREDITE", organização não governamental, que auxilia nossos pacientes com medicamentos e em demais necessidades, em especial à Dona Reuter (in memorian), que me ensinou a importância da caridade para o bem estar do outro e indiretamente do seu, e que a construção de um mundo melhor começa por pequenas atitudes em sua vida cotidiana.

Aos participantes da pesquisa e seus cuidadores, sou muito grata pela contribuição no desenvolvimento do trabalho.

Agradeço aos amigos que sempre estiveram presentes direta ou indiretamente em todos os momentos de minha formação me incentivando e torcendo por meu sucesso.

Por fim, dedico esse trabalho a minha família: minha mãe Sônia, meus irmãos Marco e Patrícia (que me deu colo, café, comida e acompanhou de perto toda essa jornada), minha tia Filomena, meus padrinhos Ruth e Marcos são alicerce forte, meu porto seguro, me dão suporte, garra e coragem para enfrentar todos os desafios.

Ao meu querido pai Marco (in memorian), onde quer que esteja, espero que tenha orgulho da pessoa que me tornei. 
"Se a educação sozinha não transforma a sociedade, Sem ela tampouco a sociedade muda"

Paulo Freire 


\title{
Avaliação de aterosclerose subclínica em pacientes com lúpus eritematoso sistêmico juvenil
}

\section{Assessment of subclinical atherosclerosis associated with pediatric systemic lupus erythematosus}

\author{
Aluno: Priscila Beatriz de Souza Medeiros \\ Orientadoras: \\ Orientadora principal: \\ Prof ${ }^{-}{ }^{-a}{ }^{\text {a }}$ Luciana Martins de Carvalho \\ Co- orientadora: \\ Prof ${ }^{a}$ Dr ${ }^{a}$ Virgínia Paes Leme Ferriani
}

Colaboradores:

Pediatria

Luciana Roberti

Nutrição

Prof $^{a}$ Drª Jacqueline Pontes Monteiro

Dr ${ }^{\text {a }}$ Roberta Garcia Salomão

Drª Priscila Giácomo Fassini

Radiologia

Drª Sara Reis Teixeira

Farmacologia

Prof ${ }^{-}$Dr ${ }^{\text {a }}$ Rita Tostes

Drª Diane Rassi

Ribeirão Preto

2019 


\section{RESUMO}

MEDEIROS, Priscila Beatriz de Souza. Avaliação de aterosclerose subclínica em pacientes com Lúpus Eritematoso Sistêmico Juvenil. 2019. 108 páginas. Dissertação (Mestrado no Programa de Saúde da Criança e do Adolescente) Faculdade de Medicina de Ribeirão Preto, Universidade de São Paulo, Ribeirão Preto, 2019.

O lúpus eritematoso sistêmico (LES) é uma doença crônica autoimune, multissistêmica, de causa desconhecida, que acomete adultos e crianças, sendo considerada um fator de risco independente para eventos cardiovasculares, em qualquer faixa etária, pela coexistência de fatores de risco tradicionais e não tradicionais para o desenvolvimento de doenças cardiovasculares (DCV). Objetivos: Realizar a medida da espessura das camadas íntima e média da artéria carótida (EMIc) para determinar a prevalência de aterosclerose subclínica (EMIc superior ao percentil 90 para sexo e idade) em pacientes com lúpus pediátrico. Avaliar a associação entre sexo, idade, raça, IMC (índice de massa corpórea), medicamentos em uso, dose acumulada de corticoide, fatores de risco tradicionais e não tradicionais para aterosclerose, exames laboratoriais, escores de atividade clínica de doença e dano cumulativo pelo LESJ com os parâmetros ultrassonográficos estudados nesses pacientes. Materiais e métodos: Foi realizado um estudo transversal com revisão de dados clínicos do prontuário, coleta de exames laboratoriais e avaliação clínica, nutricional e ultrassonográfica para determinar a espessura das camadas média e íntima (EMIc) das carótidas em pacientes com LES juvenil menores de 21 anos em seguimento no Ambulatório de Reumatologia Pediátrica do Hospital das Clínicas da Faculdade de Medicina de Ribeirão Preto (HC-FMRP-USP). O teste exato de Fischer avaliou a associação entre aterosclerose subclínica e as variáveis independente categóricas, o teste não paramétrico de Wilcoxon-Mann-Whitney comparou a distribuição das variáveis entre os pacientes com e sem aterosclerose subclínica, a análise de regressão simples e múltipla avaliou a associação das médias de EMIc as variáveis independentes e as razões de prevalência de aterosclerose subclínica estimadas para as variáveis de interesse foram ajustadas pelo modelo de regressão logbinomial simples e múltiplo. Resultados: Foram avaliados 28 pacientes com LES juvenil. $O$ coeficiente de prevalência pontual de aterosclerose subclínica foi de 32,14\% (IC 95\%: 14,8; 49,4). A média de idade foi de 13,9 \pm 3,0 anos; o tempo de doença 2,4 $\pm 2,12$ anos. A média do espessamento médio-intimal carotídeo (EMIc) foi $0,43 \pm 0,035 \mathrm{~mm}$. O SLEDAI-2K (Systemic Erythematosus Disease Activity Index) médio foi de 7,8 $\pm 6,06,25 \%$ tinham SLICC/ACR-DI (Cumulative Organ Damage index of The Systemic Lupus Erythematosus International Collaborating Clinics) de 1, proteína C reativa - ultrassensível elevada em $25 \%$, presença de nefrite em $75 \%$, envolvimento neuropsiquiátrico em $28,5 \%$, uso acumulado de corticoide de 0,48 $\pm 0,83 \mathrm{mg} / \mathrm{kg} / \mathrm{dia}$ e uso de imunossupressores em $60,7 \%$ dos pacientes. As variáveis hipertensão não controlada, relação entre proteína e creatinina maior que 0,2 , proteinúria nefrótica, taxa de filtração glomerular estimada abaixo de $75 \mathrm{ml} / \mathrm{min} / 1,73 \mathrm{~m}^{2}$ e SLEDAI-2K maior que 5 se associaram a aterosclerose subclínica. Apenas o SLEDAI-2K maior que 5 manteve associação com o EMlc após ajuste pelas variáveis de controle Conclusão: Fatores de risco tradicionais e não tradicionais se associam ao aumento do EMlc nesse grupo de 
pacientes com destaque ao SLEDAI-2K acima de 5 , indicador de doença com atividade clínica moderada a grave e ao acometimento renal.

Palavras chave: lúpus eritematoso sistêmico juvenil. risco cardiovascular. aterosclerose subclínica. espessura médio-intimal carotídea (EMIc). dislipidemia fatores de risco cardiovascular não tradicionais. dieta 


\section{ABSTRACT}

MEDEIROS, Priscila Beatriz de Souza. Assessment of Subclinical Atherosclerosis associated with Pediatric Systemic Lupus Erythematosus.2019.108pages.

Dissertation (Master's degree in the Child and Adolescent Health Program) Medical School of Ribeirão Preto, University of São Paulo, Ribeirão Preto, 2019.

Systemic lupus erythematosus (SLE) is a chronic autoimmune, multisystemic disease of unknown origin that affects adults and children and is considered an independent risk factor for cardiovascular events in any age group due to the coexistence of traditional and non-traditional risk factors for development of cardiovascular diseases (CVD). Objectives To measure carotid intima-media thickness (CIMT) to determinate the prevalence of subclinical atherosclerosis (CIMT above the $90^{\text {th }}$ percentile for sex and age) in patients with pediatric systemic lupus erythematosus. Check for association between sex, age, race, (body mass index) $\mathrm{BMI}$, medications in use, cumulative dose of corticoid, traditional and nontraditional risk factors for atherosclerosis, laboratory tests, clinical disease activity scores, and cumulative damage index with CIMT. Methods: Cross-sectional study with a chart review of clinical data and laboratory tests, clinical, nutritional and ultrasound evaluation to determine the thickness of the carotid and medial layers (IMT), and its associations, in pediatric patients with Juvenile SLE under 21 years old. Fisher,s exact test assessed the association between subclinical atherosclerosis and categorical independent variables, the Wilcoxon-Mann-Whitney nonparametric test compared the distribution of variables between patients with and without subclinical atherosclerosis, the simple and multiple regression analysis assessed the association of CIMT averages with independent variables and the prevalence ratios of subclinical atherosclerosis were estimated for the variables of interest adjusting by simple and multiple log-binomial regression model. Results: Twenty-eight patients with Juvenile SLE followed in Pediatric Rheumatology Outpatient Clinic hospital of the Ribeirão Preto Medical School - University of São Paulo, were enrolled. The prevalence of subclinical atherosclerosis was $32.14 \%(95 \% \mathrm{Cl}: 14.8,49.4)$. The mean age was $13.9 \pm 3.0$ years; SLE duration was $2.4 \pm 2.12$ years, the carotid intima-media thickness (CIMT) was $0.43 \pm 0.035 \mathrm{~mm}$. The mean SLEDAI-2K (Systemic Erythematosus Disease Activity Index) was $7.8 \pm 6.06,25 \%$ of de patients had scored 1 in SLICC / ACR damage index (Cumulative Organ Damage of the Systemic Lupus Erythematosus International Collaborating Clinics). C-reactive ultrasensitive protein was elevated in $25 \%$ of the patients. Nephritis and neuropsychiatric involvement were present in $75 \%$ and $28.5 \%$ of them respectively. Cumulative dose use of corticoid was $0.48 \pm 0.83 \mathrm{mg} / \mathrm{kg} /$ day and $60.7 \%$ used immunosuppressants. The variables uncontrolled hypertension, protein creatinine ratio above 0.2 , nephrotic proteinuria, estimated glomerular filtration rate below $75 \mathrm{ml} / \mathrm{min} / 1.73 \mathrm{~m}^{2}$ and SLEDAI-2K greater than 5 were associated with subclinical atherosclerosis. After control variables adjustment only SLEDAI-2K, greater than 5 , maintained association with CIMT. Conclusion: Traditional and nontraditional risk factors are associated with the increase in CIMT, with emphasis on SLEDAI-2K greater than 5, moderate to high disease activity, and renal impairment in our group of patients. 
Key words: juvenile systemic lupus erythematosus. cardiovascular risk. subclinical atherosclerosis. carotid intima-media thickness. CIMT. dyslipidemia. non-tradicional cardiovascular risk factor. diet. 


\section{LISTA DE SIGLAS}

AAS ácido acetil salicílico

ACO anticoncepcional

Afl anticorpo anti-fosfolípide

Anti-DNAn Anticorpo Anti-DNA nativo

AZA azatioprina

BIA bioimpedância

CFM Ciclofosfamida

CV cardiovascular

DCV doenças cardiovasculares

EMIc Espessamento/espessura médio-intimal da artéria carótida

FcyRIla/CD32 receptor Fc neutrófilico

HAS hipertensão arterial sistêmica

HCFMRP Hospital das Clinicas da Faculdade de Medicina de Ribeirão Preto

HDL lipoproteínas de alta densidade

Hoc homocisteína

ICAM-1 molécula de adesão intercelular

Ig imunoglobulina

IL-6 interleucina 6

IL-12 interleucina 12

IL-17 interleucina 17

IL-18 interleucina 18

IMC índice de massa corporal - IMC

INF-1 interferon do tipo I

IQD-R Índice de Qualidade da Dieta Revisado

IRAc índice de rigidez arterial da carótida

LDL lipoproteína de baixa densidade

LES lúpus eritematoso sistêmico

LESJ lúpus eritematoso sistêmico juvenil

MAC moléculas de adesão celular

Micof Micofenolato

NETs armadilhas neutrofílicas extracelulares

PAl-1 inibidor de ativação do plasminogênio do tipo 1 
PCR- US proteína $C$ reativa ultrassensível

PECAM-1 moléculas de adesão celular endotelial de plaquetas

Prot nef proteinúria nefrótica

Rel P/C relação proteína/ creatinina na urina

SAME Serviço de Arquivo Médico

SCORE- índice de avaliação sistemática do risco coronariano

SLEDAI- 2K Systemic Erythematosus Disease Activity Index Índice de atividade de doença

SLICC/ACR DI Cumulative Organ Damage index of The Systemic Lupus

Erythematosus International Collaborating Clinics

Índice de dano cumulativo de doença

T reg linfócito $T$ regulador

TGFe taxa de filtração glomerular estimada

Th1 linfócitoT helper 1 ,

TLRs receptores do tipo toll

TNF- $\alpha$ fator de necrose tumoral

Us ultrassonografia

VCAM-1 molécula de adesão celular vascular-1

VITB12- vitamina B 12 


\section{Sumário}

RESUMO

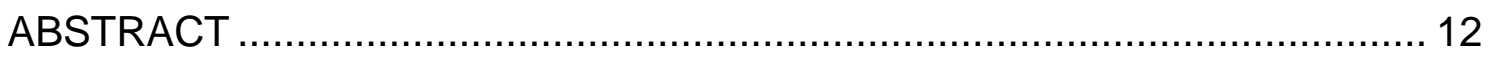

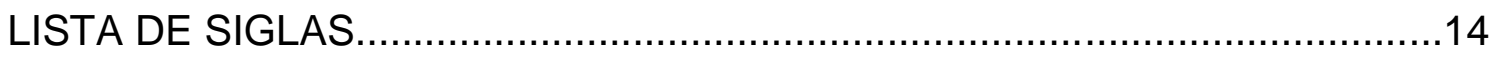

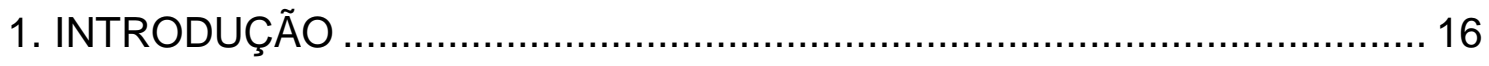

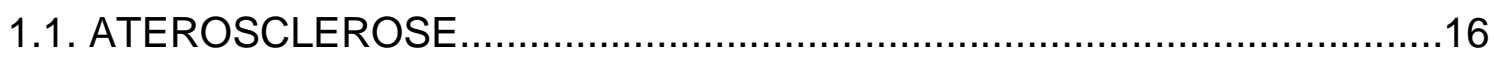

1.2.LUPUS ERITEMATOSO SISTEMICO E RISCO CARDIOVASCULAR.......17

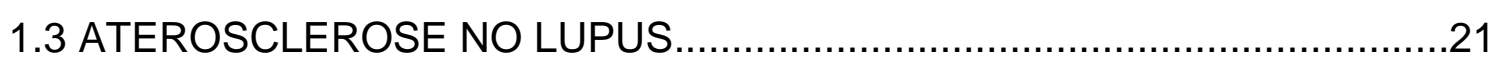

1.4. AVALIAÇÃO DE ATEROSCLEROSE SUBCLÍNICA.................................24

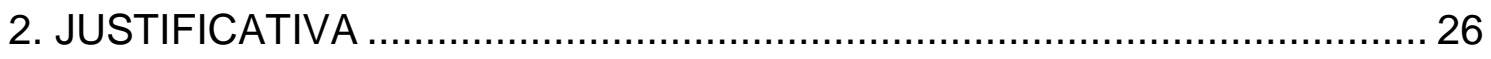

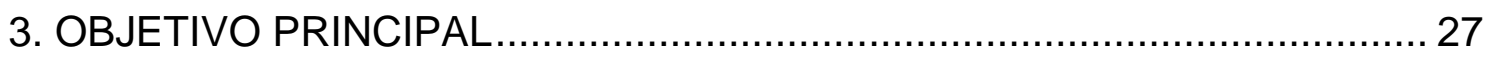

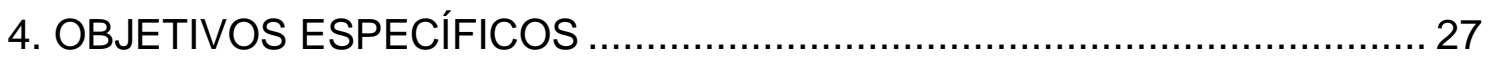

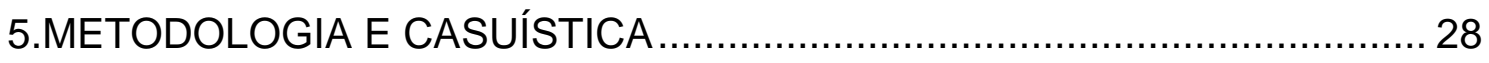

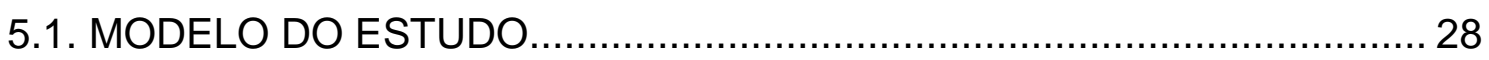

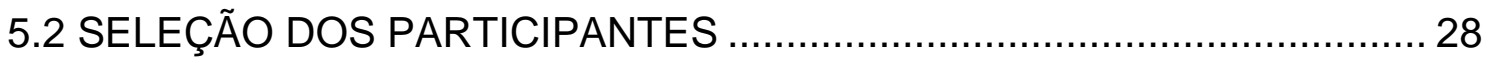

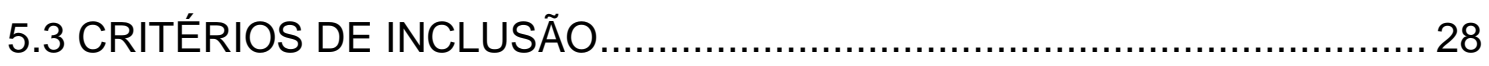

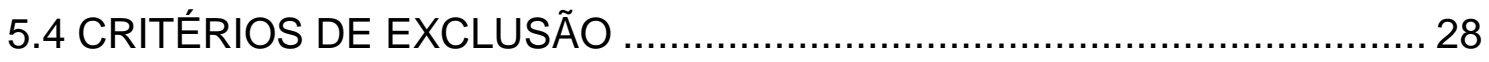

5.5 APROVAÇÃO DO COMITÊ DE ÉTICA E AUXÍLIO FINANCEIRO .............29

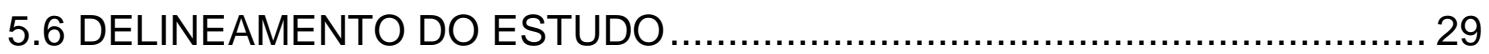

5.7 CONSENTIMENTO LIVRE E ESCLARECIDO .......................................... 31

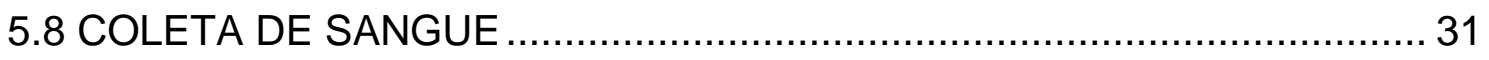

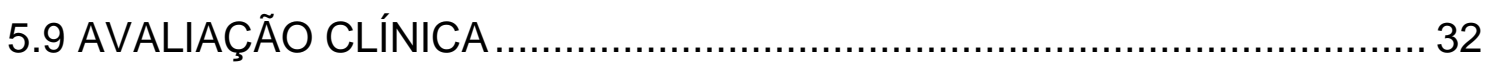

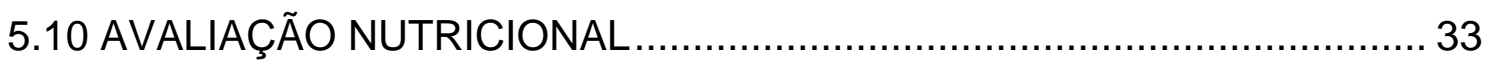

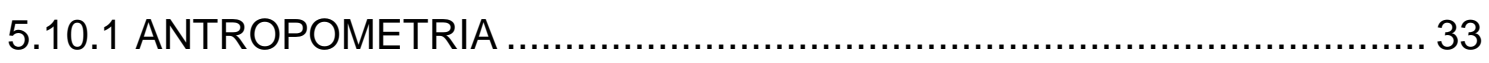

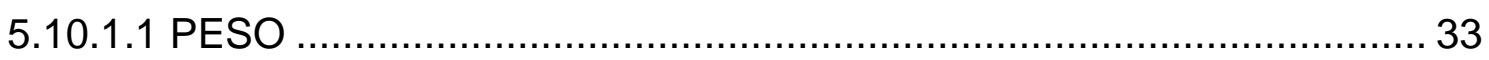

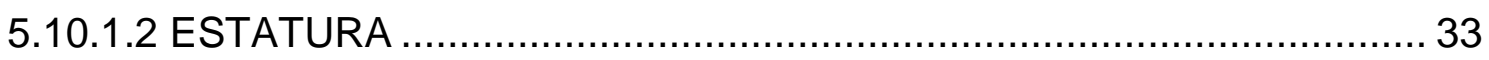

5.10.1.3 ÍNDICE DE MASSA CORPORAL (IMC) ……................................ 34

5.10.1.4 CIRCUNFERÊNCIA DA CINTURA (CC) ......................................... 34 
5.10.2 BIOIMPEDANCIA ELÉTRICA.

5.10.3 RECORDATÓRIO DE 24 HORAS (R-24hs) e ÍNDICE DE QUALIDADE

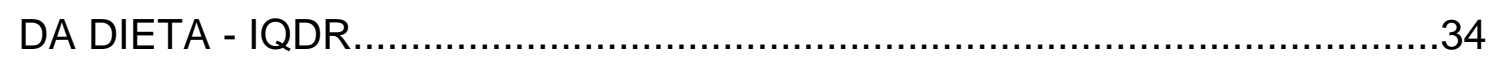

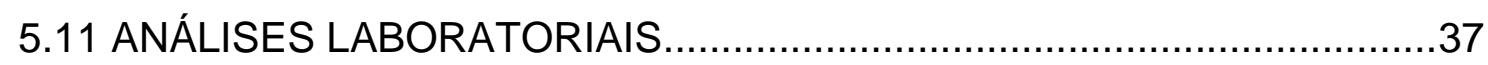

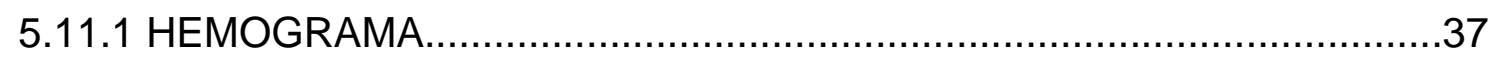

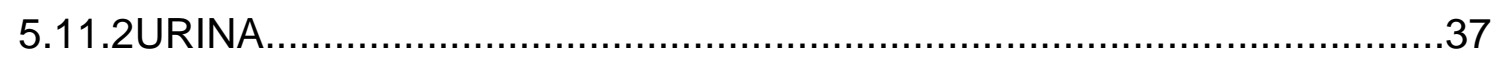

5.11.3 RELAÇÃO PROTEÍNA/ CREATININA NA URINA …...........................37

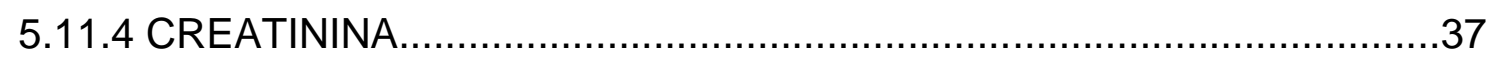

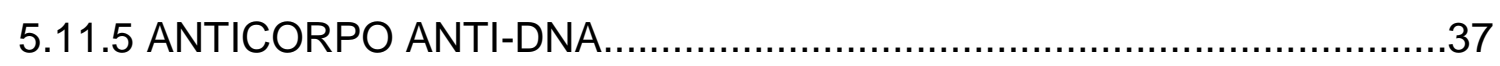

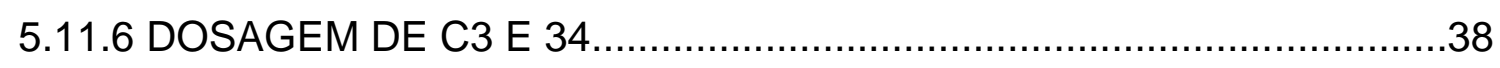

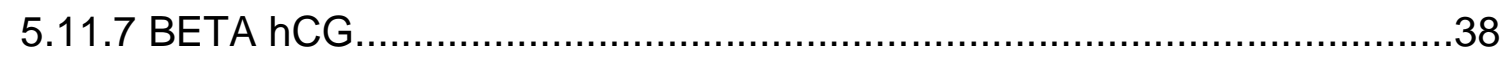

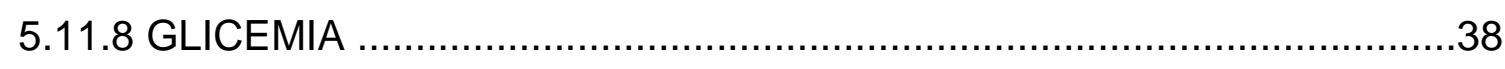

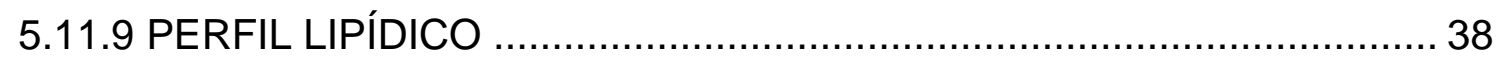

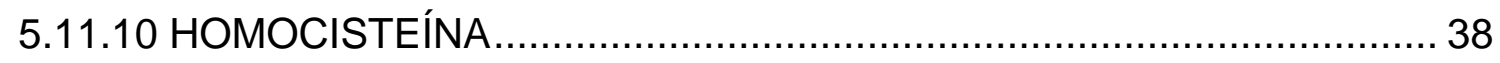

5.11.11DETERMINAÇÃO DE VITAMINA B12 E FOLATO.............................. 39

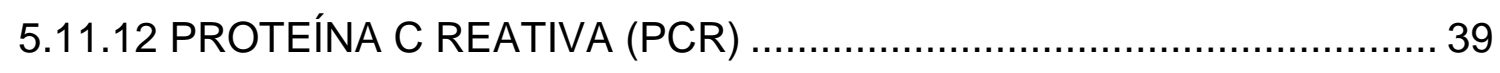

5.11.13 INTERLEUCINAS E MOLÉCULAS DE ADESÃO.................................39

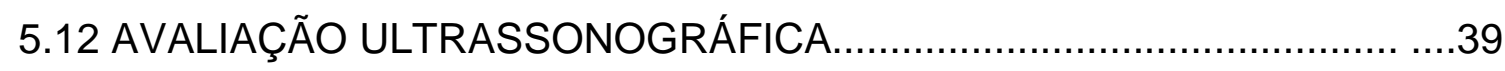

5.12.1 ESPESSAMENTO MÉDIO-INTIMAL CAROTÍDEO................................40

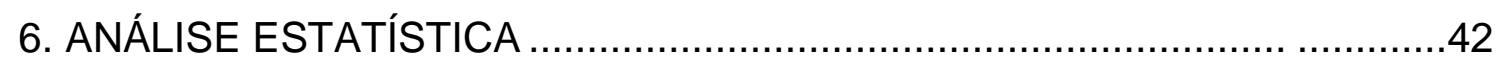

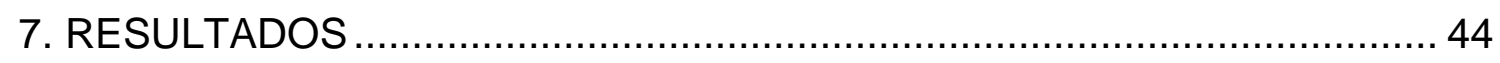

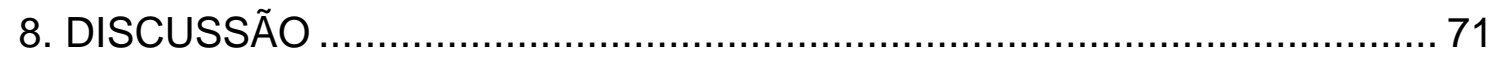

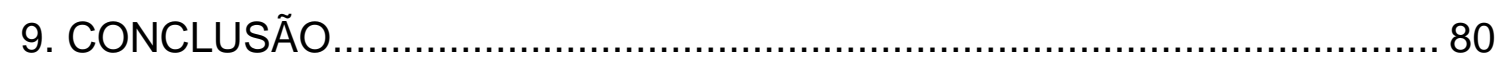

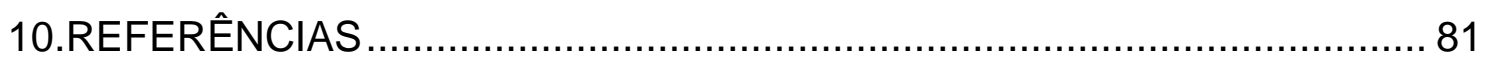

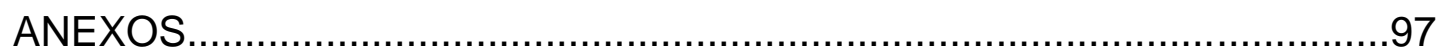




\section{Introdução}

\subsection{Aterosclerose}

Durante anos a aterosclerose foi considerada apenas um processo degenerativo resultante do depósito passivo de lipídeos na parede arterial, levando a sua oclusão e subsequentes eventos isquêmicos. Evidências acumuladas ao longo dos anos apoiam o envolvimento do sistema imune na geração da placa aterosclerótica e a relação entre doenças inflamatórias/autoimunes crônicas com o risco cardiovascular (Salmon e Roman, 2008; Gistera e Hansson, 2017).

Atualmente a aterosclerose é considerada uma doença inflamatória crônica de causa multifatorial que ocorre em resposta à agressão endotelial, principalmente na camada íntima das artérias de médio e grosso calibres (Ross, 1999). As lesões precoces, denominadas estrias gordurosas, iniciam-se já na infância e podem ser vistas na microscopia como acúmulo de colesterol em macrófagos. A lesão endotelial induz a formação da placa aterosclerótica pelo aumento da permeabilidade da íntima às lipoproteínas plasmáticas, que por sua vez, atingem o espaço subendotelial. Confinadas, as moléculas de lipoproteína de baixa densidade (LDL) sofrem oxidação, expondo diferentes neoepítopos e tornam-se imunogênicas. O acúmulo de lipoproteínas na parede arterial é proporcional à concentração destas no plasma. A LDL oxidada também expõe moléculas de adesão leucocitária na superfície do endotélio atraindo monócitos e linfócitos para dentro da parede arterial. Em resposta às quimiocinasas, os monócitos alcançam o espaço subendotelial, se diferenciam em macrófagos, e iniciam a captação das LDL oxidadas (células espumosas), sendo essas o principal componente das estrias gordurosas. Os macrófagos ativados secretam citocinas, que amplificam a inflamação, e também enzimas proteolíticas (metaloprotease) que degradam o colágeno e outros componentes teciduais, contribuindo para progressão da placa aterosclerótica e tornando-a mais susceptível a novas agressões. Subtipos de linfócitos $T$ de perfil pró-inflamatório, mesmo que em menor número na placa aterosclerótica, são de fundamental importância na aterogênese por atuarem na diferenciação dos macrófagos e reduzirem o tecido matricial por inibição da síntese de colágeno pelas 
células musculares lisas que migram para íntima vascular (Hansson, 2005; Libby, 2013; Ammirati et al., 2015; Quillard et al., 2015).

A placa aterosclerótica completamente desenvolvida é constituída por elementos celulares, matriz extracelular, núcleo lipídico e núcleo necrótico. São consideradas placas estáveis aquelas com maior quantidade de colágeno disposto em capa fibrosa espessa, com poucas células inflamatórias, e núcleo lipídico e necrótico pequenos. Já as instáveis têm grande atividade inflamatória, com marcada ação proteolítica, núcleo lipídico e necrótico maiores e capa fibrótica delgada (Libby e Theroux, 2005).

Os fatores de risco clássicos, como dislipidemia, diabetes, tabagismo e hipertensão arterial, entre outros, se relacionam a maior gravidade da aterosclerose atuando diretamente na célula endotelial. Microfilamentos liberados por neutrófilos, isquemia, alterações na pressão de arrasto hemodinâmico e cristais de colesterol também podem ativar a resposta inflamatória com consequente rotura da placa aterosclerótica ou erosão do endotélio (Ridker, 2016). A rotura e a erosão da capa fibrótica promovem a interação do fator tecidual da íntima vascular com fator VIla circulante, gerando trombina, ativando plaquetas e expondo, o material lipídico, altamente trombogênico, com consequente formação de um trombo local (aterotrombose), podendo levar ao infarto agudo do miocárdio e ao acidente vascular cerebral (AVC), principais complicações da aterosclerose (Coughlin, 2000; Mackman, 2008).

\subsection{Lúpus eritematoso sistêmico e risco cardiovascular:}

O lúpus eritematoso sistêmico (LES) é uma doença autoimune crônica caracterizada por inflamação generalizada de vasos e tecido conjuntivo. Afeta principalmente indivíduos do sexo feminino em idade reprodutiva, e, em cerca de $15 \%$ dos casos, o diagnóstico é feito antes dos 18 anos de idade (Silverman e Allison, 2010).

Nas últimas décadas, observa-se aumento na sobrevida dos pacientes com LES, decorrente principalmente do diagnóstico precoce e avanços no tratamento, predispondo esses pacientes a maior mortalidade por efeitos adversos a drogas e comorbidades. Doenças cardiovasculares (DCV) estão entre as principais causas de morbidade e mortalidade desse grupo de doenças. Mulheres com LES têm um risco 
até 50 vezes maior de doença cardiovascular prematura e de alterações na perfusão miocárdica (Ahmad e Bruce, 2004; Barsalou, Levy, et al., 2013; Knight e Kaplan, 2013).

Um estudo avaliou os óbitos que ocorreram em pacientes internados no Instituto da Criança da Faculdade de Medicina da USP por um período de 10 anos. Nesse período ocorreram 34 óbitos em pacientes com doenças reumáticas. Apesar das infecções, seguidas de sepse, estarem entre as principais causas de morte nesses pacientes, em três delas as DCVs foram fatores contribuintes ao óbito - dois por ateromas de aorta e um por infarto agudo do miocárdio. Um fato preocupante é que essas hipóteses diagnósticas não foram feitas em tempo hábil, sendo achados de necropsia (Facó et al., 2005).

$\mathrm{Na}$ população geral, os principais fatores de risco relacionados à DCV são o tabagismo, hipertensão, obesidade, dislipidemia, diabetes mellitus, sedentarismo e história prévia de doença cardiovascular. Em crianças, esses mesmos riscos são considerados, mesmo o tabagismo, visto que $80 \%$ dos adultos fumantes iniciam a prática de fumar antes dos 18 anos de idade (Rockville, 2010).

Estudos em autópsias de jovens mortos em acidentes mostram níveis relativamente avançados de aterosclerose, incluindo placas fibróticas em carótidas e coronárias (Mcgill et al., 1997; Berenson et al., 1998). Métodos não invasivos de detecção de aterosclerose precoce confirmam esses achados na infância e estão diretamente associados aos mesmos fatores de riscos estabelecidos para adultos (Urbina et al., 2009; Juonala et al., 2010).

Diante desses resultados, o tempo é fator imprescindível para que ocorram intervenções imediatas, tanto na prevenção do desenvolvimento de riscos (prevenção primária) quanto na modificação de fatores de riscos já estabelecidos (prevenção secubdária), mantendo crianças e adolescentes em baixo risco até a fase adulta (Lloyd-Jones et al., 2010; Daniels et al., 2011). O controle de fatores de risco até a idade de 50 anos está associado com risco muito baixo de DCV (LloydJones et al., 2006).

Curiosamente, no LES, a presença ou aumento desses fatores de risco tradicionais não se mostram suficientes para explicar o alto índice DCV nesses pacientes. Cadaval et al avaliaram os fatores de risco tradicionais, através do escore de risco de Framingham (figura 1), em mulheres lúpicas e não lúpicas (Wilson et al., 1998; Lloyd-Jones et al., 2010). Observaram que as pacientes com LES, mesmo 
com o escore de risco para infarto do miocárdio ou doença coronariana semelhante às mulheres sem diagnóstico de LES, apresentaram maior mortalidade por DCV. Concluindo, o escore de risco de Framingham não conseguiu estimar o risco aumentado de DCV nessas mulheres (Cadaval Ram, 2009). Estudos em adultos com LES mostram um valor preditivo positivo maior desse escore de risco quando associado ao aumento dos níveis da Proteína C reativa ultrassensível (PCR-US) (Nikpour et al., 2012).

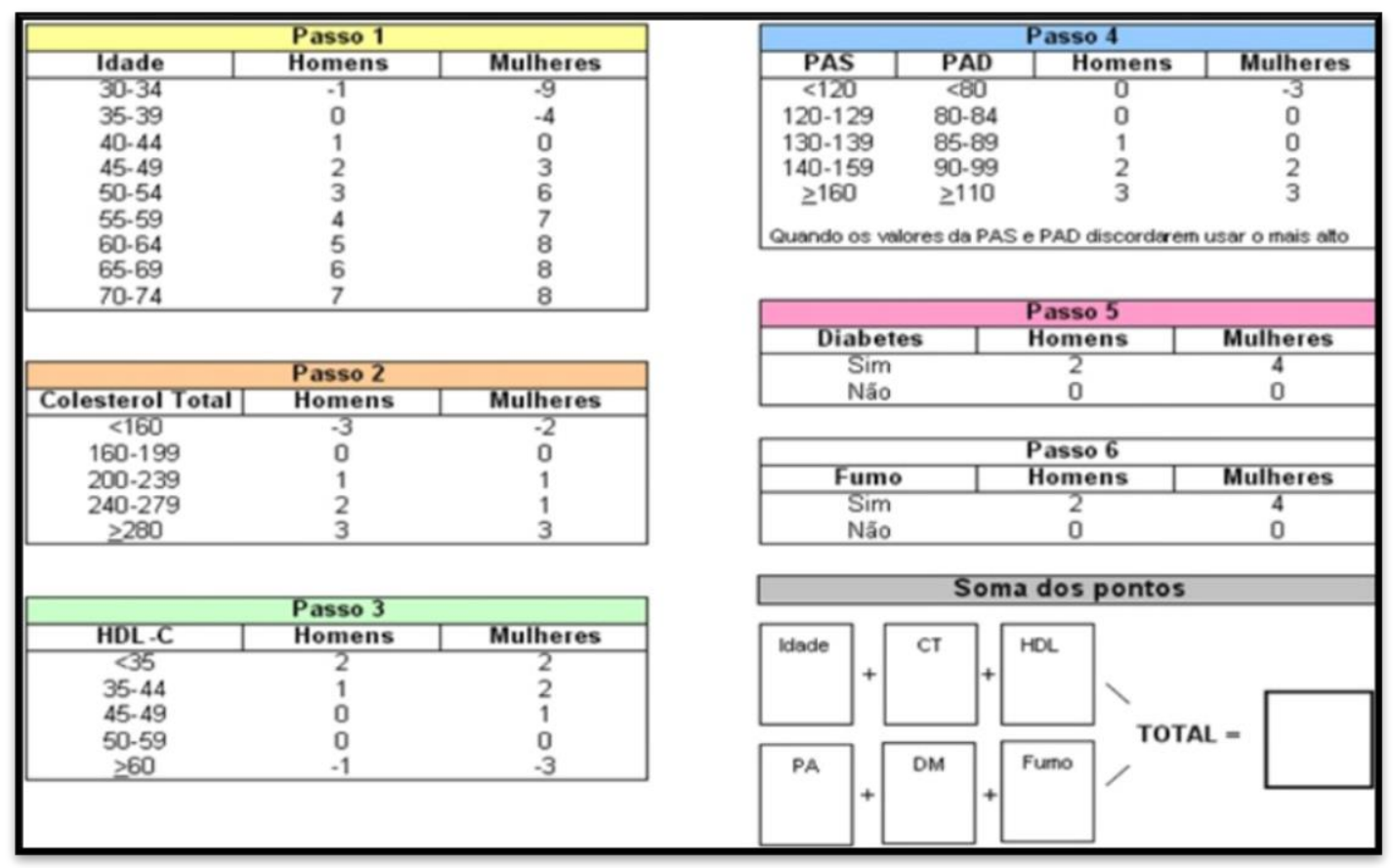

Figura 1: Escore de risco de Framingham. adaptado de Wilson et al., 1998(Wilson et al., 1998).

Dessa forma, outros fatores devem estar associados a maior morbidade e mortalidade por DCV nas doenças reumáticas crônicas. Atualmente sabe-que a causa de DCV nesses pacientes é multifatorial, envolvendo tanto os fatores de risco tradicionais, quanto os fatores relacionados à própria doença, como a inflamação, o dano endotelial mediado por imunocomplexos, a proteinúria nefrótica, os anticorpos antifosfolípides e os efeitos adversos do tratamento, entre outros (Falaschi et al., 2000). Fatores protetores para DCV associados a essas doenças como os antimaláricos, o micofenolato mofetil e controle adequado da atividade inflamatória são descritos e necessitam de mais estudos (Knight e Kaplan, 2013).

As crianças com lúpus apresentam forma mais agressiva da doença ao diagnóstico e desenvolvem sequelas mais precoces quando comparados aos adultos (Barsalou, Levy, et al., 2013). Sendo assim, é de extrema importância a 
identificação, ainda na infância, de alterações vasculares subclínicas com o objetivo de evitar complicações cardiovasculares futuras.

O desenvolvimento de novos biomarcadores de laboratório, a identificação de polimorfismos genéticos associados aos fatores de risco cardiovascular, além de novas técnicas de imagem, têm ajudado a melhorar o prognóstico de pacientes com LES (Manzi et al., 1999).

Em um estudo realizado em nosso serviço, foram avaliados 19 pacientes com lúpus eritematoso sistêmico juvenil (LESJ) entre os 10 e 18 anos e seu grupo controle (39 crianças e adolescentes atendidas em ambulatório de puericultura pareados por idade e índice de massa corporal - IMC). Houve diferença significativa dos níveis séricos de homocisteína, cianocobalamina, triglicérides, fator de necrose tumoral (TNF) alfa, proteína C reativa - PCR ultrassensível e das medidas de circunferência abdominal, todos maiores nos pacientes com LES e níveis séricos de folato menores nesses pacientes, fatores sabidamente associados ao aumento do risco de DCV . Para estudo proteômico, esses pacientes foram classificados em 3 grupos, lúpicos com perfil metabólico adequado, com perfil metabólico de risco alto (folato baixo, homocisteína, TNF alfa e PCR alta sensibilidade altos) e pacientes não lúpicos. Os pacientes de risco alto para DCV apresentavam diferença significativa na expressão de proteínas inflamatórias. O TNF alfa foi correlacionado positivamente com a dosagem de triglicérides nos pacientes e 0 colesterol total e triglicérides correlacionados com a dosagem de corticoide utilizado por eles. O PCR ultrassensível foi positivamente correlacionado com a duração da corticoterapia (Salomao et al., 2018). Esse estudo nos motivou a avaliar a repercussão clinica desses achados nos pacientes em acompanhamento.

Recentemente, Giannelou e colaboradores reafirmaram que fatores de risco tradicionais, como fumo, dislipidemia, diabetes, hipertensão, obesidade central e hiper-homocisteinemia influenciam, mas não explicam completamente, os altos índices de eventos isquêmicos no lúpus, outros fatores inerentes à doença colaboram com a elevação desses índices como tempo de doença, índices de atividade e cronicidade, fatores psicossociais, medicações, particularidades genéticas e mecanismos imunológicos (Giannelou e Mavragani, 2017). 


\subsection{Aterosclerose no lúpus}

Apesar do exato mecanismo da aterogênese no lúpus ainda não estar claramente definido, a principal causa parece ser um desequilíbrio entre a lesão endotelial, resultado de diversos fatores indutores, inerentes à doença ou não, e os mecanismos ateroprotetores. Os principais fatores que levam a ativação e apoptose das células endoteliais no LES são o maior depósito de LDL oxidado, a presença de autoanticorpos contra fosfolípides e células endoteliais, a maior expressão de citocinas, principalmente interferons do tipo I, e a presença de "armadilhas" extracelulares de neutrófilos - NETs (fibras de cromatina secretadas pelos neutrófilos para combater patógenos extracelulares) (Giannelou e Mavragani, 2017).

Entre as citocinas envolvidas na aterosclerose do lúpus, os interferons (INF) do tipo I (INF1) promovem a apoptose das células endoteliais, inibem a transcrição de vias pró-angiogênicas de interleucinas do tipo 1, estimulam o recrutamento de macrófagos para lesão aterosclerótica. aumentando a formação de células esponjosas, promovem a morte de células de músculo liso do vaso e colaboram para instabilidade da placa e ativação plaquetária (Niessner et al., 2006; Goossens et al., 2010; Lood et al., 2010; Thacker et al., 2010; Li et al., 2011)

O interferon-y é uma citocina pró-inflamatória que influencia na aterosclerose estimulando a produção de células esponjosas, desviando a resposta imune adaptativa para T helper 1 (Th1), colaborando na formação da placa aterosclerótica (Muhl e Pfeilschifter, 2003; Mclaren e Ramji, 2009).

O fator de necrose tumoral $\alpha$ (TNF $\alpha$ ) encontra-se elevado em pacientes com lúpus correlacionando com a gravidade do depósito de cálcio coronário (Rho et al., 2008), com triglicérides elevados e baixos níveis de lipoproteínas de alta densidade (HDL) (Svenungsson et al., 2003).

A interleucina 6 (IL- 6) participa do recrutamento de células inflamatórias e da homeostase lipídica. Está associada ao aumento da mortalidade cardiovascular na população geral (Lopez-Pedrera et al., 2010) e com aumento da aterosclerose no lúpus (Asanuma et al., 2006).

São relatados níveis elevados de interleucina 17 (IL-17) no soro de pacientes lúpicos. Produzida juntamente com o interferon- $\mathrm{Y}$ pelas células $\mathrm{T}$ infiltradas na parede da artéria coronária, essas citocinas atuam sinergicamente para induzir resposta pró-inflamatória nas células vasculares da musculatura lisa (Wong et al., 
2008; Eid et al., 2009). Apesar de estudos preliminares apontarem a IL-17 como citocina pró-inflamatória, ensaios em ratos mostram que a indução de sua produção diminui o infiltrado de células T e o desenvolvimento de aterosclerose (Taleb et al., 2009). Mais estudos são necessários para esclarecer o papel da IL-17 na modulação da aterogênese (Taleb et al., 2010).

As interleucina IL-12 e IL-18 são pró-aterogênicas e se relacionam com a resposta T helper -1 (Th1). A IL-12 é importante na diferenciação das células T em Th1 e T helper folicular e na ativação e função das T citotóxicas (Van Vollenhoven et al., 2018). A IL-18 se correlaciona positivamente com atividade de doença e gravidade da nefrite lúpica, tendo sua expressão aumentada na doença ativa (Mende et al., 2018).

Os linfócitos do tipo $B$ também participam do processo de aterosclerose e sua ação está correlacionada ao seu subtipo e a subclasse de anticorpos que produzem. Células B-1 produzem imunoglobulina M (Grobe et al.), enquanto linfócitos convencionais B-2 são a principal fonte de anticorpos do tipo G (Schanberg et al.; Lahoute et al., 2011). Anticorpos do tipo lgM parecem ser ateroprotetores (Zhu e Paul, 2010), enquanto os do tipo lgG têm propriedades pró-aterogênicas através da formação imunocomplexos com o LDL oxidado levando a ativação de macrófagos e outras células inflamatórias locais via receptores da porção cristalizável da imunoglobulina (receptores Fc) (Caligiuri et al., 2002).

Em relação aos linfócitos do tipo $\mathrm{T}$, o único subtipo claramente identificado como ateroprotetor são as células T reguladoras (Treg) (George, 2008). Estudos em ratos sugerem que o Treg leva a diminuição da aterosclerose e redução do acumulo de linfócitos T nas placas já existentes (Ait-Oufella et al., 2006).

Apesar de historicamente receberem pouca atenção na patogênese do lúpus, nos últimos anos os neutrófilos têm sido considerados células indispensáveis nos danos gerados pela doença (Knight e Kaplan, 2012). Armadilhas neutrofílicas extracelulares (NETs) são fibras de cromatina liberadas pelos neutrófilos com 0 objetivo de eliminar patógenos extracelulares. Recentemente, um subtipo de neutrófilos denominado granulócito de baixa densidade, caracterizado pela capacidade aumentada de produzir NETs, tem sido relacionado a patogênese da aterosclerose no lúpus, seja pela produção direta de lesão tecidual ou indiretamente pela ativação de vias de IFN I (Carmona-Rivera e Kaplan, 2013; Lewandowski e Kaplan, 2016; Mozzini et al., 2017). Células dendríticas CCL17 são derivadas da 
ação de citocinas e se acumulam no interior das lesões ateroscleróticas (Perrins e Bobryshev, 2011). A expressão de CCL17 pelas células dendríticas limita a expansão de Treg e predispõe a ateroesclerose, enquanto o anticorpo de bloqueio de CCL17 multiplica células Treg e reduz a progressão de aterosclerose em ratos (Weber et al., 2011).

Plaquetas ativadas têm um papel reconhecido na aterotrombose (Davi e Patrono, 2007) e como mediadoras de imunidade e inflamação, secretando citocinas e expressando em suas superfícies receptores como CD40 ligante, FcyRlla e TLRs (Vieira-De-Abreu et al., 2012). Pacientes com lúpus têm maior ativação plaquetária comparados a seus controles e, recentemente, a associação entre INF-1, plaquetas e lesão vascular tem sido sugerida (Nagahama et al., 2001; Tam et al., 2003). Uma assinatura própria de IFN tipo 1 e níveis elevados de proteínas cuja expressão é regulada por essa citocina têm sido descritos em transcriptossomos de plaquetas de pacientes lúpicos, principalmente nos pacientes com histórico de eventos vasculares. As plaquetas interferem na produção de INF-1 pela interação de interleucinas com seus receptores de membrana. Tanto a diminuição de plaquetas bem como sua inibição com clopidogrel podem controlar a nefrite e a atividade de doença em modelos murinos (Duffau et al., 2010).

As moléculas de adesão celular (MAC) endoteliais são proteínas transmembrana da superfamília de imunoglobulinas Essas moléculas têm sua expressão regulada positivamente por citocinas pro-inflamatórias como o TNF-alfa. As MACs são importantes para o sistema imune pois possibilitam a adesão celular, rolamento pelo endotélio e controlam a migração de leucócitos circulantes para os tecidos inflamados. Por meio da ação de quimiocinas e quimiotáticos as MACs endoteliais propiciam a interação entre leucócitos e endotélio e a transmigração desses, sendo marcadores de ativação e disfunção endotelial (Springer, 1994). Estudos anteriores mostraram níveis aumentados de MAC em pacientes com LES (Skeoch et al., 2014) associando-os a atividade de doença (Lewis et al., 2016) e tipos de manifestações clínicas no LES (Bertesias, 2012).

A ativação endotelial é um evento que precede a aterosclerose. $\mathrm{Na}$ população os níveis de MAC são preditores de eventos cardiovasculares e se associam a hipertensão (Hwang et al., 1997). No LES, onde doenças cardiovasculares são uma das principais causas de morte, um estudo de coorte prospectivo de 12 anos de seguimento, encontrou associação entre mortalidade por 
DVC e altos níveis da molécula de adesão celular vascular-1 (VCAM-1) (Gustafsson et al., 2012). A VCAM-1 elevada se associou também a atividade da nefrite lúpica, podendo ser um marcador útil para sua atividade além de suplementar marcadores indiretos de nefrite (Skeoch et al., 2014).

Um estudo brasileiro, realizado em Londrina, avaliou 126 pacientes lúpicos adultos e demonstrou maiores níveis de moléculas de adesão celular endotelial de plaquetas (PECAM-1), VCAM-1, E-selectina, P-selectina, e inibidor de ativação do plasminogênio do tipo 1(PAl-1) nesses pacientes quando comparados a controles saudáveis. Nesse estudo, o IMC se correlacionou positivamente com a E- selectina, bem como a síndrome metabólica, com os níveis de E-selectina e PAI-1, sugerindo que melhorar a saúde metabólica (modificando os componentes do IMC e da síndrome metabólica) pode ser importante no tratamento do LES em atividade. Os autores demonstraram também correlação positiva entre a idade e os níveis de VCAM-1 e P-selectina; entre os títulos de anticorpo antinuclear e PECAM-1, VCAM1, E-selectina e PAI-1; entre os níveis de PECAM-1 e a atividade do lúpus e correlação negativa entre o cortisol e PECAM-1 e ICAM-1. Dessa forma, os MAC são apontadas como possível alvo terapêutica no LES (Da Rosa Franchi Santos et al., 2018).

\subsection{Avaliação de aterosclerose subclínica}

$\mathrm{Na}$ tentativa de identificar a aterosclerose subclínica, inúmeros métodos de avaliação da estrutura arterial e da função endotelial têm sido estudados na população pediátrica: espessamento médio-intimal por ultrassom; calcificação coronária por tomografia; enrijecimento das paredes arteriais por ultrassom, ressonância, oscilômetro ou tonômetro; dilatação mediada por fluxo ou por vasodilatador com ultrassonografia (Urbina et al., 2009).

Para avaliação da estrutura arterial, o método ultrassonográfico de alta resolução tem sido o mais utilizado para determinar a medida da espessura das camadas íntima e média da artéria carótida (EMIc), por ser um método não invasivo, de alta acurácia e baixo custo. Estudos mostram que pacientes que apresentam diferença de $0,1 \mathrm{~mm}$ no EMlc tem um risco aumentado para infarto agudo do miocárdio em $10 \%$ a $15 \%$ e para acidente vascular cerebral em $13 \%$ a $18 \%$ (Bots e Sutton-Tyrrell, 2012; Peters et al., 2012). 
Existem na literatura poucos estudos transversais de EMlc em pacientes com lúpus eritematoso sistêmico juvenil (LESJ). A heterogenicidade e pequeno número da população estudada, somados a divergência dos protocolos de estudo vascular podem explicar os resultados controversos desses estudos (Falaschi et al., 2000; Bowser et al., 2008; Huang et al., 2009; Schanberg et al., 2009; Boros et al., 2011).

Alguns estudos demonstram que a média anual de progressão da EMlc em lúpus pediátrico é pequena (entre 0.0016 e $0.0024 \mathrm{~mm} / \mathrm{ano}$ ), similar a adolescentes caucasianos saudáveis (Jourdan et al., 2005; Huang et al., 2009). Por outro lado, em 2009, Schanberg et al. realizaram um estudo multicêntrico, envolvendo 21 cidades da América do Norte, no qual foi avaliada a medida das camadas média e íntima da artéria carótida de 221 pacientes lúpicos entre 10 e 21 anos. Esses dados foram correlacionados com os fatores de riscos tradicionais e os relacionados ao lúpus, e observado que ambos possuem associação com o aumento da espessura médiointimal da carótida. Entre os fatores de risco relacionados ao lúpus, tiveram associação significante o uso de azatioprina e corticoide. Apesar de ser um estudo envolvendo um grande número de pacientes, muitos foram excluídos da avaliação , como os pacientes com insuficiência renal e síndrome nefrótica, ou seja, pacientes com importantes características que podem estar correlacionadas com a incidência da aterosclerose (Schanberg et al., 2009).

$\mathrm{Na}$ população brasileira, poucos estudos avaliaram fatores de risco para aterosclerose e as alterações subclínicas da exposição precoce a esses fatores em pacientes com doenças reumáticas, principalmente na faixa etária pediátrica (Souza et al., 2005; Ceccon et al., 2013). Associação de biomarcadores específicos com a evolução para DCV deve ser melhor estabelecida, principalmente na nossa população, e tratamentos e estratégias preventivas para esses pacientes melhor avaliadas. Sendo assim, este estudo propõe a avaliação da espessura do complexo médio-intimal da artéria carótida, como medida de avaliação precoce de aterosclerose, em pacientes portadores de LESJ e sua associação com fatores de risco tradicionais e relacionados ao lúpus em pacientes com LESJ atendidos no ambulatório de reumatologia pediátrica do Hospital das Clinicas da Faculdade de Medicina de Ribeirão Preto (HC-FMRP) 


\section{Justificativa do Estudo}

Sendo o lúpus eritematoso sistêmico uma doença crônica, com alta taxa de morbimortalidade, em especial por doenças cardiovasculares, é de extrema importância o conhecimento e identificação da aterosclerose subclínica e dos fatores de risco para doença aterosclerótica em pacientes pediátricos brasileiros, com o objetivo de prevenção e tratamento precoces, propiciando melhor qualidade de vida aos pacientes. 


\section{Objetivo Principal}

Determinar a prevalência de aterosclerose subclínica em pacientes com LESJ atendidos no ambulatório de reumatologia pediátrica do Hospital das Clinicas da Faculdade de Medicina de Ribeirão Preto (HCFMRP), através da medida do espessamento médio-intimal da artéria carótida (EMIc).

\section{Objetivos específicos}

4.1. Avaliar a associação entre sexo, idade, raça e índice de massa corporal com o EMIc nos pacientes com LESJ.

4.2. Avaliar a associação de medicamentos em uso, inclusive dose acumulada de corticoide, fatores de risco tradicionais para aterosclerose e possíveis fatores de risco não tradicionais: homocisteína, vitamina B12, folato, TNF-alfa, IL1-1 alfa, IL-1 beta, IL10, INF- gama, IL- 17, IL-6) e moléculas de adesão (P- selectina, VCAM-1, ICAM-1), e PCR ultra sensível com a EMIc.

4.3. Avaliar a associação dos índices de atividade clínica de doença pelo SLEDAI-2K (Gladman et al., 2002) e cronicidade pelo SLICC/ACR DI (Gladman et al., 1996) com a EMlc. 


\section{Metodologia e casuística}

\subsection{Modelo de estudo}

Estudo clínico transversal, observacional e analítico.

\subsection{Seleção dos participantes}

Foram convidados a participar todos os pacientes com LESJ (Petri e Magder, 2004), em acompanhamento atual no ambulatório de reumatologia pediátrica do Hospital das Clínicas da Faculdade de Medicina de Ribeirão Preto (HCFMRP) com até 21 anos incompletos e diagnóstico realizado antes dos 18 anos de idade. Aceitaram participar 32 pacientes, e compareceram a avaliação 30 dos 43 pacientes elegíveis para o estudo. Foram inclusos 28 indivíduos.

\subsection{Critérios de Inclusão}

- Pacientes que cumpriram os critérios de classificação de lúpus eritematoso sistêmico juvenil (Petri e Magder, 2004), diagnosticado antes dos 18 anos

- Idade inferior a 21 anos

\subsubsection{Critérios de exclusão}

- Pacientes cujos responsáveis não autorizaram a realização do exame ultrassonográfico ou coleta de sangue

- Pacientes que não assentiram em participar do estudo

- Gestantes (realizado B-hCG para exclusão de gravidez nas pacientes que já apresentaram menarca)

- Processo infeccioso (febre não atribuível apenas à atividade de doença, com sinais e sintomas sugestivos de infecção na avaliação clínica e hemograma com evidências de infecção).

- Pacientes que faltaram à avaliação agendada 


\subsection{Aprovação do comitê de ética e auxílio financeiro}

Para realização do estudo, o termo de consentimento e o de assentimento foram aprovados pelo Comitê de Ética do Hospital das Clínicas de Ribeirão Preto, Universidade de São Paulo (USP), número do processo: 1.450.967/2016. O projeto teve auxílio financeiro para o seu desenvolvimento FAEPA/CNPQ UNIVERSAL.

\subsection{Delineamento do estudo}

Estudo clínico transversal, observacional e analítico no qual crianças e adoles centes com LESJ foram avaliados em uma única etapa, quanto aos aspectos clínicos, nutricionais, laboratoriais e ultrassonográficos, que serão pormenorizadas abaixo.

A ultrassonografia de carótida definiu quais indivíduos eram portadores de aterosclerose subclínica, objetivo principal do estudo, criando-se dois grupos para comparação: LESJ com aterosclerose subclínica e LESJ sem aterosclerose subclínica. Os grupos foram comparados quanto aos dados epidemiológicos, critérios diagnósticos para o LESJ, presença de comorbidades, medicamentos utilizados no momento, incluindo dose cumulativa de corticoide e ciclofosfamida, SLEDAI-2k, SLICC, antropometria e dados laboratoriais.

Inicialmente foram levantados junto ao Serviço de Arquivo Médico (SAME) do HCFMRP-USP os prontuários de todos pacientes abaixo de 21 anos com diagnóstico de lúpus totalizando 88 pacientes. Todos prontuários foram revisados para verificar:

- Se LESJ era realmente o diagnóstico principal e com início antes dos 18 anos

- Sendo o diagnóstico confirmado, se ainda estavam em seguimento atual no serviço e se eram acompanhados pela reumatologia pediátrica.

A figura 2 sintetiza o processo de definição do grupo de estudo. 


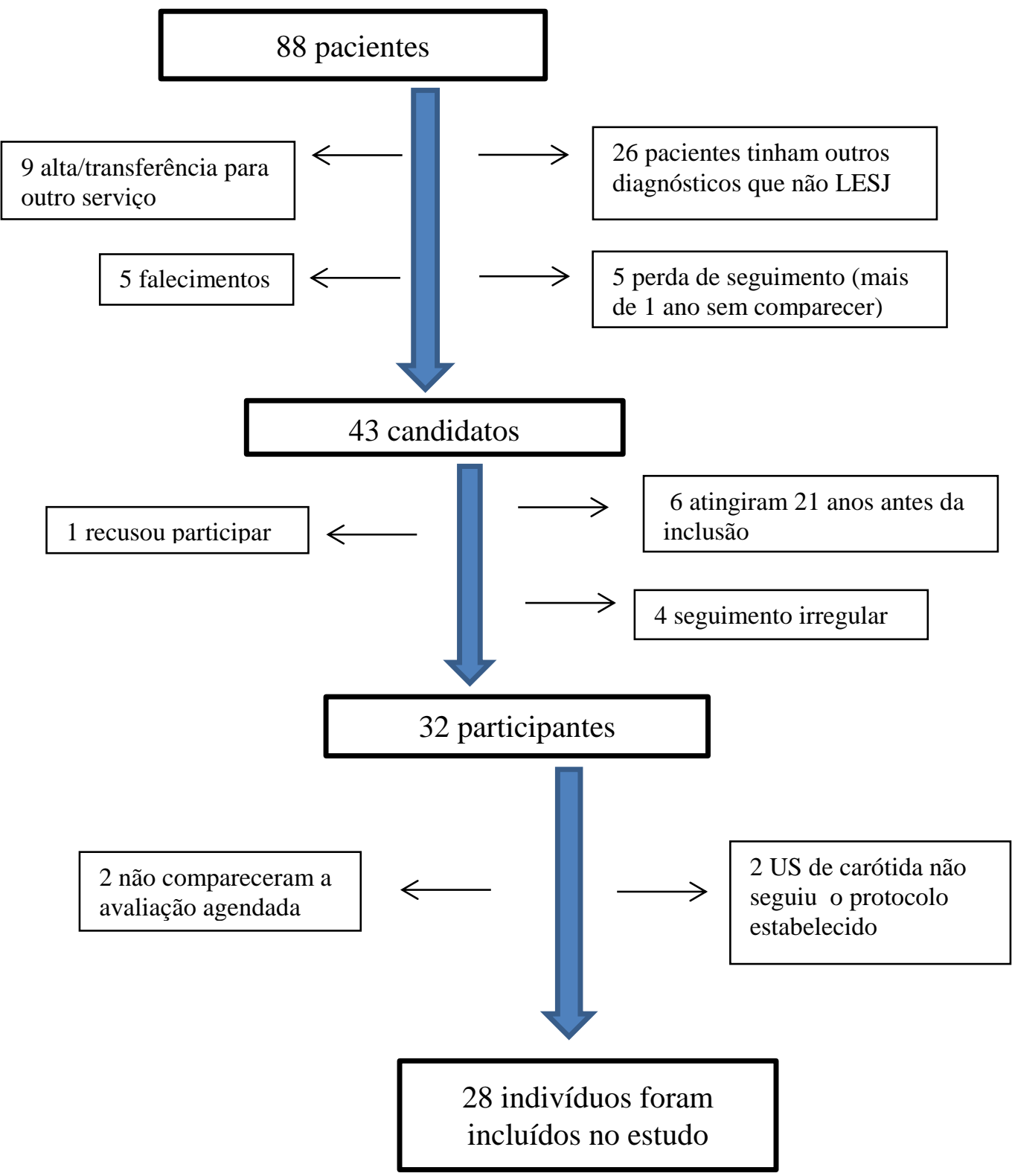

Figura 2: Fluxograma da seleção dos participantes do estudo.

LESJ: lúpus eritematoso sistêmico juvenil; US: ultrassonografia

Aqueles com o diagnóstico LESJ, em seguimento na Reumatologia Pediátrica, que se enquadravam nos critérios de inclusão do estudo, foram contatados e convidados a participar do estudo. Procuramos agendar a avaliação em data compatível com a consulta de seguimento bem como a coleta de sangue junto aos exames de rotina. Todos foram orientados a comparecer em jejum.

Após a assinatura do termo de consentimento e do de assentimento livre e esclarecido, foram coletados dados clínicos dos pacientes com LESJ nos prontuários médicos. 
Todos os participantes estavam de jejum de 12 horas para coleta de amostras de sangue. As amostras dos exames de rotina foram encaminhadas para os respectivos laboratórios para processamento. Parte das amostras foi encaminhada para o Laboratório de Aterosclerose da Farmacologia sendo processada e estocada para posterior dosagem de citocinas e moléculas de adesão pelo método de ELISA

Após a coleta de sangue, os participantes seguiram para a etapa de avaliação nutricional (recordatório de 24 horas, antropometria e bioimpedância) e avaliação clínica com exame físico, estadiamento puberal e aferição da pressão arterial. 0 protocolo utilizados na coleta de dados para LESJ e na avaliação clínica seguem em ANEXO 1.

Nesse mesmo dia, foi realizado o ultrassom de carótidas para avaliação da EMIc.

\subsection{Consentimento e assentimento livre esclarecido}

Inicialmente os participantes e seus responsáveis tomavam ciência de todas as etapas do projeto e, se fosse de comum acordo, ambos assinaram o termo de consentimento e assentimento livre e esclarecido (ANEXO 2 e 3).

\subsection{Coleta de Sangue}

Foram coletados 3 tubos de tampa roxa com K2EDTA de $4 \mathrm{~mL}$ para a extração de plasma e sobrenadante , estocados no Laboratório de Aterosclerose da Farmacologia para posterior realização de ELISA de citocinas (TNF-alfa, IL1-1 alfa, IL-1 beta, IL-10, INF- gama, IL- 17, IL-6) e moléculas de adesão ( $P$ - selectina, VCAM-1, ICAM-1); 1 tubo amarelo com gel de $3 \mathrm{~mL}$ para processamento do folato, vitamina B12 e $\beta$-hcg no Laboratório de Ginecologia e Obstetrícia do HCRP, e 1 tubo amarelo com gel de $3 \mathrm{~mL}$ para processamento da homocisteína no Laboratório de Nutrição do HCRP. A coleta de sangue foi realizada por profissional treinada, juntamente com a coleta dos exames da rotina de seguimento. Tal procedimento ofereceu risco mínimo (Categoria 2; 45 CFR 46.110) e é rotineiramente feito no Hospital das Clínicas da FMRP-USP. 


\subsection{Avaliação Clínica}

Os dados clínicos foram coletados através de revisão de prontuário (dados epidemiológicos, critérios diagnósticos para o LESJ, comorbidades associadas ao LES (atual ou prévia), medicamentos utilizados no momento) (ANEXO 1). A avaliação clínica foi realizada através dos índices de atividade da doença - SLEDAI 2-K (Systemic Lupus Erythematosus Disease Activity Index) (40) (ANEXO 4) e de danos cumulativos da doença - SLICC/ACR-DI (Systemic Lupus International Collaborating Clinics/American College of Rheumatology Damage Index) (41) (ANEXO 5) no dia da coleta de dados. Na ficha de atendimento foram avaliados os seguintes fatores de risco:

Fatores de risco tradicionais:

- Hipertensão

- Dislipidemia

- Obesidade

- Diabetes

- Tabagismo

- Uso de anticoncepcional

- Sexo masculino

- Sedentarismo

Fatores de risco não tradicionais e os associados ao lúpus:

- Tempo de doença

- Nefrite

- Envolvimento neurológico/ psiquiátrico

- Atividade de doença -SLEDAI

- Danos cumulativos - SLICC

- Uso de corticóide

- Uso de imunossupressores

- Homocisteina elevada

- Vitamina B12 baixa

- Folato baixo

- PCR elevado 
- Presença de anticorpo antifosfolípide

- Presença de anti-DNA nativo

O exame físico, o estadiamento puberal e a aferição da pressão arterial de todos os 28 pacientes, foram realizados pela mesma profissional (médica reumatologista pediátrica) devidamente treinada e anotados na ficha de acompanhamento dos pacientes (ANEXO1), no mesmo dia da coleta e da realização do ultrassom de carótidas.

\subsection{Avaliação Nutricional}

A avaliação nutricional, medidas antropométricas e história alimentar, foi realizada por uma nutricionista devidamente treinada.

\subsubsection{Antropometria}

O peso, a estatura e a circunferência da cintura foram aferidos após 12 horas de jejum, logo após a coleta de sangue.

\subsubsection{Peso}

Os pacientes foram pesados descalços, em balança eletrônica da marca Filizola ${ }^{\circledR}$, sendo descontados os gramas correspondentes às roupas padronizadas para pesagem do hospital. Antes da aferição do peso de cada paciente, a balança foi previamente tarada e sua precisão verificada por meio da pesagem de um peso padronizado, conforme técnicas descritas por Heymsfield, Tighe e Wang (1994) (Heymsfield et al., 1994)

\subsubsection{Estatura}

A estatura foi medida por meio de haste graduada fixada em superfície plana, tendo em sua extremidade um marcador adaptável ao alto da cabeça ou por meio de estadiômetro, conforme técnicas descritas por Heymsfield, Tighe e Wang (1994) (Heymsfield et al., 1994) 


\subsubsection{3 Índice de massa corpórea}

O índice de massa corporal (IMC) ou de Quetelet (peso, em kg/altura ${ }^{2}$, em m) foi calculado com os valores de peso e estatura. Para determinação do estado nutricional de acordo com o IMC, foi utilizada a distribuição em percentis $\left({ }^{\circ} \mathrm{P}\right)$ com os seguintes intervalos: $15^{\circ} \mathrm{P} \leq \mathrm{IMC}<85^{\circ} \mathrm{P}$ (eutrofia), $85^{\circ} \mathrm{P} \leq \mathrm{IMC}<97^{\circ} \mathrm{P}$ (sobrepeso) e IMC $\geq 97^{\circ} \mathrm{P}$ (Sociedade Brasileira De et al.). Utilizou-se como referência, as curvas preconizadas pela World Health Organization (2007) de acordo com idade e sexo.

\subsubsection{Circunferência da cintura}

A medida de circunferência da cintura foi realizada ao nível de uma linha horizontal imaginária em um ponto mediano entre a margem da última costela e a crista ilíaca. Se o participante era obeso, fato que dificulta o acesso dessa região, a medida foi realizada na linha da cicatriz umbilical (Fernandez et al., 2004).

\subsubsection{Bioimpedância elétrica}

O exame foi realizado por nutricionista experiente, seguindo as orientações da Associação Brasileira de Nutrologia para o procedimento (Avaliação da composição corporal por bioimpedanciometria - Associação Brasileira de Nutrologia, 2015).

\subsubsection{Recordatório alimentar de 24 horas (R-24hs) e índice de qualidade da dieta (IQD-R)}

Foi colhido um recordatório de 24 horas de cada paciente, no dia da coleta de dados. Para evitar sub e/ou super relato foi utilizado um álbum fotográfico contendo figuras com diferentes tamanhos de porções (pequeno, médio e grande) (Monteiro, 2007). Os R-24hs foram calculados por um software especialmente desenvolvido para analisar a ingestão dietética da população brasileira (Dietwin® versão 19972002) O programa tem valores nutricionais de tabelas brasileiras, de análises da composição de alimentos fornecida pelos fabricantes e, para alimentos não disponíveis no banco de dados, a tabela do USDA, 2003 (the United States Department of Agriculture) foi acrescentada no programa (Beaton et al., 1983). 
A inserção dos dados de ingestão de alimentos no computador foi efetuada duas vezes, para garantir a correta digitação. Antes da entrada dos dados, todas as informações foram revisadas para a identificação de possíveis erros na descrição dos alimentos ou preparações consumidas, bem como no tamanho e na quantidade das porções. Tais processos foram realizados por duas nutricionistas treinadas para utilizar o programa.

O Índice de Qualidade da Dieta Revisado (IQD-R) é um instrumento validado para população brasileira, é um indicador de qualidade da dieta que avalia o consumo alimentar e incorpora nas análises a correlação entre os alimentos e nutrientes, sendo desenvolvido e adaptado para as orientações nutricionais vigentes seguindo o Guia Alimentar Brasileiro de 2006. Para seu cálculo, foram utilizados 12 componentes: 9 grupos de alimentos (frutas totais; frutas integrais; vegetais totais; vegetais verdes escuros, alaranjados e leguminosas; cereais totais; cereais integrais; carnes, ovos e leguminosas) com porções diárias expressas em densidade energética; 2 nutrientes (óleos; gordura saturada) e Gord_AA (calorias provenientes de gordura sólida, álcool e açúcar de adição) (tabela 1). A programação para o cálculo do IQD-R foi desenvolvida no software Stata (versão 10.0) (Previdelli et al., 2011).

O IQD-R analisa vários componentes da dieta simultaneamente, com base na densidade energética, avaliando sua qualidade, independente da quantidade de alimentos consumida, reduzindo a um valor único, sendo possível medir e monitorar a adequação da dieta a recomendações nutricionais propostas para os diferentes estágios da vida, relaciona-lo a variáveis intermediárias ou desfechos de saúde (Hann et al., 2001)

Toffano et al validou o IQD-R para crianças e adolescentes brasileiros utilizando biomarcadores. Nesse estudo, uma "dieta ruim" foi definida por pontuação menor que 65, uma "boa dieta" por IQD-R maior ou igual a 85 e, duas categorias intermediarias, 65-74 e 75-84, as quais necessitam de adequação na dieta. A pontuação máxima do índice é 100 (Toffano et al., 2018).

O presente estudo utilizou a classificação de Toffano et al. 
Tabela 1: Distribuição da pontuação e das porções dos componentes do Índice de Qualidade da Dieta Revisado (adaptado de Previdelli et al, 2011)

\begin{tabular}{|c|c|c|c|c|c|}
\hline & & & \multicolumn{3}{|c|}{ Pontuação (pontos) } \\
\hline Componentes & 0 & 5 & 8 & 10 & 20 \\
\hline Frutas totais $^{a}$ & 0 & $\begin{array}{c}1,0 \\
\text { porção/1000kcal }\end{array}$ & & & \\
\hline Frutas integrais $^{b}$ & 0 & $\begin{array}{c}0,5 \\
\text { porção/1000kcal }\end{array}$ & & & \\
\hline Vegetais totais $^{c}$ & 0 & $\begin{array}{c}1,0 \\
\text { porção/1000kcal }\end{array}$ & & & \\
\hline Veveal $^{d}$ & 0 & $\begin{array}{c}0,5 \\
\text { porção/1000kcal }\end{array}$ & & & \\
\hline Cereais totais $^{e}$ & 0 & $\begin{array}{c}2,0 \\
\text { porção/1000kcal }\end{array}$ & & & \\
\hline Cereais integrais & 0 & $\begin{array}{c}1,0 \\
\text { porção/1000kcal }\end{array}$ & & & \\
\hline Leite e derivados $^{\dagger}$ & 0 & & & $\begin{array}{c}1,5 \\
\text { porção/1000kcal }\end{array}$ & \\
\hline $\begin{array}{l}\text { Carne, ovos e } \\
\text { leguminosas }\end{array}$ & 0 & & & $\begin{array}{c}1,0 \\
\text { porção/1000kcal }\end{array}$ & \\
\hline Óleos & 0 & & & $\begin{array}{c}0,5 \\
\text { porção/1000kcal }\end{array}$ & \\
\hline Gordura saturada & $\geq 15$ & & 10 & $\leq 7 \%$ do VET & \\
\hline Sódio & $\geq 2,0$ & & 1,0 & $\leq 0,75 \mathrm{~g} / 1000 \mathrm{kcal}$ & \\
\hline Gord_AA & $\geq 35$ & & & & $\begin{array}{c}\leq 10 \% \text { do } \\
\text { VET }\end{array}$ \\
\hline
\end{tabular}




\subsection{Análises Laboratoriais}

\subsubsection{Hemograma}

O hemograma foi realizado pelo método de contador automático de células, como rotina de seguimento dos pacientes lúpicos.

\subsubsection{Urina}

O exame de urina foi realizado pelo método de reflectância/ sedimentoscopia, como rotina de seguimento dos pacientes lúpicos.

\subsubsection{Relação proteína/ creatinina na urina}

A relação entre proteína e creatinina na urina foi realizado pelo método colorimétrico cinético, como rotina de seguimento dos pacientes lúpicos.

Foi considerado proteinúria se relação acima de 0,2 , proteinúria nefrótica se valor acima de 1 e proteinúria maciça se acima de 2 .

\subsubsection{Creatinina}

O exame de creatinina foi realizado pelo método de reação de jaffe como rotina de seguimento dos pacientes lúpicos.

A taxa de filtração glomerular estimada (TGFe), ou clearence de creatinina, foi calculada pela fórmula de Schawartz- TGFe $=0,55 \times$ altura $(\mathrm{cm}) /$ creatinina. Valores menores que $75 \mathrm{ml} / \mathrm{min} / 1,73 \mathrm{~m}^{2}$, no nosso estudo, foram considerados indicativos de insuficiência renal crônica

\subsubsection{Anticorpo Anti-DNA nativo (Anti-DNAn)}

O Anti- DNAn foi realizado pelo método imunofluorescencia indireta, como rotina de seguimento dos pacientes lúpicos, com kit NOVA lite® ds DNA da Inova diagnostics. 


\subsubsection{Dosagem de complemento C3 e C4}

A dosagem de C3 e C4 foi realizado pelo método de nefelometria como rotina de seguimento dos pacientes lúpicos.

\subsubsection{Beta hCG}

$\mathrm{O} \beta$ hCG foi realizado pelo método quimiluminescência, nas meninas menacmes.

\subsubsection{Glicemia}

21A glicemia de jejum foi realizada pelo método enzimático, como rotina de seguimento dos pacientes lúpicos. Os valores de referencia são: normais $<100$ $\mathrm{mg} / \mathrm{dl}$, pré diabetes 100-125 mg/dl, diabetes se >126 (American Diabetes, 2019).

\subsubsection{Perfil Lipídico}

A I Diretriz de prevenção da aterosclerose na infância e adolescência preconizada pela Sociedade Brasileira de Cardiologia desde 2005 foi utilizada para definir perfis lipídicos anormais nas crianças e adolescentes participantes do estudo. Para diagnóstico de dislipidemias, foi considerado valor de lipoproteína de alta densidade $(\mathrm{HDL})<45 \mathrm{mg} / \mathrm{dl}$. Hipercolesterolemia foi definida com níveis de colesterol de jejum $>170 \mathrm{mg} / \mathrm{dl}$ e para lipoproteína de baixa densidade, níveis $\geq 130 \mathrm{mg} / \mathrm{dl}$ foram considerados elevados. Hipertrigliceridemia foi considerada quando os valores forem $\geq 130 \mathrm{mg} / \mathrm{dl}$. Hiperlipidemia foi definida quando o triglicéride sérico $\geq 130 \mathrm{mg} / \mathrm{dl}$ e/ou colesterol sérico $>170 \mathrm{mg} / \mathrm{dl}$ (Sociedade Brasileira De et al., 2005).

O perfil lipídico foi realizado pelo método enzimático, como rotina de seguimento dos pacientes lúpicos, após jejum de 12 horas.

\subsubsection{Homocisteína}

Os níveis plasmáticos de homocisteína foram avaliados com IMMULITE ${ }^{\circledR}$ 1000 em imunoensaio competitivo, usando reagentes e anticorpos. Valores $<12 \mathrm{mmol} / \mathrm{L}$ foram adotados como referência para níveis de homocisteína . 


\subsubsection{Determinação de vitamina B12 e Folato}

As dosagens de vitamina B12 e folato em amostras de soro de sangue de jejum foram determinadas usando a técnica de imunoensaio do IMMULITE® 1000 $(52,53)$.

Para vitamina B12 foi adotado o intervalo de $128 \mathrm{pmol} / \mathrm{L}$ a 648pmol/L de acordo com o manual do fabricante. Para folato foi adotado o intervalo de $3 \mathrm{ng} / \mathrm{mL}$ a $17 \mathrm{ng} / \mathrm{mL}$ de acordo com o manual do fabricante.

\subsubsection{Proteína C reativa ultrassensível (PCR)}

A PCR do soro dos participantes do estudo foi dosada com um kit de elevada sensibilidade em ensaio quantitativo, imunométrico quimioluminescente em fases sólida e líquida, no analisador IMMULITE 1000. Valores inferiores a 3mg/L foram adotados como referência, conforme manual do fabricante.

\subsubsection{Determinação de interleucinas e moléculas de adesão}

As amostras coletadas de cada paciente, para dosagem de interleucinas e moléculas de adesão, foram transportadas imediatamente após coleta em caixa térmica para o Laboratório de Farmacologia Cardiovascular da FMRP. Após extração de plasma e sobrenadante, as amostras identificadas foram mantidas no freezer à temperatura de -80 graus celsius até realização dos testes enzimáticos.. $A$ dosagem de citocinas (TNF-alfa, IL1-1 alfa, IL-1 beta, IL-10, INF- gama, IL- 17, IL-6) e moléculas de adesão ( $P$ - selectina, VCAM-1, ICAM-1) foi realizada por Elisa utilizando kit comercial da Human R\&D System®.

\subsection{Avaliação Ultrassonográfica}

A preparação do paciente seguiu recomendações internacionais (Laurent et al., 2006; Urbina et al., 2009; Thijssen et al., 2011).

Os exames de ultrassonografia foram realizados pela manhã entre 07:30h e 09:00h após descanso do paciente em uma posição confortável, deitado por cerca de 15 minutos, em sala com temperatura controlada a cerca de $23^{\circ} \mathrm{C}$, em ambiente calmo e em silêncio. Os pacientes foram avaliados em jejum e com restrição de exercícios físicos extenuantes, ingesta de álcool, cafeína ou suplementos 
alimentares 12 horas antes do exame. Todos os exames foram realizadas em aparelho Logic E9 (CGE corporate) com transdutores lineares de alta frequência (ML6-15 MHz).

\subsubsection{Espessura médio-intimal das carótidas}

A avaliação da espessura médio-intimal carotídea (EMIc) seguiu as recomendações internacionais para pesquisa de aterosclerose subclínica em crianças e adolescentes (Urbina et al., 2009). O pescoço foi discretamente estendido com a cabeça voltada cerca de 45 para o lado oposto ao examinador. As artérias carótidas comuns direita e esquerda foram visibilizadas em um plano longitudinal perpendicular ao plano de insonação para melhor identificação da camada médiointimal distal. A espessura médio-intimal foi medida automaticamente com software disponível no aparelho de ultrassonografia

Auto-IMT ((CGE corporate) a $10 \mathrm{~mm}$ abaixo da bifurcação carotídea (figura 3).

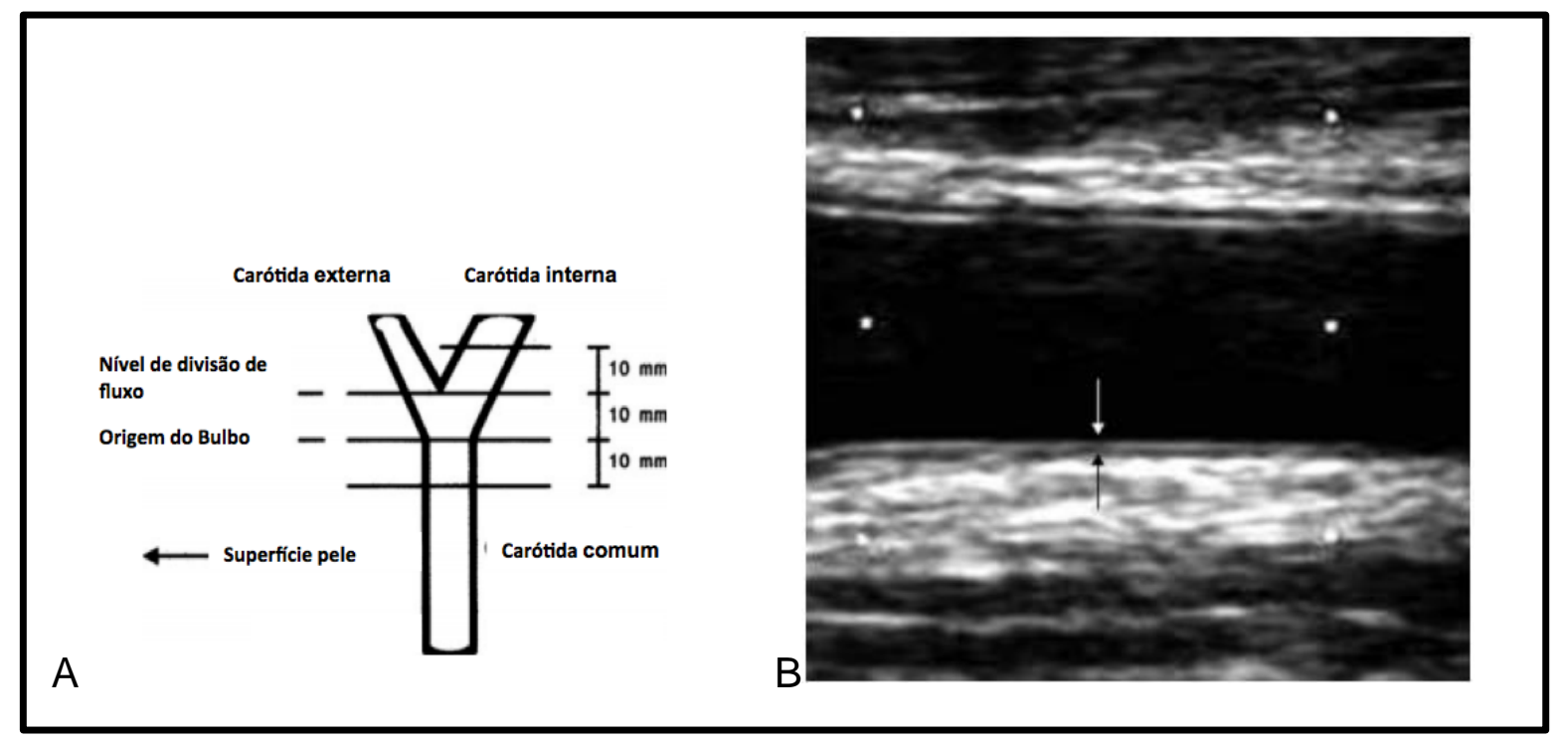

Figura 3: Representação esquemática da artéria carótida e seus níveis; B. Entre as setas é visualizada a camada médio-intimal em imagem de ultrassonografia (Urbina et al, 2009).

A média de três medidas foi utilizada para compor os dados. Foram disponibilizados os dados da média da espessura médio-intimal e média da espessura máxima médio-intimal da carótida direita e carótida esquerda. Uma média geral das medidas das duas carótidas também foi obtida para análise dos 
resultados. Os valores de normalidade utilizados foram baseados em estudo populacional para crianças, menores de 18 anos (figura 3) (Doyon et al., 2013; Dalla Pozza et al., 2016), e para os adolescentes entre 18 e 21 anos (tabela 2) (Denarie et al., 2000; Jourdan et al., 2005), um espessamento médio-intimal carotídeo superior ao percentil 90 foi considerado como alto e sugestivo de aterosclerose subclínica (Magnussen et al., 2009).

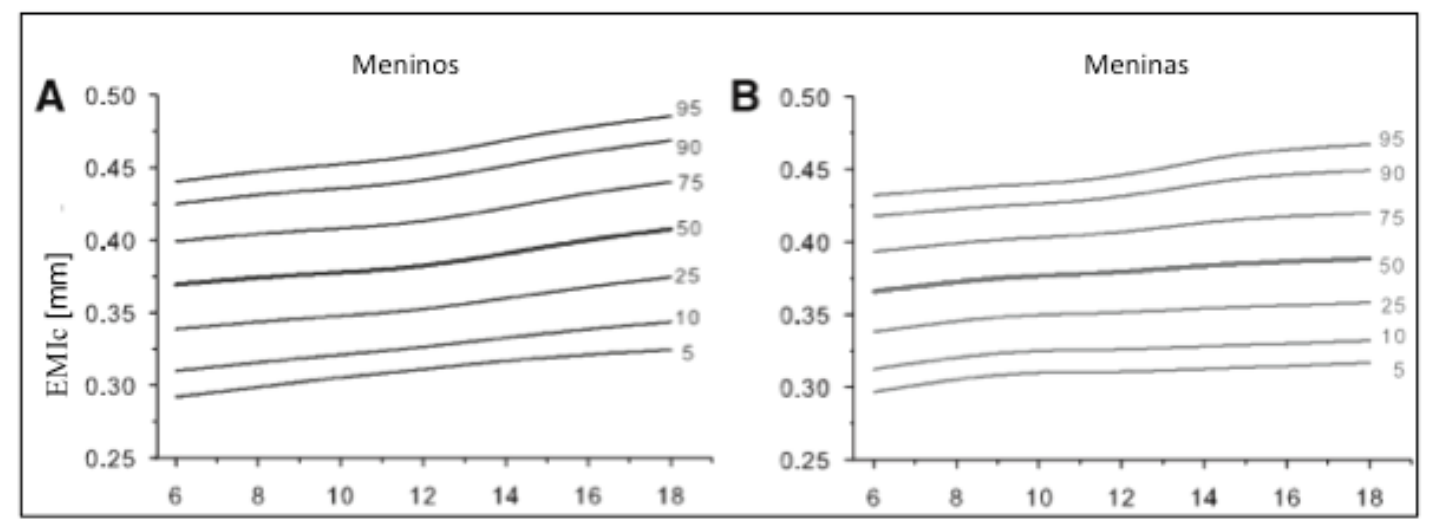

Figura 4: Curvas de percentis para avaliação da espessamento médio-intimal para menores de 18 anos (Doyon et al, Hypertension, 2013)- utilizada nos pacientes de 6 a 18 anos

Tabela 2: Avaliação do espessamento médio-intimal da carótida em homens e mulheres saudáveis mediana e percentis 10 e 90 - utilizada nos paciente com mais de 18 anos.

\begin{tabular}{llll}
\hline & \multicolumn{3}{c}{$\leq 30$ anos $(\mathbf{n = 1 6})$} \\
Homens & Mediana & P10 & P90 \\
\hline EMlc $(\mathbf{m m})$ & & & \\
Direita & 0,43 & 0,38 & 0,50 \\
Esquerda & 0,44 & 0,37 & 0,55
\end{tabular}

\begin{tabular}{llll}
\hline & \multicolumn{3}{l}{$\leq \mathbf{3 0}$ anos $(\mathbf{n = 2 6})$} \\
Mullheres & \multicolumn{1}{l}{ Mediana } & $\mathbf{P 1 0}$ & P90 \\
\hline EMlc $(\mathbf{m m})$ & & & \\
Direita & 0,40 & 0,37 & 0,46 \\
Esquerda & 0,44 & 0,40 & 0,50
\end{tabular}

EIMc: espessamento médio-intima I(Adaptada de Denarie, N., et al., Atherosclerosis, 2000) 


\section{Analise estatística}

Inicialmente, foi feita uma análise exploratória dos dados obtidos em todos os participantes, com a caracterização da população estudada quanto aos aspectos sociodemográficos, clínicos, nutricionais e laboratoriais. A amostra para o estudo foi de conveniência.

As medidas ultrassonográficas foram analisadas tanto com os valores absolutos das medidas quanto pela classificação por percentis de normalidade, baseando-se na literatura internacional, para sexo e idade. Para análise estatística foi utilizado o valor de EMIc geral obtido pela média das médias das três medidas de EMIc das carótidas esquerda e direita pelo ultrassom. Os pacientes foram classificados em dois grupos: LESJ com aterosclerose subclínica $(n=9)$ e LESJ sem aterosclerose subclínica $(n=19)$, de acordo com os critérios descritos em material e métodos e foram realizados os cálculos de prevalência e razão de prevalência de aterosclerose subclínica nessa população .

A utilização de duas abordagens de análise foi proposta pois a referência de normalidade dos valores de EMIc por idade e estatura foi obtida de uma população que não possui as mesmas características étnicas e epidemiológicas do grupo populacional que foi estudado. Portanto, as duas análises permitiram a melhor avaliação dos dados obtidos também para efeito comparativo dos resultados.

As variáveis quantitativas foram representadas como média, mediana e desvio padrão e as variáveis qualitativas foram representadas pelo número de casos e valores percentuais.

Foi utilizando o teste exato de Fisher para avaliar a associação entre aterosclerose subclínica e as variáveis independentes categóricas. Para comparar a distribuição das variáveis entre pacientes com e sem aterosclerose subclínica foi realizado o teste não paramétrico de Wilcoxon-Mann-Whitney

Foi calculada a correlação de Spearman e testada sua significância entre as medidas de EMIc e as variáveis que apresentaram associação com espessamento de carótida na literatura: idade na coleta, circunferência de cintura, clearance estimado de creatinina abaixo de $75 \mathrm{ml} / \mathrm{min}$, dose média de prednisona em uso, dose cumulativa de prednisona no dia da coleta, tempo do diagnóstico em meses, índice de massa corporal, valores de SLEDAI-2K, níveis séricos de HDL, LDL, 
triglicérides, colesterol, homocisteína, folato, Vit B12, PCR, IL- 6, , ICAM-1, VCAM-1 e P-selectina.

Para estimar as razões de prevalência $(\mathrm{RP})$ de aterosclerose de acordo com as variáveis de interesse foram ajustados os modelo de regressão log-binomial simples e múltiplo dado que a resposta era binária (Aterosclerose subclínica = Sim ou Não), com seu respectivo intervalo de 95\% de confiança (Skov et al., 1998). Os fatores de risco não tradicionais para DCV foram ajustados na regressão múltipla pelas seguintes variáveis de ajuste: dose cumulativa de corticoide, tempo de diagnóstico, hipertensão, dislipidemia e obesidade, com exceção do modelo de presença de anticorpo antifosfolípide que foi ajustado apenas por dose cumulativa de corticoide e tempo de diagnóstico.

Modelos de análise de regressão simples e múltipla foram utilizados para avaliação da associação das médias de diferenças dos valores absolutos de EMlc (variável dependente) e as variáveis independentes : SLEDAI maior que 5 pontos, clearance de creatinina abaixo de $75 \mathrm{ml} / \mathrm{min}$, proteinúria presente e proteinúria nefrótica presente. As variáveis a serem controladas na análise foram dose cumulativa de prednisona, média de tempo de diagnóstico em meses, presença de alteração dos níveis de triglicérides, LDL, HDL e colesterol, hipertensão não controlada e baixa estatura (estatura abaixo do p3).

Foi estabelecido um nível de significância de $5 \%$.

As análises foram feitas através do software SAS 9.2 (The SAS system for Windows. Release 9.2. SAS Inst., Cary, NC. 2011 e o software R 3.51.) 


\section{Resultados}

O coeficiente de prevalência pontual de aterosclerose subclínica foi de $32,14 \%$ (IC 95\%: 14,8; 49,4) nos 28 indivíduos avaliados.

\subsection{Resultados descritivos}

\subsubsection{Características sociodemográficas e clínicas dos participantes}

As características sociodemográficas e os critérios para classificação de LESJ dos participantes se encontram na tabela 3 . A maioria era do sexo feminino $(78,6 \%)$, a média de idade na avaliação foi de 13,9 anos, com tempo de médio de doença de 30 meses. Quanto aos critérios de classificação de LESJ, os mais frequentes foram ANA reagente $(100 \%)$, outro autoanticorpo reagente $(100 \%)$, acometimento renal $(89,2 \%)$, alteração hematológica $(78,6 \%)$ e presença de artrite $(64,2 \%)$. 
Tabela 3: Características sociodemográficos e critérios para classificação dos pacientes com LESJ participantes do estudo

\section{Caraterísticas}

Sexo $n(\%)$

Feminino

$22(78,6)$

Idade ao diagnóstico

$11,43(6,3-16,2)$

anos(média/mínimo-máximo)

Idade na avaliação

$13,9(6,4-19,5)$

anos(média/ mínimo-máximo)

Tempo de doença

meses(média/ mínimo-máximo)

$29,96(1-110)$

Raça $\mathrm{n}(\%)$

Não Brancos

$17(60,7)$

Púberes

$\geq \mathrm{M} 2$ ou $\mathrm{G} 2$

$27(96,4)$

\section{Critérios de Classificação' n(\%)}

Eritema malar

Lúpus discoide

0

Fotossensibilidade

$4(14,2)$

Úlceras Orais

7 (25)

Artrite

$18(64,2)$

Serosite

$9(32,1)$

Alteração renal

$25(89,2)$

Alteração Neurológica

$8(28,5)$

Alteração Hematológica

$22(78,6)$

ANA*

$28(100)$

Outros autoanticorpos ${ }^{* *}$

$28(100)$

Anti-DNAn

$22(78,5)$

Anti- SM

$17(60,7)$

Anti-fosfolípides

Presença de pelo menos um

14(50)

ACA

Anti-B2

$10(35,7)$

$8(28,6)$

PIL

$3(10,7)$

Nefrite classes ${ }^{2} \mathrm{n}(\%)$

Classe I

$3 / 21(14,2)$

Classe II

$2 / 21(9,5)$

Classe III

0

Classe IV

$12 / 21(57,1)$

Classe V

$4 / 21(19)$

Classe VI

0

-ACR revised criteria for the classification of systemic lupus erythematosus 2- Segundo International Society of Nefrology/ Renal Pathology Society (Weening et al., 2004) *ANA- anticorpo antinucleo; Anti DNAn: anti DNA nativo; Anti SM: Anti Smith; * ACA; anticorpo anticardiolipina,Anti-B2; anticorpo anti BETA 2 glicoproteina e PIL: anticoagulante lúpico 


\subsubsection{Medicamentos utilizados pelos pacientes do estudo}

As medicações utilizadas pelos pacientes, no momento da avaliação, incluindo a dose acumulada de corticoide, estão descritas na tabela 4. Apenas dois pacientes não fizeram uso de corticoide. Daqueles que utilizaram, metade tinha dose cumulativa moderada de uso de prednisona, vinte e um faziam uso de algum imunossupressor e todos de hidroxicloroquina.

Tabela 4: Medicações utilizadas pelos pacientes com lúpus eritematoso juvenil avaliados no estudo.

\section{Medicações}

\section{Imunomoduladores/imunossupressores}

Prednisona atual $(\mathrm{mg})$

média/mediana (mínimo/máximo)

$9,16 / 5(0-40)$

Dose acumulada de prednisona total(g)

média/mediana (mínimo/máximo)

$19 / 13,11(0-60,4)$

Dose acumulada de prednisona(mg/kg/dia) $\mathrm{n}(\%)$

$<0,15 \mathrm{mg} / \mathrm{kg} / \mathrm{dia}$ - baixa

$0,15-0,40 \mathrm{mg} / \mathrm{kg} / \mathrm{dia}$ - moderada

$>0,40 \mathrm{mg} / \mathrm{kg} / \mathrm{dia}$ - alta

Ciclofosfamida $n(\%)$

Azatioprina $\mathrm{n}(\%)$

Micofenolato $n(\%)$

Hidroxicloroquina $\mathrm{n}(\%)$

Outros n(\%)

Anti-hipertensivos

$10(35,7)$

AAS

$5(17,8)$

Cálcio

Vitamina D

$15(53,6)$

Ácido fólico $2(7)$ 


\subsection{3 Índice de atividade da doença - SLEDAI-2K e Índice de danos cumulativos da doença- SLLIC}

Os pacientes com LESJ apresentaram média de 7,8 (0-22) na avaliação do índice de atividade SLEDAI-2K, sendo que $42,8 \%$ dos pacientes apresentaram índices na faixa de moderada atividade (tabela 5). Baseado no índice de cronicidade SLICC, sete (25\%) dos participantes já apresentavam algum dano consequente do LESJ (SLICC maior ou $=1$ ).

Tabela 5: Índices de atividade e dano cumulativo em pacientes com lúpus eritematoso sistêmico juvenil

İndices

\begin{tabular}{|c|c|}
\hline $\begin{array}{l}\text { Índice de atividade de doença - SLEDAI 2k } \\
\text { média/mediana (mínimo-máximo) }\end{array}$ & $7,88 / 7(0-22)$ \\
\hline sem atividade de doença $=0 \mathrm{n}(\%)$ & $3(10,7)$ \\
\hline $0-5$ - atividade mínima da doença $n(\%)$ & $8(28,6)$ \\
\hline 5-12- atividade moderada de doença $n(\%)$ & $12(42,8)$ \\
\hline$\geq 12$ - atividade importante da doença $n(\%)$ & $5(17,8)$ \\
\hline \multicolumn{2}{|l|}{$\begin{array}{l}\text { Índice de dano cumulativo da doença- } \\
\text { SLICC }\end{array}$} \\
\hline $\begin{array}{cc}0 & \mathrm{n}(\%) \\
\geq 1 & \mathrm{n}(\%)\end{array}$ & $\begin{array}{l}21(75) \\
7(25)\end{array}$ \\
\hline
\end{tabular}

\subsubsection{Fatores de risco para aterosclerose tradicionais e fatores de risco não tradicionais relacionados ao LESJ}

Os fatores de risco avaliados se encontram sumarizados na tabela 6 . Em relação aos fatores de risco tradicionais, $89,3 \%$ dos pacientes apresentavam algum subtipo de dislipidemia; dentre os não tradicionais, $50 \%$ dos pacientes apresentavam anticorpos antifosfolípides reagentes, $75 \%$ anti- Dna nativo positivo, 60,7\% SLEDAI-2k > 5, 89,2\% nefrite, 92,8\% faziam uso de corticoide e $75 \%$ estavam em uso de algum imunossupressor. 
Tabela 6: Fatores de risco para doenças cardiovasculares presentes nos 28 pacientes com lúpus eritematoso sistêmico juvenil avaliados.

Fatores de risco tradicionais para doenças
cardiovasculares

Idade

(>40 em homens e >45 em mulheres)

\author{
0
}

Sexo masculino

$6(21,4)$

Hipertensão atual ${ }^{1}$

Controlada com medicamentos

$2 / 6(33,3)$

Não controlada

$4 / 6(66,6)$

Dislipidemia $^{2}$

Obesidade $^{3}$

Diabetes $^{4}$

Tabagismo

0

Anticoncepcional $^{5}$

$3 / 14(10,7)$

Fatores de risco não tradicionais para doenças cardiovasculares

Presença de anticorpo antifosfolípide

Presença de anti-DNA nativo

Atividade de doença - SLEDAI $>5$

Danos cumulativos - SLICC >0

Tempo de doença - média em meses

Nefrite

Envolvimento neurológico/ psiquiátrico

Uso de corticoide

Uso de imunossupressores

Homocisteína alta ${ }^{6}$

Vitamina B12 baixa $^{7}$

Folato baixo ${ }^{8}$

PCR ultrassensível alta ${ }^{9}$

1- AAP guideline updates practicefor pediatric hypertension, Pediatrics 2017; 2- I Diretriz de Prevenção da 1AAP guideline updates practicefor pediatric hypertension, Pediatrics 2017; 2- I Diretriz de Prevenção da Aterosclerose na Infância e na Adolescência Arq. Bras. Cardiol. 2005; 3- WHO growth reference data for 5-19 years, 2007; 4. American Diabetes Association. Diabetes Care, 2019; 5- acetato de medroxiprogesterona, 14 dos 22 do sexo feminino já apresentaram menarca ; 6- valores de referência no método utilizado < 14uMol/L; 7valores de referência no método utilizado 174 a $878 \mathrm{PG} / \mathrm{mL}$; 8- valores de referência no método utilizado 3 - 17 $\mathrm{ng} / \mathrm{mL}$; 9- valores de referência no método utilizado até $0,5 \mathrm{MG} / \mathrm{DL}$ 


\subsection{Avaliação Nutricional}

\subsubsection{Antropometria e bioimpedância elétrica}

Os dados antropométricos e de bioimpedância dos indivíduos avaliados estão descritos na tabela 7. Quanto a estatura, a maioria (64,3\%) tinha estatura adequada para sexo e idade. Apenas 4 pacientes (14,3\%) foram classificados como obesos pelo IMC, porém, 18 (64,3\%) apresentaram excesso de gordura abdominal, fator relacionado a maior risco de doença cardiovascular .

Tabela 7: Parâmetros antropométricos e de bioimpedância nos pacientes com lúpus eritematoso sistêmico juvenil avaliados

\section{Estatura $^{1}$ n (\%)}

Baixa estatura $(<\mathrm{P} 3)$

Risco para baixa estatura (P3-P15)

Estatura adequada (P15-P85)

Alta para idade (P85-97)

$\mathrm{IMC}^{2} \mathrm{n}(\%)$

Risco nutricional (P3-P15)

Eutrofia (P15-P85)

Sobrepeso (P85-P97)

Obesidade (>97)

Circunferência da Cintura $^{3}$ n (\%)

Normalidade

Excesso de gordura abdominal

Bioimpedância $^{4}$ n (\%)

Normalidade

Excesso de gordura corporal

1 e 2- WHO growth reference data for 5-19 years, 2007; 3- McCarthy, 2001 (Mccarthy et al., 2001), Fernandez J, 2004 (Fernandez et al., 2004) and WHO, 2008 4- McCarthy HD, 2006 (Mccarthy et al., 2006) 


\subsection{2 Índice de qualidade da dieta revisado- IQDR}

A tabela 8 descreve as informações sobre o IQDR. A média do IQDR foi de 55,9 , nenhum paciente apresentou uma boa qualidade de dieta e 22 deles $(78,6 \%)$ apresentam uma qualidade de dieta ruim.

Tabela 8: Índices de qualidade de dieta -IQDR em pacientes com lúpus eritematoso sistêmico juvenil Qualidade de dieta

\begin{tabular}{ll}
\hline $\begin{array}{l}\text { IQDR } \\
\text { média/mediana (mínimo-máximo) }\end{array}$ & $55,9 / 53,8(30,6-82,5)$ \\
$\begin{array}{l}\text { Dieta ruim } \\
\text { IQDR<65 } \mathrm{n}(\%)\end{array}$ & $\mathbf{2 2 ( 7 8 , 6 )}$ \\
& \\
Dieta com necessidade de adequação & \\
IQDR 65-74 $\mathrm{n}(\%)$ & \\
IQDR 75-84 $\mathrm{n}(\%)$ & $5(17,8)$ \\
Dieta boa & $\mathbf{1 ( 3 , 5 )}$ \\
IQDR $85 \mathrm{n}(\%)$ & 0 \\
\hline
\end{tabular}

\subsection{Análise Laboratorial}

\subsubsection{Exames relacionados à atividade de doença}

A tabela 9 apresenta os exames utilizados para o cálculo do SLEDAI-2K, além do clearence estimado de creatinina dos pacientes estudados. A proteinúria foi positiva em doze pacientes, atingindo níveis nefróticos em oito pacientes $(28,86 \%)$. $O$ clearence foi inferior a $75 \mathrm{ml} / \mathrm{min} / 1,73 \mathrm{~m}^{2}$ em 3 dos pacientes. $O$ anti- DNA nativo foi detectável em $75 \%$ dos participantes. 
Tabela 9: Exames laboratoriais relacionados à atividade de doença em 28 pacientes com lúpus eritematoso sistêmico juvenil

\begin{tabular}{|c|c|}
\hline $\begin{array}{l}\text { Urina } \\
\text { Cilindros urinários }\end{array}$ & $\mathbf{N}(\%)$ \\
\hline$\overline{\text { Granulosos ou hemáticos }}$ & $2(7,1)$ \\
\hline \multicolumn{2}{|l|}{ Hematúria } \\
\hline$\overline{>5 \text { por campo }}$ & $11(39,3)$ \\
\hline \multicolumn{2}{|l|}{ Proteinúria } \\
\hline relação proteína/creatinina $<0,2$ & $16(57,1)$ \\
\hline relação proteína/creatinina $\geq 0,2$ & $4(14,3)$ \\
\hline relação proteína/creatinina $\geq 1$ & $6(21,4)$ \\
\hline relação proteína/creatinina $\geq 2$ & $2(7,4)$ \\
\hline \multicolumn{2}{|l|}{ Leucocitúria } \\
\hline$\overline{>5 \text { por campo }}$ & $10(35,7)$ \\
\hline \multicolumn{2}{|l|}{ Clearence de creatinina } \\
\hline$<75 \mathrm{ml} / \mathrm{min} / 1,73 \mathrm{~m}^{2}$ & $3(10,7)$ \\
\hline$>75 \mathrm{ml} / \mathrm{min} / 1,73 \mathrm{~m}^{2}$ & $25(89,3)$ \\
\hline \multicolumn{2}{|l|}{ Diminuição do complemento } \\
\hline C3 & $13(46,4)$ \\
\hline C4 & $11(39,3)$ \\
\hline C3 e C4 & $8(28,6)$ \\
\hline Anti DNAn & $21(75 \%)$ \\
\hline \multicolumn{2}{|l|}{ Leucopenia } \\
\hline < 3000 leucócitos $/ \mathrm{mm}^{3}$ & $3(10,7)$ \\
\hline \multicolumn{2}{|l|}{ Plaquetopenia } \\
\hline$<100000$ plaquetas $/ \mathrm{mm} 3$ & 0 \\
\hline
\end{tabular}




\subsubsection{Exames relacionados à metabologia/ nutrição}

Nenhum paciente apresentou alteração dos níveis de glicemia, porém, 89,3\% dos pacientes avaliados foram classificados como dislipidêmicos. A tabela 10 sumariza os dados referentes ao lipidograma dos pacientes com LESJ avaliados.

Tabela 10: Classificação de diabetes dislipidemia nos 28 pacientes com lúpus eritematoso sistêmico juvenil avaliados

\begin{tabular}{|c|c|c|}
\hline & $\begin{array}{c}N \\
(28)\end{array}$ & $\begin{array}{c}\text { Porcentagem } \\
(\%)\end{array}$ \\
\hline Diabetes $^{1}$ & 1 & 3,5 \\
\hline \multicolumn{3}{|l|}{ Dislipidêmicos ${ }^{2}$} \\
\hline \multicolumn{3}{|l|}{ Hipercolesterolemia } \\
\hline$(\mathrm{CT}>170 \mathrm{mg} / \mathrm{dl})$ & 4 & 14,3 \\
\hline \multicolumn{3}{|l|}{ Hipertrigliceridemia } \\
\hline (TG $\geq 130$ mg/dl) & 4 & 14,3 \\
\hline \multicolumn{3}{|l|}{ Hiperlipidemia mista } \\
\hline \multicolumn{3}{|l|}{$(\mathrm{CT}>170 \mathrm{mg} / \mathrm{dl} \mathrm{e}$} \\
\hline $\mathrm{TG} \geq 130 \mathrm{mg} / \mathrm{dl})$ & 6 & 21,4 \\
\hline \multicolumn{3}{|l|}{ HDL-c Baixo } \\
\hline$(\mathrm{HDL}<45)$ & 18 & 64,3 \\
\hline Redução isolada de HDL & 10 & 35,7 \\
\hline Sem dislipidemia & 3 & 10,7 \\
\hline
\end{tabular}




\subsubsection{Medida de marcadores inflamatórios}

A tabela 11 apresenta as citocinas e moléculas de adesão que foram detectáveis em 19 pacientes. A P-selectina e ICAM-1 foram detectadas em todos pacientes, enquanto a IL 17 foi detectada em apenas 2 indivíduos.

Tabela 11: Detecção de citocinas e moléculas de adesão em 19 pacientes com lúpus eritematoso sistêmico juvenil

\begin{tabular}{ll}
\hline Variáveis & $\mathrm{n}(\%)$ \\
\hline Citocinas* & $4(21,0)$ \\
IL-1 alfa & $3(15,8)$ \\
IL-1 beta & $4(21)$ \\
IL-10 & $7(36.8)$ \\
INF-gama & $4(21)$ \\
IL-17 & $2(10,5)$ \\
IL-6 & $18(94,7)$ \\
Moléculas de adesão* & $19(100)$ \\
P- selectina & $18(94,7)$ \\
VCAM-1 & $19(100)$ \\
ICAM-1 & \\
\hline * método Elisa; IL: interleucina; TNF: fator de necrose tumoral; VCAM: molécula de adesão vascular; \\
ICAM: molécula de adesão de célula intracelular
\end{tabular}

\subsection{Avaliação ultrassonográfica do espessamento médio-intimal (EMIc) das carótidas}

A tabela 12 contém a distribuição das medidas de EMlc em percentis. Um dos meninos e 8 meninas se encontravam acima do P90, sendo então considerados portadores de aterosclerose subclínica. 
Tabela 12: Avaliação do espessamento médio-intimal (EMIc) da carótida em 28 pacientes com lúpus eritematoso sistêmico juvenil

\begin{tabular}{|c|c|c|c|}
\hline EMIcPercentil & D & $E$ & $\begin{array}{c}\text { EMIc geral } \\
\text { (média D+E) } \\
\text { N (\%) }\end{array}$ \\
\hline \multicolumn{4}{|l|}{$\begin{array}{l}\text { Meninos } \\
<18 \text { anos }^{1}(5)\end{array}$} \\
\hline $50-75$ & 2 & 1 & 0 \\
\hline $75-90$ & 2 & 2 & $4(66.6)$ \\
\hline $90-95$ & 1 & 2 & $1(16,7)$ \\
\hline \multicolumn{4}{|l|}{$>18 \operatorname{anos}^{2}(1)$} \\
\hline $10-90$ & 1 & 1 & $1(16,7)$ \\
\hline \multicolumn{4}{|l|}{ Meninas } \\
\hline $25-50$ & 2 & 3 & $1(4,5)$ \\
\hline $50-75$ & 7 & 7 & $10(45,4)$ \\
\hline $75-90$ & 4 & 3 & $3(13,6)$ \\
\hline $90-95$ & 3 & 3 & $2(9,1)$ \\
\hline$>95$ & 4 & 4 & $5(22,7)$ \\
\hline \multicolumn{4}{|l|}{$>18 \operatorname{anos}^{2}(2)$} \\
\hline $10-90$ & $1(50)$ & $1(50)$ & $1(4,5)$ \\
\hline$>90$ & $1(50)$ & $1(50)$ & $1(4,5)$ \\
\hline
\end{tabular}

1- Doyon, 2013 (Doyon et al., 2013) ; 2- Denarie , 2000 (Denarie et al., 2000) 


\subsection{Resultados analíticos}

\subsubsection{Testes de associação}

As análises de associação entre aterosclerose subclínica e as variáveis independentes categóricas estão descritas na tabela 13 e 14 Observou-se associação entre clearence estimado de creatinina abaixo de $75 \mathrm{ml} / \mathrm{min} / 1,73 \mathrm{~m}^{2}$ clearence $<75(p=0,02)$, relação entre proteína e creatinina acima de $0,2(p=0,02)$, e aumento do colesterol total $(p=0,03)$ com aterosclerose subclínica, enquanto a relação entre proteína e creatinina maior que 1 (proteinúria nefrótica) se aproximou da significância $(p=0,06)$. Mesmo quando avaliada a presença ou não de aterosclerose subclínica em carótidas direita e esquerda, separadamente, não houve significância estatística entre os fatores associados ao lúpus (nefrite lúpica, alterações neurológicas, presença de proteinúria, SLICC/ACR DI maior que zero um e uso de corticoide).

O clearance estimado de creatinina abaixo de $75 \mathrm{ml} / \mathrm{min} / 1,73 \mathrm{~m}^{2}$ foi associado à aterosclerose subclínica tanto em carótida direita $(p=0,037)$ quanto em esquerda $(p=0,037)$. O índice de atividade de doença SLEDAI-2K acima de 5 mostrou associação com aterosclerose subclínica, tanto em relação à carótida $D(p=0,04)$ quanto à $E(p=0,04)$. A avaliação da associação de proteinúria nefrótica com aterosclerose subclínica mostrou valores de $p$ próximos ao nível de significância, direita $(p=0,09)$ e esquerda $(p=0,06)$.

Entre as variáveis quantitativas, somente houve evidência de diferença na distribuição o aumento dos níveis séricos do colesterol total $(p<0,01)$. 
Tabela 13: Comparação dos dados sociodemográficos e clínicos dos 28 pacientes com lúpus eritematoso sistêmico juvenil, com aterosclerose subclínica (9) e, sem aterosclerose subclínica (19), avaliados no estudo.

Variáveis (n)

Aspectos sociodemográficos

Sexo feminino (22)

Raça branca (11)

Aterosclerose subclínica $\mathrm{n}(\%) \quad \boldsymbol{P}$

Idade na coleta (m/DP)

SIM

NÃO

Tempo de diagnóstico

em meses(m/DP)

\begin{tabular}{lll}
\multicolumn{1}{r}{ SIM } & \multicolumn{1}{c}{ NÃO } \\
$8(36,4)$ & $14(63,6)$ & 0,68 \\
$5(45,4)$ & $6(54,5)$ & 0,41 \\
$13 \pm 3,3$ & $14,4 \pm 2,8$ & 0,29 \\
$39 \pm 34,2$ & $25,7 \pm 20,4$ & 0,34
\end{tabular}

\section{Características Clínicas}

Nefrite (25)

$8(32)$

$17(68)$

1

Nefrite classe IV ou/e V (16)

$7(43,7)$

$9(56,2)$

0,12

Comprometimento neurológico (8)

$3(37,5)$

$5(62,5)$

1

SLEDAI >5 (17)

$9(52,9 \%)$

8 (47)

0,004

SLEDAI quantitativo

$10,9 \pm 5,7$

$6,4 \pm 5,6$

0,05

SLICC >0 (7)

$2(28 \%)$

5 (71)

1

Hipertensão arterial controlada

$1(25 \%)$

$3(75)$

1

Hipertensão arterial não controlada

$3(75)$

$1(25)$

0,08

Menarca (15)

$4(26,7)$

$11(73,3)$

0,34

Estadio puberal $>$ ou $=$ M2/G2 (27)

$8(29,6)$

$19(70,3)$

0,32

P3 de estatura

(5)

$2(40)$

$3(60)$

1

P3-15 de estatura (3)

$2(66,7)$

$1(33,3)$

0,23

\section{Medicações utilizadas}

Dose corticoide $<0,15 \mathrm{mg} / \mathrm{kg} / \mathrm{dia}$ (2)

0

$2(100)$

1

Dose corticoide $>0,4 \mathrm{mg} / \mathrm{kg} / \mathrm{dia}$ (10)

$3(30)$

$7(70)$

1

Dose média atual de prednisona

$0,4 \pm 0,3$

$0,5 \pm 1$

0,64

$\mathrm{mg} / \mathrm{kg}(\mathrm{m} / \mathrm{DP})$

Dose acumulada de prednisona $\mathrm{mg} / \mathrm{kg}$ (m/DP)

Ciclofosfosfamida (15)

$22,6 \pm 18,1$

$16,8 \pm 14,8$

0,46

$5(33)$

$10(67)$

1 
Tabela 13 (continuação): Comparação dos dados demográficos e clínicos dos 28 pacientes com lúpus eritematoso sistêmico juvenil, com aterosclerose subclínica (9) e, sem aterosclerose subclínica (19), avaliados no estudo.

\begin{tabular}{llll}
\hline Azatioprina (9) & $3(33)$ & $6(67)$ & 1 \\
Micofenolato (7) & $2(25)$ & $6(75)$ & 1 \\
Anti-hipertertensivo (10) & $5(50)$ & $5(50$ & 0,2 \\
AAS (5) & $2(40)$ & $3(60)$ & 1 \\
Uso de anticoncepcional (3) & $1(33,3)$ & $2(66,7)$ & 1 \\
Avaliação nutricional & & & \\
Cintura- excesso de gordura & $2(15,4)$ & $11(84,6)$ & 0,11 \\
abdominal (13) & & & \\
Sobrepeso (5) & $1(20)$ & $4(80)$ & 1 \\
Obesidade (4) & 0 & $4(100)$ & 0,27 \\
BIA excesso de gordura abdominal $(7)$ & $3(42,9)$ & $4(57,1)$ & 0,33 \\
BIA obesidade (7) & $1(14,3)$ & $6(85,7)$ & 0,61 \\
Dieta ruim (22) & $8(36,4)$ & $14(63,6)$ & 0,63 \\
Dieta inadequada (6) & $1(16,7)$ & $5(83,3)$ & 0,62
\end{tabular}

Teste exato de fisher para variáveis qualitativas e teste não- paramétrico de Wilcoxon Mann-Whitney para variáveis quantitativas, $m=$ média, $D P=$ desvio padrão, SLEDAI- índice de atividade de doença, SLICC- índice de danos cumulativos de doença , AASácidoacetilsalicílico, BIA- bioimpedância elétrica 
Tabela 14: Comparação dos dados laboratoriais dos 28 pacientes com lúpus eritematoso sistêmico juvenil, com aterosclerose subclínica (9) e sem aterosclerose subclínica (19) avaliados no estudo.

\begin{tabular}{|c|c|c|c|}
\hline Variáveis & Ateroscle & subclínica n(\%) & $P$ \\
\hline & SIM (9) & $\mathrm{NÃO}(19)$ & \\
\hline Alterações hematológicas & & & \\
\hline Anemia & $4(40)$ & $6(60)$ & 0,67 \\
\hline Leucopenia & $2(66,7)$ & $1(33,3)$ & 0,23 \\
\hline Linfopenia & $3(27,3)$ & $8(72,7)$ & 1 \\
\hline Alterações renais & & & \\
\hline Hematuria & $5(45,4)$ & $6(54,5)$ & 0,40 \\
\hline Leucocitúria & $5(50)$ & $5(50)$ & 0,21 \\
\hline Cilindrúria & $1(50)$ & $1(50)$ & 1 \\
\hline Proteinúria p/c & $7(58)$ & $5(41,7)$ & 0,02 \\
\hline Proteinuria nefrótica & $5(62,5)$ & $3(37,5)$ & 0,06 \\
\hline $\begin{array}{l}\text { Clearance estimado de creatinina } \\
\text { abaixo de } 75 \mathrm{ml} / \mathrm{min}\end{array}$ & $3(100)$ & 0 & 0,02 \\
\hline $\begin{array}{l}\text { Clearance estimado valores totais em } \\
\mathrm{ml} / \mathrm{min}(\mathrm{m} / \mathrm{DP})\end{array}$ & $125,5 \pm 58,9$ & $162,8 \pm 42,9$ & 0,14 \\
\hline Alterações imunológicas & & & \\
\hline Anti DNA nativo & $7(33)$ & $14(66,7)$ & 1 \\
\hline Presença de antifosfolípides & $7(50)$ & $7(50)$ & 0,10 \\
\hline Complemento baixo & $6(37,5)$ & $10(62,5)$ & 0,68 \\
\hline C3 & $5(38)$ & $8(61)$ & 0,69 \\
\hline C4 & $4(36,4)$ & $7(63,6)$ & 1 \\
\hline Alterações do perfil lipídico(n) & & & \\
\hline Dislipidemia & $8(34,8)$ & $15(65,2)$ & 1 \\
\hline Hipertrigliceridemia & $5(50)$ & $5(50)$ & 0,2 \\
\hline Níveis de triglicérides (m/DP) & $189,5 \pm 139,8$ & $118,3 \pm 82,4$ & 0,07 \\
\hline Hipercolesterolemia & $6(60)$ & $4(40)$ & 0,03 \\
\hline Níveis de colesterol (m/DP) & $196,1 \pm 52,5$ & $148,2 \pm 33,9$ & $<0,01$ \\
\hline LDL aumentado & $2(50)$ & $2(50)$ & $\begin{array}{c}0,57 \\
\text { Continua }\end{array}$ \\
\hline
\end{tabular}


Tabela 14 (continuação): Comparação dos dados laboratoriais dos 28 pacientes com lúpus eritematoso sistêmico juvenil, com aterosclerose subclínica (9) e sem aterosclerose subclínica (19) avaliados no estudo.

\begin{tabular}{llll}
\hline Níveis de LDL (m/DP) & $84,9 \pm 22,1$ & $112,6 \pm 47,9$ & 0,14 \\
HDL aumentados & $5(31,2)$ & $11(68,7)$ & 1 \\
Níveis de HDL (m/DP) & $43 \pm 8$ & $37,3 \pm 11,9$ & 0,20 \\
PCR ultrassensível (7) & $1(14,3)$ & $6(85,7)$ & 0,37 \\
Homocisteina elevada (3) & $2(67)$ & $1(33)$ & 0,23 \\
Níveis de homocisteína (m/DP) & $8,4 \pm 3,2)$ & $15 \pm 14)$ & 0,18 \\
VIT B12 alterada ( Libby et al.) & 0 & $1(100)$ & 1 \\
Níveis de VIT B 12 (m/DP) & $433,7 \pm 221,5)$ & $411,5 \pm 201)$ & 0,81 \\
Folato alterado ( Libby et al.) & 0 & $1(100)$ & 1 \\
Níveis de folato (m/DP) & $9,4 \pm 3,7$ & $10,7 \pm 3,8$ & 0,5
\end{tabular}

\section{Avaliação do padrão de citocinas}

Detecção das citocinas no plasma (n)

IL-1 alfa (3)
IL-17 (2)
INF-gama (4)
IL-10 (7)
IL-1 beta (4)
TNF- alfa (4)
IL- 6 (m/DP)
ICAM - 1 (m/DP)
VCAM-1 (m/DP)
P-selectina (m/DP)

$1(33,3)$

0

0

0

$8,6 \pm 10,5$

$302,9 \pm 81,4$

$728,2 \pm 626$

$52,0 \pm 21,3$
2(66,7)

$2(100)$

$3(75)$

$5(71,4)$

4(100)

4 (100)

$14,4 \pm 22,8$

$231,8 \pm 100,9$

$418,9 \pm 237,4$

$191,9 \pm 288,5$
1

1

1

1

0,25

0,25

0,42

0,12

0,42

0,11

Teste exato de Fischer para variáveis categóricas e teste nao- paramétrico de Wilcoxon- Mann-Whitney para variáveis quantitativas, $\mathrm{LDL}=$ lipoproteína de baixa densidade, $\mathrm{HDL}=$ lipoproteína de alta densidade, $\mathrm{PCR}=$ proteína $\mathrm{c}$ reativa, VIT $\mathrm{B} 12=$ vitamina $\mathrm{B} 12, \mathrm{IL}=$ interleucina, $\mathrm{INF}=$ interferon, $\mathrm{TNF}=$ fator de necrose tumoral, ICAM= molécula de adesão, VCAM= molécula de adesão celular vascular

Quando as variáveis avaliadas foram comparadas com a diferença das médias do EMlc em valores absolutos, o SLEDAI-2k $>5(p=0,04)$, hipertensão não controlada ( $p=0,04)$, baixa estatura (abaixo do P3) ( $p=0,04)$, uso de antihipertensivos $p=0,01)$, proteinúria $(p=0,02)$ e clearance de creatinina abaixo de 75 $\mathrm{ml} / \mathrm{min} / 1,73 \mathrm{~m}^{2}$ foram significantes ( tabela. 15 e 16 . e figura 5 ). 
Tabela 15: Comparação dos dados sociodemográficos, clínicos e avaliação nutricional, dos 28 pacientes com lúpus eritematoso sistêmico juvenil, em relação ao espessamento médio-intimal da carótida (média entre carótidas direita e esquerda)

EMlc $-\mathrm{mm} \quad P^{*}$

(DP)

Aspectos demográficos

Sexo feminino

$0,42(0,04)$

Sexo masculino

$0,46(0,05) \quad 0,08$

Raça branca

$0,44(0,04)$

Não brancos

$0,43(0,04) \quad 0,69$

Características Clínicas

Nefrite

$\begin{array}{lll}\mathrm{S} & 0,43(0,04) & \\ \mathrm{N} & 0,42(0,02) & 0,74\end{array}$

Nefrite classe IV ou/e V

S $\quad 0,44(0,04)$

$\mathrm{N} \quad 0,41(0,02)$

0,052

neurológico

$0,43(0,04)$

$\mathrm{N} \quad 0,43(0,04)$

1

SLEDAI >5

$\begin{array}{ll}\mathrm{S} & 0,44(0,05) \\ \mathrm{N} & 0,41(0,02)\end{array}$

0,04

SLICC $>0$

S

$0,43(0,03)$

$\mathrm{N} \quad 0,43(0,05)$

0,83

Hipertensão controlada

$\begin{array}{ll}\mathrm{S} & 0,43(0,03) \\ \mathrm{N} & 0,43(0,04)\end{array}$

1

Hipertensão nao controlada

$\begin{array}{lll}S & 0,46(0,02) & \\ N & 0,43(0,04) & \mathbf{0 , 0 4}\end{array}$

Menarca

$\begin{array}{ll}\mathrm{S} & 0,42(0,03) \\ \mathrm{N} & 0,43(0,05)\end{array}$

0,68

Estadio puberal $>$ ou $=\mathrm{M} 2$ ou $\mathrm{G} 2$

$\begin{array}{ll}\mathrm{S} & 0,43(0,04) \\ \mathrm{N} & 0,43\end{array}$

P3 de estatura

S $\quad 0,46(0,03)$

$\mathrm{N} \quad 0,43(0,04)$

0,04

P3-15 de estatura

S $\quad 0,45(0,02)$

$\mathrm{N} \quad 0,43(0,04) \quad 0,24$

continua 
Tabela 15 (continuação): Comparação dos dados sociodemográficos, clínicos e avaliação nutricional, dos 28 pacientes com lúpus eritematoso sistêmico juvenil, em relação ao espessamento médio-intimal da carótida (média entre carótidas direita e esquerda)

\section{Medicações utilizadas}

Dose corticoide $<0,15 \mathrm{mg} / \mathrm{kg} / \mathrm{dia}$

Dose corticoide 0,15- 0,4 mg/kg/dia

$\begin{array}{lll}\mathrm{S} & 0,39(0,02) & \\ \mathrm{N} & 0,43(0,04) & 0,12\end{array}$

Dose corticoide $>0,4 \mathrm{mg} / \mathrm{kg} / \mathrm{dia}$

$\mathrm{S} \quad 0,44(0,04)$

$\mathrm{N} \quad 0,42(0,04)$

0,38

$S \quad 0,42(0,03)$

$\mathrm{N} \quad 0,44(0,05) \quad 0,74$

Ciclofosfosfamida

S $\quad 0,44(0,04)$

$\mathrm{N} \quad 0,42(0,04)$

0,14

Azatioprina

$\mathrm{S}$

$0,43(0,03)$

$\mathrm{N} \quad 0,43(0,05)$

0,85

Micofenolato

S $\quad 0,44(0,05)$

$\mathrm{N} \quad 0,43(0,04)$

0,44

Uso de anti-hipertertensivo

S $\quad 0,46(0,04)$

$\mathrm{N} \quad 0,42(0,03) \quad \mathbf{0 , 0 1}$

AAS

S $\quad 0,42(0,04)$

$\mathrm{N} \quad 0,43(0,04)$

0,95

Uso de anticoncepcional

S

$\mathrm{N} \quad 0,42(0,04) \quad 0,42$

Avaliação nutricional

Obesidade

$0,43(0,02)$

$\begin{array}{lll}\mathrm{S} & 0,43(0,02) & \\ \mathrm{N} & 0,43(0,04) & 0,74\end{array}$

Circunferencia de Cintura

S $\quad 0,42(0,04)$

$\mathrm{N} \quad 0,44(0,04) \quad 0,22$

Sobrepeso

S $\quad 0,43(0,07)$

$\mathrm{N} \quad 0,43(0,04) \quad 0,46$

Excesso de peso corporal (BIA)

$S \quad 0,42(0,02)$

$\mathrm{N} \quad 0,43(0,04) \quad 0,65$

Obesidade (BIA)

$\begin{array}{lll}\mathrm{S} & 0,43(0,03) & \\ \mathrm{N} & 0,42(0,04) & 0,68\end{array}$

Dieta ruim

$\mathrm{S} \quad 0,43(0,03)$

$\mathrm{N} \quad 0,44(0,06) \quad 0,89$

Dieta inadequada

$\begin{array}{lll}\mathrm{S} & 0,44(0,06) & \\ \mathrm{N} & 0,43(0,03) & 0,89\end{array}$

* teste nao paramétrico de Wilxocon.: EMlc - espessamento médio-intimal. DP: desvio padrão.

S: sim; N: não; mm: milímetros 
Tabela 16: Comparação dos dados laboratoriais, dos 28 pacientes com lúpus eritematoso sistêmico juvenil, em relação ao espessamento médio-intimal da carótida (média direita e esquerda)

\begin{tabular}{|c|c|c|c|}
\hline & & EMlc (DP) & $P$ \\
\hline \multicolumn{4}{|c|}{ Alterações hematológicas } \\
\hline \multirow[t]{2}{*}{ Anemia } & $S$ & $0,44(0,03)$ & \\
\hline & $\mathrm{N}$ & $0,43(0,05)$ & 0,22 \\
\hline \multirow[t]{2}{*}{ Leucopenia } & S & $0,43(0,03)$ & \\
\hline & $\mathrm{N}$ & $0,43(0,04)$ & 0,58 \\
\hline \multirow[t]{2}{*}{ Linfopenia } & S & $0,42(0,42)$ & \\
\hline & $\mathrm{N}$ & $0,44(0,05)$ & 0.40 \\
\hline \multicolumn{4}{|l|}{ Alterações renais } \\
\hline \multirow[t]{2}{*}{ Hematuria } & S & $0,44(0,05)$ & \\
\hline & $\mathrm{N}$ & $0,43(0,04)$ & 0,29 \\
\hline \multirow[t]{2}{*}{ Leucocituria } & S & $0,44(0,05)$ & \\
\hline & $\mathrm{N}$ & $0,43(0,04)$ & 0,77 \\
\hline \multirow[t]{2}{*}{ Cilindruria } & S & $0,41(0,03)$ & \\
\hline & $\mathrm{N}$ & $0,43(0,04)$ & 0,45 \\
\hline \multirow[t]{2}{*}{ Proteinúria } & S & $0,45(0,04)$ & \\
\hline & $\mathrm{N}$ & $0,42(0,04)$ & 0,02 \\
\hline \multirow[t]{2}{*}{ Proteinuria nefrótica } & S & $0,44(0,03)$ & \\
\hline & $\mathrm{N}$ & $0,43(0,04)$ & 0,28 \\
\hline \multicolumn{4}{|l|}{ Clearance estimado de } \\
\hline creatinina abaixo de 75 & S & $0,47(0,02)$ & \\
\hline $\mathrm{ml} / \mathrm{min}$ & $\mathrm{N}$ & $0,43(0,04)$ & 0,04 \\
\hline \multicolumn{4}{|l|}{ Alteracoes imunológicas } \\
\hline & S & $0,43(0,04)$ & \\
\hline Anti-DNA nativo & $\mathrm{N}$ & $0,43(0,05)$ & 0,79 \\
\hline \multicolumn{4}{|l|}{ Presença de } \\
\hline antifosfolípides & $\begin{array}{l}\mathrm{S} \\
\mathrm{N}\end{array}$ & $\begin{array}{l}0,42(0,04) \\
0,44(0,05)\end{array}$ & 0.68 \\
\hline \multicolumn{4}{|l|}{ Complemento baixo } \\
\hline & S & $0,44(0,05)$ & \\
\hline & $\mathrm{N}$ & $0,43(0,03)$ & 0,61 \\
\hline \multirow[t]{2}{*}{ C3 } & S & $0,43(0,05)$ & \\
\hline & $\mathrm{N}$ & $0,43(0,04)$ & 0,75 \\
\hline \multirow[t]{2}{*}{$\mathrm{C} 4$} & S & $0,43(0,04)$ & \\
\hline & $\mathrm{N}$ & $0,43(0,04)$ & $\begin{array}{l}0,74 \\
\text { continua }\end{array}$ \\
\hline
\end{tabular}


Tabela 16 (continuação): Comparação dos dados laboratoriais, dos 28 pacientes com lúpus eritematoso sistêmico juvenil, em relação ao espessamento médio-intimal da carótida (média direita e esquerda)

Alterações do perfil lipídico
Dislipidemia

$\mathrm{S}$

$0,43(0,04)$

$0,44(0,06)$

0,95

Hipertrigliceridemia

$\begin{array}{lll}\mathrm{S} & 0,43(0,04) & \\ \mathrm{N} & 0,43(0,05) & 0,94\end{array}$

Hipercolesterolemia

S $\quad 0,44(0,03)$

$\mathrm{N} \quad 0,43(0,05)$

0,24

LDL aumentado

$\mathrm{S}$

$0,04(0,05)$

$0,43(0,04)$

0,54

HDL aumentados

$\mathrm{S} \quad 0,43(0,04)$

$\mathrm{N} \quad 0,44(0,04)$

0,66

PCR ultrassensível

S

$0,42(0,03)$

$0,44(0,04)$

0,58

Homocisteina alterada

$\mathrm{S}$

$0,45(0,02)$

$0,43(0,04)$

0,24

VITB12 alterada

$\begin{array}{ll}\mathrm{S} & 0,43 \\ \mathrm{~N} & 0,43(0,04)\end{array}$

Folato alterado
$\mathrm{S} \quad 0,38$
$\mathrm{N} \quad 0,43(0,04)$

Presença ou não das citocinas no plasma

IL-1 alfa

S $\quad 0,46(0,08)$

$\mathrm{N} \quad 0,43(0,04)$

0,75

IL-17

$\mathrm{S}$

$0,42(0,01)$

$0,44(0,05)$

0,39

INF gama

$\begin{array}{ll}\mathrm{S} & 0,45(0,06) \\ \mathrm{N} & 0,43(0,04)\end{array}$

0,84

IL-10

$\mathrm{S}$

$0,42(0,02)$

$0,45(0,05)$

IL-1 beta

$\begin{array}{ll}\mathrm{S} & 0,41(0,02) \\ \mathrm{N} & 0,44(0,05)\end{array}$

TNF-alfa

$\begin{array}{ll}\mathrm{S} & 0,41(0,02) \\ \mathrm{N} & 0,44(0,05)\end{array}$

0,46

0,24

* teste não paramétrico de Wilxocon-Mann-Whitney.: EMlc - espessamento médio-intimal. DP: desvio padrão. S: sim; N: não; mm: milímetros; IL= interleucina, INF= interferon,TNF= fator de necrose tumoral, ICAM= molécula de adesão, VCAM= molécula de adesão celular vascular 

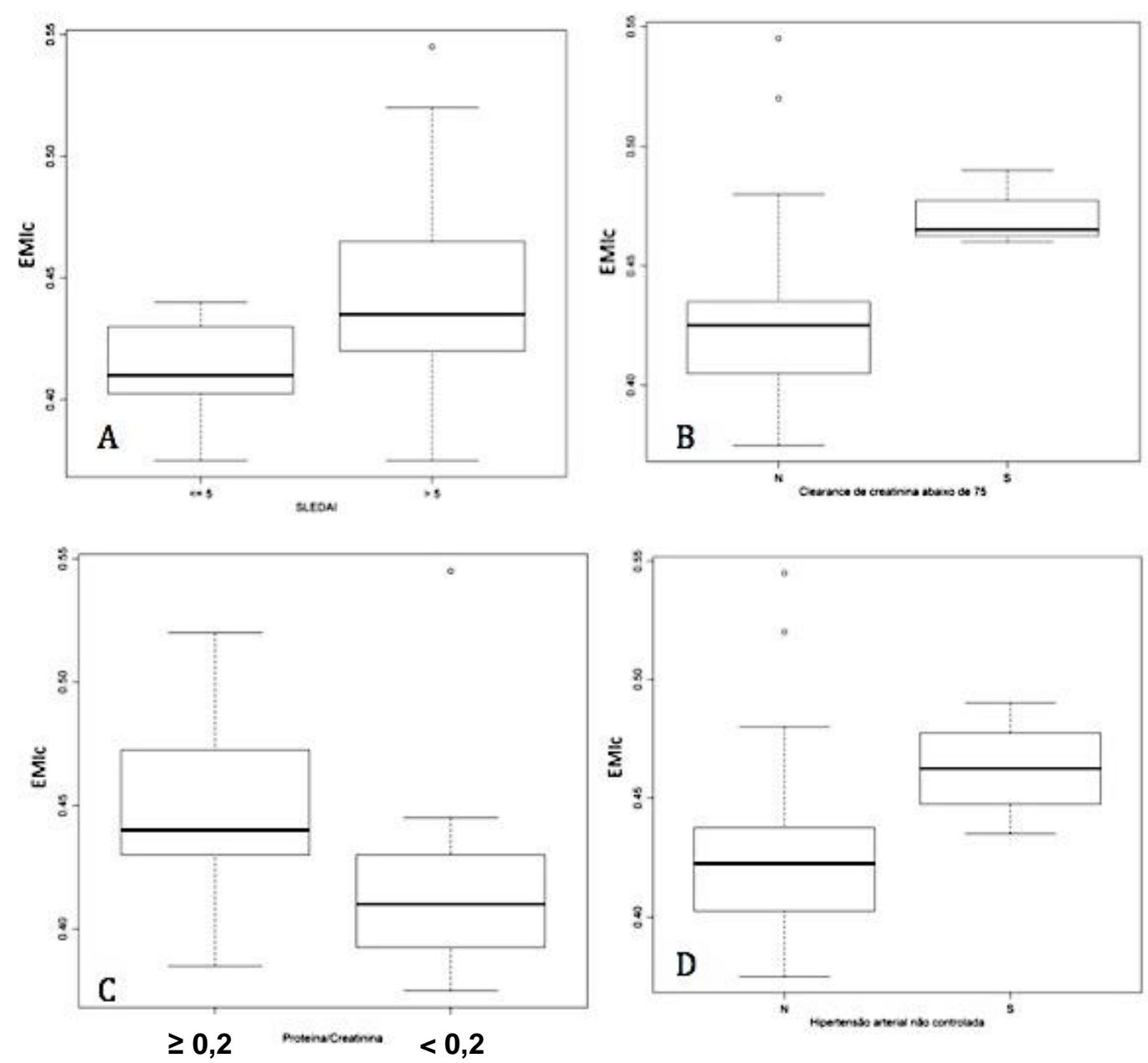

Figura 5: Boxplots da distribuição dos valores absolutos em milímetros das medidas de espessura médio-intimal (EMIc) pelas variáveis: A- índice de SLEDAI-2K ( $\leq 5$ ou $>5$ ), B clearence de creatinina $<75 \mathrm{ml} / \mathrm{min} / 1,73 \mathrm{~m}^{2}$ (sim ou não), C- relação proteína/creatinina $(\geq 0,2$ ou $<0,2$ ) e D- hipertensão arterial não controlada(não ou sim)

\subsubsection{Coeficiente de Correlação}

Não foi encontrado nenhum coeficiente de correlação fortemente ou perfeitamente positivo entre as medidas de EMlc e as variáveis estudadas.

Encontrada correlação moderadamente positiva entre medidas EMlc e dose cumulativa de prednisona rho $=0,52(p<0,01)$ e entre tempo do diagnóstico em meses rho $=0,52(p<0,01)$ ( figuras 6 e 7 , tabela 17). 


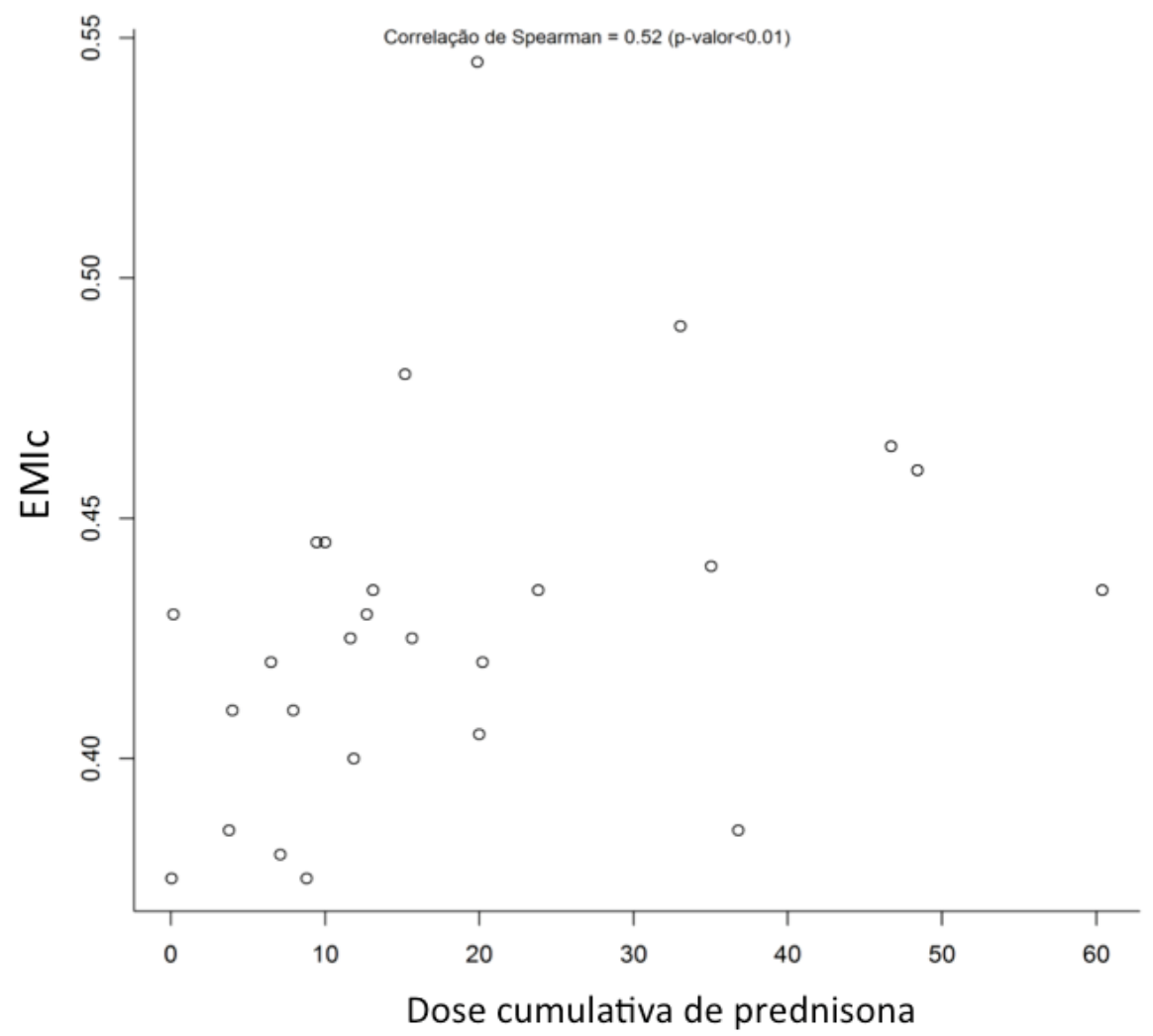

Figura 6: Avaliação da correlação entre dose cumulativa de prednisona e espessura médio-intimal de carótida em pacientes com lúpus eritematoso sistêmico juvenil. 


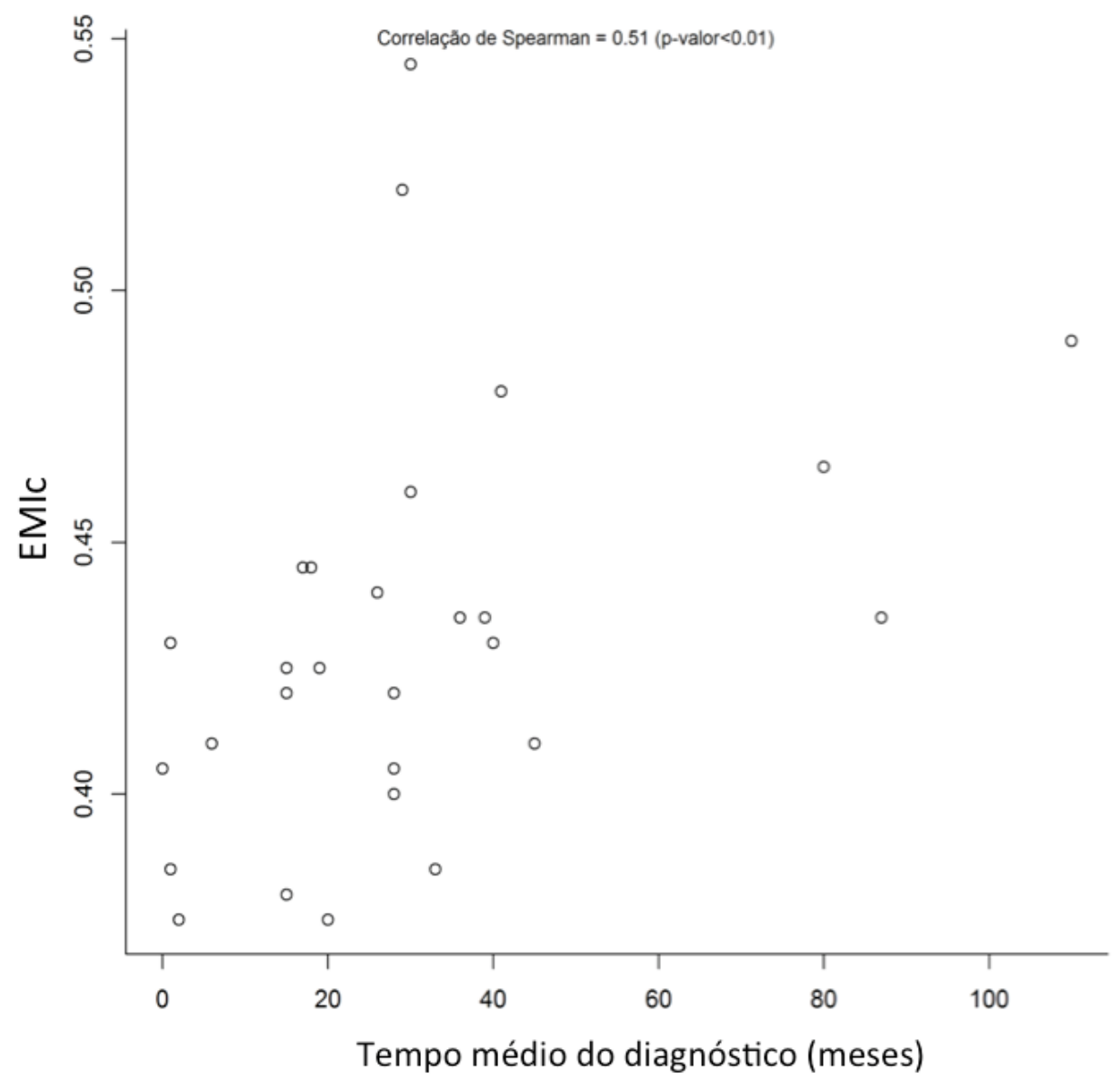

Figura 7: Avaliação da correlação entre tempo médio do diagnóstico no dia da coleta de dados e espessura médio-intimal carótida (EMIc) em pacientes com lúpus eritematoso sistêmico juvenil. 
Tabela 17: Correlações entre variáveis de risco cardiovascular e marcadores inflamatórios com a espessura médio-intimal da carótida em pacientes com lúpus eritematoso sistêmico juvenil

Rho: Coeficiente de correlação de Spearman. EMlc - espessura médio-intimal de carótida.

\begin{tabular}{|c|c|}
\hline Variáveis & EMIc \\
\hline idade na coleta & Rho $=-0,19(p=0,32)$ \\
\hline Tempo do diagnóstico em meses & Rho $=0,51 \quad(p<0,01)$ \\
\hline SLEDAI & Rho $=0,22 \quad(p=0,26)$ \\
\hline Índice de massa corporal & Rho $=-0,09(p=0,65)$ \\
\hline Circunferência de cintura & $\mathrm{Rho}=0,10 \quad(p=0,62)$ \\
\hline Dose média de prednisona em uso & Rho $=-0,006(p=0,97)$ \\
\hline $\begin{array}{l}\text { Dose cumulativa de prednisona na data } \\
\text { da coleta }\end{array}$ & Rho $=0,52(p<0,01)$ \\
\hline Clearance estimado de creatinina & Rho $=-0,13(p=0,50)$ \\
\hline Níveis de Homocisteína & $\mathrm{Rho}=0,16(p=0,42)$ \\
\hline Níveis de folato & Rho $=0,02(p=0,91)$ \\
\hline Níveis de Vitamina B12 & Rho $=-0,20(p=0,31)$ \\
\hline PCR & Rho $=-0,11(p=0,59)$ \\
\hline Níveis de HDL & Rho $=0,28(p=0,14)$ \\
\hline Níveis de LDL & Rho $=-0,35(p=0,08)$ \\
\hline Níveis de triglicérides & $\mathrm{Rho}=0,06(p=0,76)$ \\
\hline Níveis de Colesterol & $\mathrm{Rho}=0,38(p=0,04)$ \\
\hline Dosagem de IL6 & Rho $=-0,18(p=0,46)$ \\
\hline ICAM-1 & Rho $=-0,20(p=0,41)$ \\
\hline VCAM-1 & Rho $=0,005(p=0,98)$ \\
\hline P-selectina & Rho $=-0,16(p=0,51)$ \\
\hline
\end{tabular}

\section{Razões de prevalência}

Quanto aos fatores de riscos tradicionais, apenas a hipertensão não controlada foi significante $(p=0,02)$, demonstrando que a prevalência de aterosclerose subclínica é maior nos pacientes com hipertensão não controlada (tabela 18).

Entre os fatores de riscos NÃO tradicionais, a relação entre proteína e creatinina acima de $0,2(p=0,03)$ e proteinúria nefrótica $(p=0,03)$ apresentaram evidências de diferença entre as prevalências, demonstrando que a prevalência de aterosclerose subclínica é maior nos pacientes com relação proteína/creatinina acima de 0,2 e proteinúria nefrótica. Porém, quando ajustadas pelas variáveis de controle, a diferença entre as prevalências dessas duas variáveis deixa de ser significante $(p>0,05)$ (tabela 19). 
Não foi possível calcular as razões de prevalência para as seguintes variáveis: obesidade, vitamina b12, folato, SLEDAI-2K $>5$ e clearence $<75$ uma vez que não estavam presentes nos dois grupos (com e sem aterosclerose subclínica).

TABELA 18: Regressão log-binominal simples para fatores de risco tradicionais de doença cardiovascular nos pacientes com lúpus eritematoso sistêmico juvenil estudados

\begin{tabular}{|c|c|c|c|c|}
\hline & \multicolumn{2}{|c|}{ Aterosclerose subclínica } & \multirow{2}{*}{$\begin{array}{l}\text { Razão de } \\
\text { prevalência } \\
\text { (IC 95\%) }\end{array}$} & \multirow{2}{*}{$\mathbf{P}$} \\
\hline & Não & Sim & & \\
\hline HAS CONTROLADA & $18(75 \%)$ & $6(25 \%$ & & \\
\hline $\begin{array}{l}\text { NAO }(n=24) \\
\text { SIM }(n=4)\end{array}$ & $1(25 \%)$ & $\begin{array}{l}3(75 \%) \\
3(75 \%)\end{array}$ & $3(1,2 ; 7,3)$ & 0,02 \\
\hline DISLIPIDEMIA & & & & \\
\hline $\begin{array}{l}\text { NÃO }(n=5) \\
\operatorname{SIM}(n=23)\end{array}$ & $\begin{array}{c}4(80 \%) \\
15(65,2 \%)\end{array}$ & $\begin{array}{c}1(20 \%) \\
8(34,8 \%)\end{array}$ & $\begin{array}{c}1 \\
1,74(0,3 ; 10,9)\end{array}$ & 0,56 \\
\hline $\begin{array}{l}\text { ACO } \\
\text { NÃO }(n=19) \\
\operatorname{SIM}(n=3)\end{array}$ & $\begin{array}{c}12(63,2 \%) \\
2(66,7 \%)\end{array}$ & $\begin{array}{l}7(36,8 \%) \\
1(33,3 \%)\end{array}$ & $\begin{array}{c}1 \\
0,9(0,2 ; 4,9)\end{array}$ & 0,91 \\
\hline $\begin{array}{l}\text { SEXO } \\
F(n=26) \\
M(n=2)\end{array}$ & $\begin{array}{c}14(63,64 \%) \\
5(83,33 \%)\end{array}$ & $\begin{array}{l}8(36,36 \%) \\
1(16,67 \%)\end{array}$ & $\begin{array}{c}2,18(0,3 ; 14,2) \\
1\end{array}$ & 0,41 \\
\hline
\end{tabular}

Tabela 19 : Regressão log-binominal simples e múltipla para fatores de risco não tradicionais de doença cardiovascular nos pacientes com lúpus eritematoso sistêmico juvenil estudados

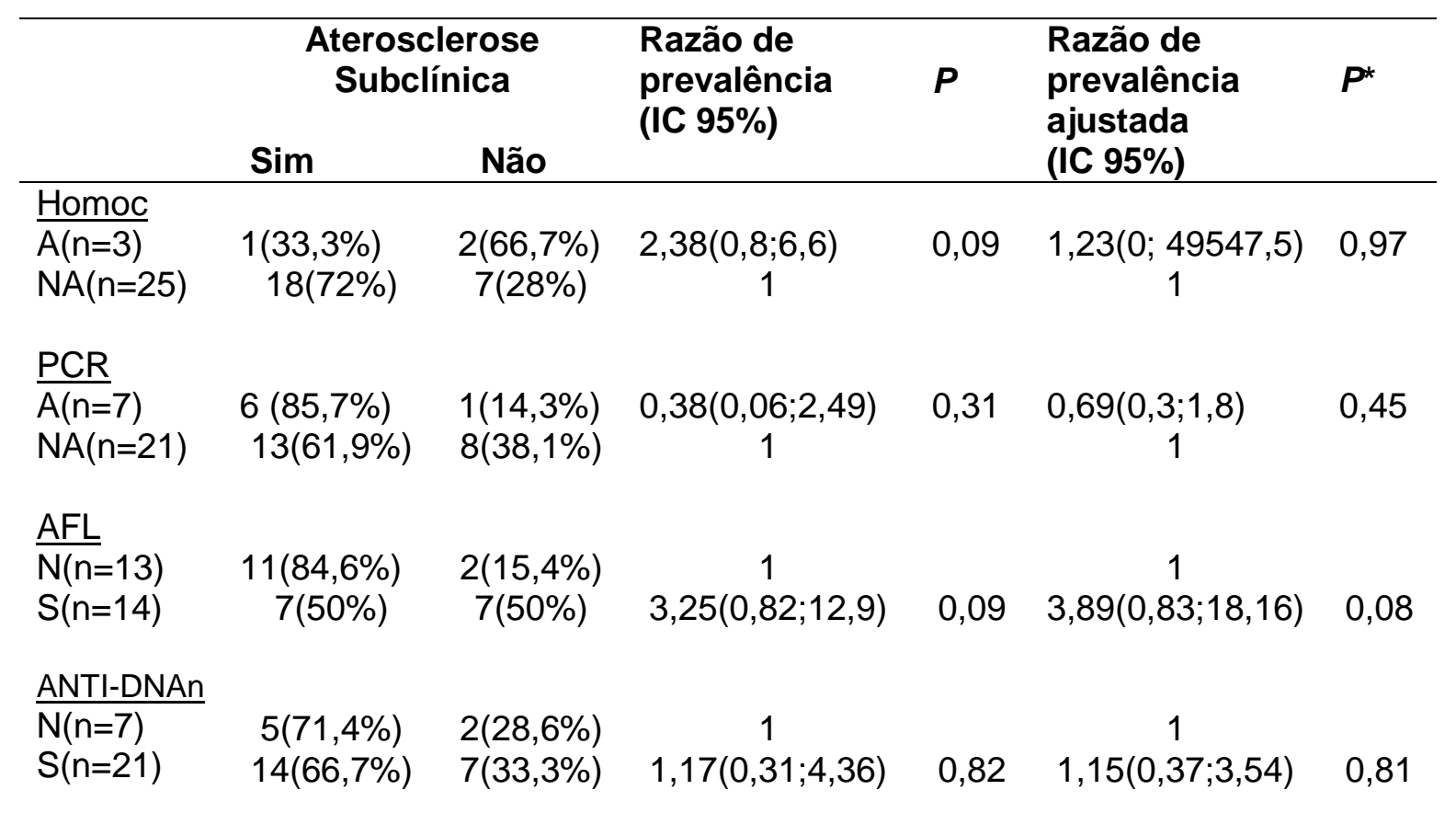




\section{continua}

Tabela 19 : Regressão log-binominal simples e múltipla para fatores de risco não tradicionais de doença cardiovascular nos pacientes com lúpus eritematoso sistêmico juvenil estudados

\section{$\underline{\text { SLICC }>0}$}

$\mathrm{N}(\mathrm{n}=21)$

$S(n=7)$

$$
14(66,6 \%) \quad 7(33,3 \%)
$$

$$
5(71,4 \%) \quad 2(28,5 \%)
$$

$0,86(0,23 ; 3,2)$

0,82

$0,47(0,08 ; 2,75)$

0.40

$\underline{\text { Tempo }}$

diag. $(\mathrm{M})$

m/DP

$$
25,68(20,3) \quad 39(34,2) \quad 1,01(1 ; 1,03) \quad 0,10
$$

$\underline{\text { Nefrite }}$

$\mathrm{N}(\mathrm{n}=3)$

$2(66,6 \%) \quad 1(33, \%)$

1

$\mathrm{S}(\mathrm{n}=25)$

$17(68 \%)$

$8(32 \%)$

$0,96(0,18 ; 5,25)$

0,96

$\stackrel{1}{0,69}(0,08 ; 6,2)$

0,74

$\underline{\text { Alt neuro }}$

$\mathrm{N}(\mathrm{n}=20)$

$14(70 \%)$

$6(30 \%)$

1

$\mathrm{S}(\mathrm{n}=8)$

$5(62,5 \%)$

$3(37,5 \%)$

$1,25(0,41 ; 3.82)$

0,70

1
$1,3(0,44 ; 3.82)$

0,63

Dose Cum

$\operatorname{pred}(\mathrm{g})$

média/DP

$16,75(14,8) \quad 22,6(18)$

$1,01(0,98 ; 1,0)$

0,40

$1.0(0,93 ; 1,07)$

0,90

$\underline{\mathrm{CFM}}$

$\mathrm{N}(\mathrm{n}=13)$

$\begin{array}{cc}9(69,2 \%) & 4(30,7 \%) \\ 10(66,7 \%) & 5(33,3 \%)\end{array}$

1
$1,08(0,3 ; 3,2)$

0,88

1
$0,93(0,3 ; 3,08)$

0,90

$S(n=15)$

$10(66,7 \%) \quad 5(33,3 \%)$

$13(68,4 \%) \quad 6(31,5 \%)$

1
$1,06(0,3 ; 3,3)$

0,93

1
$1,04(0,4 ; 2,6)$

0,94

$S(n=9)$

$6(66,6 \%)$

$3(33.3 \%)$

Micof

$\mathrm{N}(\mathrm{n}=20)$

$$
13(65 \%)
$$

$7(35 \%)$

$6(75 \%)$

2(25\%)

$0,71(0,2 ; 2,7)$

0,62

$1,14(0,3 ; 3,6)$

0,82

$\frac{\text { Rel } P / C}{A(n=12)}$

$\mathrm{A}(\mathrm{n}=12)$
$\mathrm{NA}(\mathrm{n}=16)$

$5(41,6 \%)$

$7(58,3 \%)$

$4,67(1,17 ; 18,58)$

0,03

$1,65(0,57 ; 4,74)$
1

0,35

$\underline{\text { Prot nef }}$

$\mathrm{A}(\mathrm{n}=8)$

$14(87,5 \%) \quad 2(12,5 \%)$

1

$\mathrm{NA}(\mathrm{n}=20)$

$\begin{array}{ccc}3(37,5 \%) & 5(62,5 \%) & 3,13(1,12 ; 8,73) \\ 16(80 \%) & 4(20 \%) & 1\end{array}$

0,03

$1,34(0,51 ; 3,53)$

0,55

$\mathrm{A}=$ alterado, $\mathrm{NA}=$ não alterado, $\mathrm{N}=$ não. $\mathrm{S}=$ sim, $\mathrm{Homoc}=$ homocisteina, $\mathrm{PCR}=$ proteína $\mathrm{C}$ reativa ultrassensível, $\mathrm{AFL}=$ anticorpo antifosfolípide, Anti-DNA = anticorpo anti-DNA- nativo, SLICC- índice de dano cumulativo no lúpus, Tempo $\operatorname{diag}(\mathrm{M})=$ tempo de diagnóstico em meses, Alt neuro= alteração neurológica, dose cum red $(\mathrm{g})=$ dose cumulativa de prednisona em gramas, CFM= ciclofosfamida, $A Z A=$ azatioprina, Micof = micofenolato, Rel $\mathrm{P} / \mathrm{C}=$ relação proteína creatinina $>0,2 ;$ Prot nef $=$ proteinúria nefrótica/relação proteína creatinina $>1, P$ *- $\mathrm{P}$ valor após ajuste 


\subsubsection{Regressão linear simples e múltipla}

A tabela 20 apresenta os resultados de modelos de análise de regressão simples e múltipla para avaliação da associação das médias de diferenças dos valores absolutos de EMlc e as variáveis descritas.

Observou-se que as variáveis SLEDAI-2K maior que 5 , presença de proteinúria definida pela relação proteína creatinina acima de 0,2 e proteinúria nefrótica se associaram estatisticamente com o $\Delta$ dos valores absolutos do EMlc entre os grupos.

O SLEDAI-2K acima de 5 mantém associação significativa com o espessamento da carótida, no modelo dois, ajustado por triglicérides, LDL, HDL, colesterol total e no modelo três, ajustado por triglicérides, LDL, HDL e colesterol total, hipertensão arterial sistêmica não controlada e estatura abaixo do percentil 3. No modelo um, por dose cumulativa de prednisona e tempo do diagnostico, a variável se aproxima de uma associação significante ( $\mathrm{p} 0,06$ ).

As variáveis proteinúria e proteinúria nefrótica não mantiveram associação com o espessamento de carótida após ajuste. (tabela 20).

Tabela 20: Modelo de Regressão Linear Simples e múltiplo para avaliar as

associações das variáveis de interesse com a diferença dos valores absolutos de EMlc entre os pacientes com lúpus eritematoso sistêmico juvenil

\begin{tabular}{|c|c|c|c|c|c|c|c|c|c|}
\hline \multirow[b]{4}{*}{ Mod } & \multicolumn{9}{|c|}{ EMlc média mm } \\
\hline & \multirow[b]{3}{*}{ Variável } & \multicolumn{3}{|c|}{ Modelo simples } & & \multicolumn{3}{|c|}{ Modelo ajustado } & \\
\hline & & \multirow[b]{2}{*}{ DM } & \multirow[b]{2}{*}{$\begin{array}{l}\mathrm{p}- \\
\text { valo }\end{array}$} & \multicolumn{2}{|r|}{ IC95\% } & \multirow[b]{2}{*}{ DM } & \multirow[b]{2}{*}{$\begin{array}{l}\mathrm{p}- \\
\text { valo }\end{array}$} & \multicolumn{2}{|c|}{ IC95\% } \\
\hline & & & & $\mathrm{LI}$ & LS & & & $\mathrm{LI}$ & LS \\
\hline 1 & SLEDAI >5 & $-0,033$ & 0,03 & $-0,064$ & $-0,0029$ & $-0,026$ & 0,06 & $-0,054$ & 0,001 \\
\hline 2 & SLEDAI>5 & $-0,033$ & 0,03 & $-0,064$ & $-0,0029$ & $-0,038$ & 0,03 & $-0,073$ & $-0,0029$ \\
\hline 3 & SLEDAI>5 & $-0,033$ & 0,03 & $-0,064$ & $-0,0029$ & $-0,044$ & 0,02 & $-0,081$ & $-0,0065$ \\
\hline 4 & Proteinúria & 0,032 & 0,04 & 0,0017 & 0,06 & 0,017 & 0,24 & $-0,012$ & 0,047 \\
\hline 5 & Clearence $<75$ & $-0,045$ & 0,07 & $-0,094$ & 0,004 & $-0,023$ & 0,41 & $-0,082$ & 0,034 \\
\hline 6 & Clearence $<75$ & $-0,045$ & 0,07 & $-0,094$ & 0,004 & 0,012 & 0,87 & $-0,14$ & 0,16 \\
\hline 7 & Prot Nef & 0,011 & 0,52 & $-0,024$ & 0,047 & 0,005 & 0,84 & $-0,045$ & 0,055 \\
\hline 8 & Prot Nef & 0,011 & 0,52 & $-0,024$ & 0,047 & 0,006 & 0,7 & $-0,026$ & 0,039 \\
\hline
\end{tabular}

SLEDAI >5: índice de SLEDAI-2K > 5; Clearance $<75$ : clearance estimado de creatinina menor que $75 \mathrm{ml} / \mathrm{min} / 1,73 \mathrm{~m}^{2} ;$ Prot Nef - proteinuria em níveis nefroticos, relação proteína/creatinina maior que 1. LI: limite inferior do intervalo; LS: limite superior do intervalo; IC: intervalo de confiança; DM: diferença entre as médias

Modelo 1, 4, 5, 8 ajustado por dose cumulativa de prednisona e tempo do diagnóstico

Modelo 2 ajustado por triglicerides, LDL, HDL, Colesterol

Modelo 3,6,7, ajustado por triglicerides, LDL, HDL, Colesterol, Hipertensão arterial sistêmica não controlada e estatura abaixo do percentil 3 . 


\section{Discussão}

A prevalência de aterosclerose subclínica, avaliada pelo espessamento médiointimal da carótida, em pacientes com lúpus eritematoso sistêmico juvenil, atendidos no ambulatório de reumatologia pediátrica do Hospital das Clinicas da Faculdade de Medicina de Ribeirão Preto, foi de 32 \% no presente estudo.

A prevalência de aterosclerose subclínica em mulheres adultas com lúpus varia de 30 a 40\%, sendo o diagnóstico realizado pela presença de placas em carótida ou perfusão miocárdica anormal (Esdaile et al., 2001). No Brasil, estudos mostram uma frequência de $50 \%$ de placas ateroscleróticas em mulheres com lúpus eritematoso sistêmico com média de idade de 34 anos (Souza et al., 2005).

Em crianças, poucos estudos avaliam aterosclerose subclínica em lúpus e seus fatores de risco. No Brasil, não encontramos nenhum estudo que avaliou o espessamento da carótida no lúpus juvenil.

A primeira dificuldade foi estabelecer parâmetros de normalidade dos índices do espessamento de carótida (EMIc) na população pediátrica brasileira. Nesse estudo, utilizamos valores de normalidade em curvas de percentis, para crianças abaixo de 18 anos (Doyon et al., 2013; Dalla Pozza et al., 2016), e para os adolescentes entre 18 e 21 anos (Denarie et al., 2000; Jourdan et al., 2005) e consideramos aterosclerose subclínica um espessamento médio-intimal carotídeo superior ao percentil 90 (Magnussen et al., 2009).

A maioria dos estudos avalia comparativamente os valores absolutos das medidas EMlc para avaliação de fatores de risco, dessa forma, realizamos, além da classificação em percentis, a análise dos valores absolutos de EMlc em relação aos fatores de risco avaliados. A utilização de duas abordagens de análise foi proposta pois a referência de normalidade dos valores de EMIc por idade e estatura foi obtida de uma população que não possui as mesmas características étnicas e epidemiológicas do grupo estudado, e não tivemos um grupo controle. Porém, os resultados foram semelhantes nas duas formas de avaliação.

O lúpus eritematoso sistêmico está associado ao desenvolvimento de aterosclerose precoce e os pacientes apresentam risco até seis vezes maior de desenvolver lesões ateroscleróticas quando comparados com a população geral (Bjornadal et al., 2004; Bartels et al., 2014). Esse maior risco de aterosclerose é resultado dos fatores de risco cardiovascular tradicionais associados a fatores de 
risco relacionados à própria doença, como a complexa interação entre autoanticorpos e o processo inflamatório na parede dos vasos, e o seu tratamento (Ahmad et al., 2007; Skaggs et al., 2012).

Pacientes com lúpus têm uma taxa de mortalidade 2,6 vezes maior quando comparados à população geral, ajustada por sexo e idade em estudos de coorte prospectivos (Lee et al., 2016). Até sete anos do início dos sintomas, as principais causas de morte são infecções decorrentes da imunossupressão e complicações relacionadas à atividade de doença, sobretudo nefrite lúpica e acometimento do sistema nervoso central. Após 7 anos de doença, as doenças cardiovasculares estão entre as principais causas de morte nesses pacientes, juntamente com a toxicidade ao tratamento e às comorbidades, como a doença renal crônica (Fors Nieves e Izmirly, 2016).

Em 2017, uma revisão sobre doença cardiovascular no lúpus estimou a prevalência de doença cardíaca isquêmica entre 3,8 e 16 \% (Badui et al., 1985; Gladman e Urowitz, 1987; Petri et al., 1992; Borchers et al., 2004; Fernandez-Nebro et al., 2015) com risco 10 vezes maior quando comparado à população geral e 50 vezes maior em mulheres jovens em idade reprodutiva. O risco de acidente vascular cerebral em pacientes lúpicos também é aumentado, variando de 2 a 8 vezes em diferentes estudos (Esdaile et al., 2001; Arkema et al., 2017; Avina-Zubieta et al., 2017). No Brasil, estudos mostram progressão do aumento de placas ateroscleróticas e espessamento da carótida em $27 \%$ e 19,7\%, respectivamente, dos pacientes com lúpus, no período de um ano (Telles et al., 2013).

Em 2018, Ocampo-Piraquive e colaboradores, revisaram causas de mortalidade no lúpus e encontraram taxa de mortalidade de 2,4 (IC $95 \% 2,3-2,5$ ) nesses pacientes, agrupando as causas de morte em três situações: atividade de doença, infecções e doenças cardiovasculares (Ocampo-Piraquive et al., 2018). As causas de morte no lúpus variam em frequência, de acordo com a área geográfica em que os pacientes se encontram, sendo os eventos cardiovasculares a principal causa de morte nos países desenvolvidos, como a França, enquanto infecções e doenças renais são as principais causas de óbito em países em desenvolvimento , incluindo o Brasil (Souza et al., 2012; Thomas et al., 2014).

Tselios et al, em revisão sistemática, compararam 101 estudos sobre eventos cardiovasculares no lúpus e sugeriram diretrizes para investigar e monitorar o risco de doença aterosclerótica no LES. Nessa revisão, vários fatores de risco tradicionais 
e não tradicionais foram identificados como determinantes do alto risco cardiovascular no LES. Os fatores de risco tradicionais foram idade, sexo masculino, história familiar positiva de doença coronariana prematura, obesidade, hipertensão arterial, diabetes, dislipidemia, síndrome metabólica, hiperhomocisteinemia e tabagismo. Os fatores de risco relacionados ao lúpus foram a atividade e duração da doença, dano cumulativo, presença de anticorpos antifosfolípides e anti-DNA nativo, proteína $C$ reativa aumentada, presença de nefrite, envolvimento neuropsiquiátrico, uso de corticoide e imunossupressores (Tselios et al., 2016).

Outros estudos avaliaram os riscos de aterosclerose no lúpus. Uma metanálise e revisão sistemática de 2016, incluiu 80 estudos com 6085 pacientes lúpicos e 4794 controles e demonstrou que os pacientes lúpicos têm maior EMlc e prevalência de 2,5 vezes maior da presença de placas ateroscleróticas quando comparados à população geral. Concluíram que o LES se associa a aterosclerose subclínica, um importante preditor de risco cardiovascular futuro. As variáveis de risco tradicional estudadas: maior idade, níveis aumentados de HDL e triglicerídeos e os fatores de risco relacionados ao LES: duração de doença, velocidade de hemossedimentação, SLEDAl e uso de corticoide influenciaram significativamente o EMlc (Wu et al., 2016). Todas essas variáveis de possível associação com aterosclerose subclínica, descritas em estudos anteriores, foram avaliadas no presente estudo.

Em nosso grupo de estudo, a idade média ao diagnóstico foi de 11, 4 anos, tendo o paciente mais novo seis anos de idade, 78,6\% dos participantes eram do sexo feminino, o acometimento renal foi o critério de classificação mais frequente $(89,2 \%)$ e $60 \%$ dos pacientes apresentavam moderada a alta atividade de doença. $O$ perfil dos pacientes do estudo é semelhante ao descrito na literatura, em relação ao lúpus juvenil. $A$ frequente e marcada atividade renal, necessitando de imunossupressão mais intensa, e maior dose de corticoide para induzir remissão, o longo tempo de doença crônica, com inicio ainda na infância, acumulando mais danos resultantes da própria doença e os efeitos colaterais do tratamento, aumentam os riscos de doenças cardiovasculares dessas crianças em relação aos adultos (Brunner et al., 2008).

A aterosclerose subclínica pode estar presente muito tempo antes do aparecimento dos sintomas clínicos associados às doenças cardiovasculares. Porém, é possível a determinação de sua presença e a atuação mais efetiva em 
relação à exposição aos fatores de risco, atuando na prevenção de sua evolução. Assim, vários estudos avaliaram métodos de detecção de aterosclerose subclínica. Entre eles, o mais utilizado é o ultrassom de carótida, que avalia a EMlc, medida não invasiva, de baixo risco, reprodutível, sendo possível avaliar sua variabilidade durante o acompanhamento dos pacientes. Esse foi o método de avaliação utilizado (Barsalou, Bradley, et al., 2013).

Em nosso estudo, foram avaliados 28 pacientes, em 4 etapas sucessivas, em um mesmo tempo. Além da avaliação ultrassonográfica, foram realizadas avaliação clínica, avaliação nutricional e avaliação laboratorial visando estabelecer associações dos fatores de risco com o espessamento médio-intimal da carótida.

A média de EMlc nos nossos pacientes foi de 0,42 +/- 0,04 mm no sexo feminino e 0,46 +/- 0,05 mm no sexo masculino, sendo significante a associação das médias em relação as variáveis estudadas: hipertensão arterial não controlada e baixa estatura, atividade moderada de doença (SLEDAI-2K maior que 5), presença de proteinúria e clearance estimado de creatinina abaixo de $75 \mathrm{ml} / \mathrm{min} / 1,73 \mathrm{~m}^{2}$. Encontramos também correlação moderadamente positiva entre as medidas de EMIc e a dose cumulativa de prednisona e entre o tempo do diagnóstico em meses. Após ajuste, a única variável que manteve-se significante para associação ao risco aumentado de aterosclerose foi a atividade moderada de doença.

Quanto à classificação de aterosclerose subclínica pelos percentis, 9 pacientes se encontravam acima do percentil 90 (32\%). Foram fatores associados a ter aterosclerose: hipercolesterolemia, atividade de doença moderada (SLEDAI-2K > 5), proteinúria, proteinúria nefrótica e clearance estimado de creatinina abaixo de $\mathrm{ml} / \mathrm{min} / 1,73 \mathrm{~m}^{2}$. Mesmo em valores absolutos, os índices de atividade de doença e níveis de colesterol foram maiores nos pacientes com aterosclerose subclínica. $\mathrm{Na}$ estimativa de razão de prevalência, apenas a hipertensão não controlada se associou de forma significativa com a presença de aterosclerose subclínica.

Estudos semelhante avaliaram o espessamento médio-intimal carotídeo no contexto do lúpus eritematoso sistêmico juvenil e de sua relação com características do grupo avaliado.

Em relação aos fatores de risco tradicionais e lúpus juvenil, Boros et al em 2011, demostraram que a hipertensão, triglicérides elevados, apolipoproteina $B$, hemoglobina glicada, insulina, homocisteína e fibrinogênio se associaram positivamente em 54 adolescentes com lúpus (Boros et al., 2011). Bowser et al, em 
2008, avaliaram associação de infecção por Chlamydia pneumoniae e o EMlc, e não detectaram associação entre a infecção e o espessamento, porém os níveis de triglicérides foram significativamente maiores nos pacientes com lúpus (Bowser et al., 2008).

No nosso grupo, o fator de risco tradicional mais significativo para aterosclerose foi a hipertensão não controlada, que permaneceu significante mesmo após ajustes. Apresentavam algum tipo de dislipidemia, 89,3\% dos pacientes avaliados, a maioria baixos níveis de HDL (64\%). Houve diferença significativa nos níveis de colesterol total, sendo níveis mais elevados entre os pacientes com aterosclerose subclínica. Somado como agravante, está o fato de $78,6 \%$ dos participantes terem uma qualidade de dieta ruim (IQDR <65) e apenas dois realizarem atividade física regular, fora as atividades de vida diária e recreativas. É provável que a qualidade da dieta não tenha estimado corretamente os hábitos alimentares de nossos pacientes pois se basearam em apenas um único recordatório alimentar de 24 horas, obtido no dia da coleta, mas reflete a necessidade de orientação alimentar adequada desses pacientes para controle dos riscos adicionais.

Outros fatores de risco tradicionais foram detectados em nossos pacientes: seis indivíduos do sexo masculino, um diabético, quatro obesos e três meninas em uso de anticoncepcional. Apesar de nenhuma dessas variáveis, incluindo a dislipidemia e obesidade, se associarem significativamente à presença de aterosclerose subclínica no presente estudo, o controle desses fatores é de extrema importância, visto que se somam ao fatores inerentes ao próprio lúpus.

O índice de massa corpórea, sobrepeso e obesidade (Schanberg et al., 2009) e dislipidemias (Giannelou e Mavragani, 2017) foram associados com aterosclerose precoce em adultos e crianças em outros estudos. Sacre et al, avaliaram 49 pacientes lúpicos e controles saudáveis e identificaram a obesidade e o sobrepeso como fator contribuinte para aterosclerose. O excesso de tecido adiposo pode liberar níveis patológicos de hormônios, proteínas e citocinas que não só elevam o risco cardiovascular como agravam a doença autoimune de base (Sacre et al., 2015). A presença de biomarcadores proaterogênicos já foi descrita no lúpus, mesmo em crianças com baixa dose de corticoide e baixa atividade de doença (Machado et al., 2017).

Quanto aos fatores de risco relacionados à própria doença, destaca-se a 
presença de nefrite lúpica. A doença renal está envolvida no risco cardiovascular, sendo um preditor independente de eventos cardiovasculares, aumento da rigidez da parede aórtica, aumento da EMI carotídea e de placas ateroscleróticas (Tselios et al., 2016).

Falaschi et al, em 2000, avaliaram 26 pacientes com LESJ e seus controles, pareados por sexo e idade. A média do EMlc nos lúpicos foi significantemente maior do que nos controles $(0.57+/-0.05 \mathrm{~mm}$ e $0.54+/-0.03 \mathrm{~mm}$, respectivamente; $P=$ 0.006), principalmente nos lúpicos com proteinúria nefrótica (Falaschi et al., 2000).

A doença renal crônica contribui para progressão da aterosclerose no lúpus pediátrico (Barsalou, Bradley, et al., 2013), sendo um importante fator preditor de mortalidade por LES na vida adulta (Ocampo-Piraquive et al., 2018).

Em nosso estudo, a proteinúria e a proteinúria nefrótica foram fatores de associação em análises univariadas, mas não mantiveram significância após ajustes em modelos de regressão. O mesmo aconteceu com a variável clearance de creatinina abaixo de $75 \mathrm{ml} / \mathrm{min} / 1,73 \mathrm{~m}^{2}$. Porém, acreditamos que um cuidado especial deve ser dirigido a esses pacientes no intuito de controlar os demais fatores associados a aterosclerose precoce, principalmente a atividade de doença renal, uma vez que o acometimento renal, está associado ao maior risco para o desenvolvimento de doenças cardiovasculares.

Outro fator importante relacionado ao LESJ, que influencia no desenvolvimento da aterosclerose é a atividade de doença, uma vez que esta cursa com maior resposta imune e inflamatória, alterações patológicas no perfil lipídico e demanda maior dose de corticoide e, por vezes, uso de imunossupressores potentes para controle da doença (Fadda et al., 2015).

Em nosso estudo, a média do índice de atividade de doença, SLEDAI-2K, foi de 7,9 considerado atividade moderada de doença. O SLEDAI-2K maior que 5, ou seja, atividade de doença moderada ou alta, se associou a aterosclerose subclínica na análise univariada, mantendo associação significativa com o espessamento da carótida, mesmo após ajuste na regressão por níveis de triglicérides, LDL, HDL, colesterol total, isoladamente e associados à hipertensão arterial sistêmica não controlada. Quando ajustado por dose cumulativa de prednisona e tempo do diagnóstico a variável SLEDAI-2K se aproximou da associação significativa $(p 0,06)$ 
Dessa forma, consideramos no presente estudo, atividade do lúpus, moderada a alta, fator de risco independente para aterosclerose subclínica em pacientes com lúpus eritematoso sistêmico juvenil.

Su-angka et al em 2017, avaliaram o EMIc e o índice de rigidez arterial carotídeo (IRAc) em 102 pacientes com LESJ e 103 controles, subdividindo os pacientes em doença ativa (SLEDAI $\geq 6$ ) e não ativa. A diferença das média do EMIc entre os grupos não foi significativa, porém o IRAc no lúpus ativo e inativo foi significantemente maior nos pacientes do que nos controles, sem diferença significativa entre as medidas de IRAc dos LESJ ativos e não ativos. O maior IRAc nos lúpicos implica alteração funcional das artérias, alteração anterior ao maior EMlc (Su-Angka et al., 2017).

Huang et al em 2009, acompanharam 76 pacientes com LESJ e seus 38 controles com avaliações a cada seis meses através de ultrassom de carótida, exames laboratoriais e avaliação clínica pelo período de 6 anos a fim de identificar os fatores de risco para aterosclerose nessa população. A média do EMlc diferiu significativamente entre pacientes e controles $(0.63+/-0.08 \mathrm{~mm}$ versus $0.54+/-0.06$ $\mathrm{mm} ; \mathrm{P}<0.001)$. Linfopenia ao diagnóstico; linfopenia, níveis elevados de creatinina e da proteína $C$ reativa na primeira avaliação se associaram positivamente com a progressão do EMlc ( $P=0.006, P=0.043, P=0.037$, and $P=0.049$, respectivamente). $A$ presença de linfopenia foi o único fator de risco independente para progressão (Huang et al., 2009). Alterações de hemograma não se associaram a aterosclerose subclínica em nosso grupo de estudo.

O maior número de pacientes pediátricos avaliados foi no estudo de Schanberg et al, em 2009, que acompanhou uma coorte de 221 pacientes com LESJ por 3 anos, em um estudo denominado APPLE (Schanberg et al.). A média do EMIc na inclusão foi de $0,59 \pm 0,05 \mathrm{~mm}$. Os fatores de risco tradicionais, associados ao aumento da EMIc, foram idade, sexo masculino e maior IMC. Os fatores de risco associados ao lúpus foram o tratamento com azatioprina e dose de corticoide por peso corporal. (Schanberg et al., 2009)

Altas doses de corticoide, cumulativo ou diário, também configuram um preditor independente dessas alterações (Tselios et al., 2016). No entanto, não verificamos associação do EMlc com o uso atual ou com a dose cumulativa de prednisona, em nosso grupo. Houve apenas correlação moderada entre dose 
cumulativa de prednisona e espessura médio-intimal de carótida.

Quanto ao índice de danos cumulativos (SLICC/ACR DI), 25\% de nossos pacientes apresentam score acima de zero, porém ter sequelas associadas ao lúpus não se associou à aterosclerore subclínica. Um estudo publicado em 2019 avaliou 276 pacientes adultos com lúpus quanto ao risco cardiovascular pelo índice de avaliação sistemática do risco coronariano- SCORE (Miura et al.). Em uma primeira análise, apenas 6\% apresentavam alto risco cardiovascular segundo o SCORE, porém, ao ser realizado ultrassom para avaliação de EMlc foi detectado placas ateroscleróticas em 85 pacientes, mesmo com risco CV baixo ou intermediário no SCORE. Após o ultrassom, os pacientes foram reclassificados, passando a frequência, de 6 para 37\%, de pacientes com alto risco para doença cardiovascular. Os fatores que mais se associaram a reclassificação foram o tempo de doença, o SLICC/ACR ID >0 e os níveis de C3. Pela primeira vez na literatura, a reclassificação de risco CV se atribuiu a dano causado pela doença (QuevedoAbeledo et al., 2019). Dessa forma, a realização de ultrassonografia para avaliação do espessamento de carótida deve ser rotina para avaliação de risco de aterosclerose e sequelas relacionadas ao lúpus, principalmente em pacientes com outros riscos associados.

Em nosso estudo, não encontramos associação entre provas de atividade inflamatória e citocinas (PCR ultra sensível, TNF-alfa, IL1-1 alfa, IL-1 beta, IL-10, INF- gama, IL- 17, IL-6), bem como moléculas de adesão (P-selectina, VCAM-1, ICAM-1) e o EMlc. Os dados em relação às citocinas provavelmente não foram representativos e adequados para análise pois excluímos nove pacientes da análise por amostra inadequada (separado soro e não plasma), e não contamos com um grupo controle para avaliação comparativa.

Consideramos que nosso estudo apresentou limitações: pequeno tamanho amostral, desenho transversal e a ausência de um grupo controle saudável para comparação dos resultados. Apesar do objetivo principal ser a comparação das variáveis de risco para aterosclerose entre lúpicos com e sem aterosclerose subclínica, poderíamos ter uma amostra comparativa dos valores de EIMc pareados pela idade e sexo em não lúpicos. Infelizmente a realização da ultrassonografia por outra equipe, treinada e habilitada, e a logística complexa do processo impediu o aumento do número de pacientes avaliados e a definição de um grupo controle. Outro fator limitante, foi a indisponibilidade dos pais em acompanharem os pacientes 
na avaliação em mais um outro dia, quando não foi possível avaliá-los no dia do atendimento regular.

Independente dessas limitações, poucos estudos internacionais, e na nossa revisão, nenhum estudo nacional, avaliaram o EMlc no lupús eritematoso sistêmico juvenil e sua relação com fatores de risco tradicionais e não tradicionais para aterosclerose subclínica. A atividade moderada a alta de doença, definida pelo SLEDAI-2K acima de 5, foi fator de risco independente no nosso estudo. Dessa forma, o controle adequado da doença pode diminuir o risco de aterosclerose nesses pacientes. Pacientes com alta atividade de doença apresentam um risco aumentado de aterosclerose e devem ser rigorosamente monitorados quanto aos fatores de risco adicionais.

Outra sugestão do nosso estudo, através desse achado, é que pacientes com lúpus com atividade moderada a alta de doença, realizem avaliação periódica de EMlc. Estudos longitudinais prospectivos e com maior número de pacientes são necessários para melhor avaliar o papel da atividade do lúpus na formação da aterosclerose e o papel da intervenção precoce no controle de doença na diminuição de risco de doença cardiovascular nesses pacientes.

Nosso estudo foi relevante em nossa prática clínica diária, uma vez que possibilita o desenvolvimento de estratégias de intervenção, com a finalidade de prevenir e reduzir ao máximo o risco de doença cardiovascular futura em nossos pacientes pediátricos com LES. Além de sua importância em nossa unidade, nosso estudo pode se tornar referência para o planejamento de estudos mais amplos, multicêntricos, com maior período de observação capazes de fornecer dados mais acurados e representativos de preditores de risco para população brasileira com LESJ 


\section{Conclusões}

1- O coeficiente de prevalência pontual de aterosclerose subclínica foi de $32,14 \%$ (IC 95\%: 14,8; 49,4) em nosso grupo de estudo.

2- Não houve associação entre sexo, idade, raça e índice de massa corporal e o EMlc nos pacientes com LESJ.

3- Não houve associação entre medicamentos em uso, dose acumulada de corticoide, fatores de risco tradicionais para aterosclerose (dislipidemia, obesidade, diabetes, tabagismo e uso de anticoncepcional) e fatores de risco não tradicionais (homocisteína, vitamina B12, folato, PCR ultra sensível, TNF-alfa, IL1-1 alfa, IL-1 beta, IL-10, INF- gama, IL-17, IL-6, P- selectina, VCAM-1, ICAM-1) e o EMIc nos pacientes com LESJ.

4- Entre os fatores de risco tradicionais para doença cardiovascular, a hipertensão não controlada se associa à aterosclerose subclínica.

5- Entre os fatores de risco não tradicionais, a proteinúria, avaliada pela relação proteína creatinina $>0,2$, proteinúria nefrótica, clearance estimado de creatinina menor que $75 \mathrm{ml} / \mathrm{min} / 1,73 \mathrm{~m}^{2} \mathrm{e}$ índice de atividade de doença moderado a alto (SLEDAI-2K >5) se associaram à aterosclerose subclínica.

6- Apenas 0 índice de atividade de doença moderado a alto (SLEDAI-2K >5) manteve associação com o EMlc nos pacientes com LESJ após ajuste pelas variáveis de controle.

7- O índice de danos cumulativos (SLICC/ACR DI) não se associou ao EMlc em nossos pacientes com LESJ. 


\section{Referências}

AHMAD, Y.; BRUCE, I. N. Subclinical atherosclerosis in systemic lupus erythematosus. J Rheumatol, v. 31, n. 5, p. 841-3, May 2004. ISSN 0315-162X (Print)

0315-162X (Linking). Disponível em: < http://www.ncbi.nlm.nih.gov/pubmed/15124239 $>$.

AHMAD, Y. et al. Subclinical atherosclerosis in systemic lupus erythematosus (SLE): the relative contribution of classic risk factors and the lupus phenotype. Rheumatology (Oxford), v. 46, n. 6, p. 983-8, Jun 2007. ISSN 1462-0324 (Print) 1462-0324 (Linking). Disponível em: < https://www.ncbi.nlm.nih.gov/pubmed/17384179 $>$.

AIT-OUFELLA, $\mathrm{H}$. et al. Natural regulatory $\mathrm{T}$ cells control the development of atherosclerosis in mice. Nat Med, v. 12, n. 2, p. 178-80, Feb 2006. ISSN 1078-8956 (Print)

1078-8956 (Linking). Disponível em: < https://www.ncbi.nlm.nih.gov/pubmed/16462800 $>$.

AMERICAN DIABETES, A. 2. Classification and Diagnosis of Diabetes: Standards of Medical Care in Diabetes-2019. Diabetes Care, v. 42, n. Suppl 1, p. S13-S28, Jan 2019. ISSN 1935-5548 (Electronic)

0149-5992 (Linking). Disponível em: < https://www.ncbi.nlm.nih.gov/pubmed/30559228 $>$.

AMMIRATI, E. et al. The role of $T$ and $B$ cells in human atherosclerosis and atherothrombosis. Clin Exp Immunol, v. 179, n. 2, p. 173-87, Feb 2015. ISSN 13652249 (Electronic)

0009-9104 (Linking). Disponível em: < https://www.ncbi.nlm.nih.gov/pubmed/25352024 $>$.

ARKEMA, E. V. et al. Stroke in systemic lupus erythematosus: a Swedish population-based cohort study. Ann Rheum Dis, v. 76, n. 9, p. 1544-1549, Sep 2017. ISSN 1468-2060 (Electronic)

0003-4967 (Linking). Disponível em: < https://www.ncbi.nlm.nih.gov/pubmed/28400384 $>$.

ASANUMA, Y. et al. Increased concentration of proatherogenic inflammatory cytokines in systemic lupus erythematosus: relationship to cardiovascular risk factors. J Rheumatol, v. 33, n. 3, p. 539-45, Mar 2006. ISSN 0315-162X (Print) 0315-162X (Linking). Disponível em: < https://www.ncbi.nlm.nih.gov/pubmed/16463434 $>$.

Avaliação da composição corporal por bioimpedanciometria - Associação Brasileira de Nutrologia. 2015. Disponível em: < http://diretrizes.amb.org.br/_DIRETRIZES/Avalia\%C3\%A7\%C3\%A3o_da_Composi\%C3\% A7\%C3\%A3o_Corporal_por_Bioimpedanciometria_(BIA)_aut_autores/O Meu Cat\%C3\%A1logo/files/assets/common/downloads/publication.pdf >. Acesso em: 20/09. 
AVINA-ZUBIETA, J. A. et al. Risk of Myocardial Infarction and Stroke in Newly Diagnosed Systemic Lupus Erythematosus: A General Population-Based Study. Arthritis Care Res (Hoboken), v. 69, n. 6, p. 849-856, Jun 2017. ISSN 2151-4658 (Electronic)

2151-464X (Linking). Disponível em: < https://www.ncbi.nlm.nih.gov/pubmed/28129475 $>$.

BACK GIULIANO IDE, C. et al. [I guidelines of prevention of atherosclerosis in childhood and adolescence]. Arq Bras Cardiol, v. 85 Suppl 6, p. 4-36, Dec 2005. ISSN 0066-782X (Print)

0066-782X (Linking). Disponível em: < https://www.ncbi.nlm.nih.gov/pubmed/16597097 $>$.

BADUI, E. et al. Cardiovascular manifestations in systemic lupus erythematosus. Prospective study of 100 patients. Angiology, v. 36, n. 7, p. 431-41, Jul 1985. ISSN 0003-3197 (Print)

0003-3197 (Linking). Disponível em: < https://www.ncbi.nlm.nih.gov/pubmed/4025948 >

BARSALOU, J.; BRADLEY, T. J.; SILVERMAN, E. D. Cardiovascular risk in pediatric-onset rheumatological diseases. Arthritis Res Ther, v. 15, n. 3, p. 212, 2013. ISSN 1478-6362 (Electronic)

1478-6354 (Linking). Disponível em: < https://www.ncbi.nlm.nih.gov/pubmed/23731870 $>$.

BARSALOU, J.; LEVY, D. M.; SILVERMAN, E. D. An update on childhood-onset systemic lupus erythematosus. Curr Opin Rheumatol, v. 25, n. 5, p. 616-22, Sep 2013. ISSN 1531-6963 (Electronic)

1040-8711 (Linking). Disponível em: < http://www.ncbi.nlm.nih.gov/pubmed/23836073 >

BARTELS, C. M. et al. Mortality and cardiovascular burden of systemic lupus erythematosus in a US population-based cohort. J Rheumatol, v. 41, n. 4, p. 680-7, Apr 2014. ISSN 0315-162X (Print)

0315-162X (Linking). Disponível em: < https://www.ncbi.nlm.nih.gov/pubmed/24532834 $>$.

BEATON, G. H. et al. Source of variance in 24-hour dietary recall data: implications for nutrition study design and interpretation. Carbohydrate sources, vitamins, and minerals. Am J Clin Nutr, v. 37, n. 6, p. 986-95, Jun 1983. ISSN 0002-9165 (Print) 0002-9165 (Linking). Disponível em: < https://www.ncbi.nlm.nih.gov/pubmed/6846242 >.

BERENSON, G. S. et al. Association between multiple cardiovascular risk factors and atherosclerosis in children and young adults. The Bogalusa Heart Study. N Engl J Med, v. 338, n. 23, p. 1650-6, Jun 4 1998. ISSN 0028-4793 (Print)

0028-4793 (Linking). Disponível em: < http://www.ncbi.nlm.nih.gov/pubmed/9614255 >.

BERTESIAS, G. C., R. ; BOUMPAS, D. T. Systemic lupus erythematosus: Pathogenesis and clinical features. In: BMJ (Ed.). EULAR textbook on rheumatic diseases. London, 2012. p.476-505. 
BJORNADAL, L. et al. Cardiovascular disease a hazard despite improved prognosis in patients with systemic lupus erythematosus: results from a Swedish population based study 1964-95. J Rheumatol, v. 31, n. 4, p. 713-9, Apr 2004. ISSN 0315-162X (Print)

0315-162X (Linking). Disponível em: < https://www.ncbi.nlm.nih.gov/pubmed/15088296 $>$.

BORCHERS, A. T. et al. Surviving the butterfly and the wolf: mortality trends in systemic lupus erythematosus. Autoimmun Rev, v. 3, n. 6, p. 423-53, Aug 2004. ISSN 1568-9972 (Print)

1568-9972 (Linking). Disponível em: < https://www.ncbi.nlm.nih.gov/pubmed/15351310 $>$.

BOROS, C. A. et al. Early determinants of atherosclerosis in paediatric systemic lupus erythematosus. Clin Exp Rheumatol, v. 29, n. 3, p. 575-81, May-Jun 2011. ISSN 0392-856X (Print)

0392-856X (Linking). Disponível em: < https://www.ncbi.nlm.nih.gov/pubmed/21640055 $>$.

BOTS, M. L.; SUTTON-TYRRELL, K. Lessons from the past and promises for the future for carotid intima-media thickness. J Am Coll Cardiol, v. 60, n. 17, p. 1599604, Oct 23 2012. ISSN 1558-3597 (Electronic)

0735-1097 (Linking). Disponível em: < http://www.ncbi.nlm.nih.gov/pubmed/22999720 >.

BOWSER, C. S. et al. Absence of Chlamydia pneumoniae and signs of atherosclerotic cardiovascular disease in adolescents with systemic lupus erythematosus. Pediatr Cardiol, v. 29, n. 3, p. 545-51, May 2008. ISSN 0172-0643 (Print)

0172-0643 (Linking). Disponível em: < https://www.ncbi.nlm.nih.gov/pubmed/18080155 $>$.

BRUNNER, $\mathrm{H}$. I. et al. Difference in disease features between childhood-onset and adult-onset systemic lupus erythematosus. Arthritis Rheum, v. 58, n. 2, p. 556-62, Feb 2008. ISSN 0004-3591 (Print)

0004-3591 (Linking). Disponível em: < https://www.ncbi.nlm.nih.gov/pubmed/18240232 $>$.

CADAVAL RAM, M. J., MAZZOIN MA, BARROS RGT, ALMEIDA FA. Avaliação do risco coronariano em mulheres com lupus eritematoso sistêmico. Rev Bras Reumatol v. 49, n. 62, p. 658-669, 2009.

CALIGIURI, G. et al. Protective immunity against atherosclerosis carried by B cells of hypercholesterolemic mice. J Clin Invest, v. 109, n. 6, p. 745-53, Mar 2002. ISSN 0021-9738 (Print)

0021-9738 (Linking). Disponível em: < https://www.ncbi.nlm.nih.gov/pubmed/11901183 $>$.

CARMONA-RIVERA, C.; KAPLAN, M. J. Low-density granulocytes: a distinct class of neutrophils in systemic autoimmunity. Semin Immunopathol, v. 35, n. 4, p. 455-63, Jul 2013. ISSN 1863-2300 (Electronic) 
1863-2297 (Linking). Disponível em: < https://www.ncbi.nlm.nih.gov/pubmed/23553215 $>$.

CECCON, F. T. et al. Avaliação da aterosclerose subclínica e de níveis plasmáticos de LDL minimamente modificada em pacientes com espondilite anquilosante e sua correlação com a atividade da doença. Rev Bras Reumatol, v. 53, n. 6, p. 470-475, 2013.

COUGHLIN, S. R. Thrombin signalling and protease-activated receptors. Nature, v. 407, n. 6801, p. 258-64, Sep 14 2000. ISSN 0028-0836 (Print)

0028-0836 (Linking). Disponível em: < https://www.ncbi.nlm.nih.gov/pubmed/11001069 $>$.

DA ROSA FRANCHI SANTOS, L. F. et al. Increased adhesion molecule levels in systemic lupus erythematosus: relationships with severity of illness, autoimmunity, metabolic syndrome and cortisol levels. Lupus, v. 27, n. 3, p. 380-388, Mar 2018. ISSN 1477-0962 (Electronic)

0961-2033 (Linking). Disponível em: < https://www.ncbi.nlm.nih.gov/pubmed/29400123 $>$.

DALLA POZZA, R. et al. Beyond intima-media-thickness: Analysis of the carotid intima-media-roughness in a paediatric population. Atherosclerosis, v. 251, p. 164169, Aug 2016. ISSN 1879-1484 (Electronic)

0021-9150 (Linking). Disponível em: < https://www.ncbi.nlm.nih.gov/pubmed/27341532 $>$.

DANIELS, S. R.; PRATT, C. A.; HAYMAN, L. L. Reduction of risk for cardiovascular disease in children and adolescents. Circulation, v. 124, n. 15, p. 1673-86, Oct 11 2011. ISSN 1524-4539 (Electronic)

0009-7322 (Linking). Disponível em: < http://www.ncbi.nlm.nih.gov/pubmed/21986774 >.

DAVI, G.; PATRONO, C. Platelet activation and atherothrombosis. N Engl J Med, v. 357, n. 24, p. 2482-94, Dec 13 2007. ISSN 1533-4406 (Electronic)

0028-4793 (Linking). Disponível em: < https://www.ncbi.nlm.nih.gov/pubmed/18077812 $>$.

DENARIE, N. et al. Distribution of ultrasonographically-assessed dimensions of common carotid arteries in healthy adults of both sexes. Atherosclerosis, v. 148, n. 2, p. 297-302, Feb 2000. ISSN 0021-9150 (Print)

0021-9150 (Linking). Disponível em: < https://www.ncbi.nlm.nih.gov/pubmed/10657565 $>$.

DOYON, A. et al. Carotid artery intima-media thickness and distensibility in children and adolescents: reference values and role of body dimensions. Hypertension, $v$. 62, n. 3, p. 550-6, Sep 2013. ISSN 1524-4563 (Electronic)

0194-911X (Linking). Disponível em: < https://www.ncbi.nlm.nih.gov/pubmed/23817494 $>$. 
DUFFAU, P. et al. Platelet CD154 potentiates interferon-alpha secretion by plasmacytoid dendritic cells in systemic lupus erythematosus. Sci Transl Med, v. 2, n. 47, p. 47ra63, Sep 01 2010. ISSN 1946-6242 (Electronic)

1946-6234 (Linking). Disponível em: < https://www.ncbi.nlm.nih.gov/pubmed/20811042 $>$.

EID, R. E. et al. Interleukin-17 and interferon-gamma are produced concomitantly by human coronary artery-infiltrating $\mathrm{T}$ cells and act synergistically on vascular smooth muscle cells. Circulation, v. 119, n. 10, p. 1424-32, Mar 17 2009. ISSN 1524-4539 (Electronic)

0009-7322 (Linking). Disponível em: < https://www.ncbi.nlm.nih.gov/pubmed/19255340 $>$.

ESDAILE, J. M. et al. Traditional Framingham risk factors fail to fully account for accelerated atherosclerosis in systemic lupus erythematosus. Arthritis Rheum, v. 44, n. 10, p. 2331-7, Oct 2001. ISSN 0004-3591 (Print)

0004-3591 (Linking). Disponível em: < https://www.ncbi.nlm.nih.gov/pubmed/11665973 $>$.

FACÓ, M. M. et al. Avaliação do óbitos e necropsias em pacientes internados em um serviço de reumatologia pediátrica pou um periodo de dez anos. Rev Bras Reumatol, v. 45, n. 2, p. 55-63, 2005.

FADDA, S. et al. Subclinical atherosclerosis in systemic lupus erythematosus patients and its relationship to disease activity and damage indices. $\mathbf{Z}$ Rheumatol, $v$. 74, n. 6, p. 529-32, Aug 2015. ISSN 1435-1250 (Electronic)

0340-1855 (Linking). Disponível em: < https://www.ncbi.nlm.nih.gov/pubmed/25098691 $>$.

FALASCHI, F. et al. Nephrotic-range proteinuria, the major risk factor for early atherosclerosis in juvenile-onset systemic lupus erythematosus. Arthritis Rheum, v. 43, n. 6, p. 1405-9, Jun 2000. ISSN 0004-3591 (Print)

0004-3591 (Linking). Disponível em: < https://www.ncbi.nlm.nih.gov/pubmed/10857801 $>$.

FERNANDEZ, J. R. et al. Waist circumference percentiles in nationally representative samples of African-American, European-American, and MexicanAmerican children and adolescents. J Pediatr, v. 145, n. 4, p. 439-44, Oct 2004. ISSN 0022-3476 (Print)

0022-3476 (Linking). Disponível em: < https://www.ncbi.nlm.nih.gov/pubmed/15480363 $>$.

FERNANDEZ-NEBRO, A. et al. Cardiovascular Events in Systemic Lupus Erythematosus: A Nationwide Study in Spain From the RELESSER Registry. Medicine (Baltimore), v. 94, n. 29, p. e1183, Jul 2015. ISSN 1536-5964 (Electronic) 0025-7974 (Linking). Disponível em: < https://www.ncbi.nlm.nih.gov/pubmed/26200625 $>$. 
FORS NIEVES, C. E.; IZMIRLY, P. M. Mortality in Systemic Lupus Erythematosus: an Updated Review. Curr Rheumatol Rep, v. 18, n. 4, p. 21, Apr 2016. ISSN 15346307 (Electronic)

1523-3774 (Linking). Disponível em: < https://www.ncbi.nlm.nih.gov/pubmed/26984805 $>$.

GEORGE, J. Mechanisms of disease: the evolving role of regulatory $T$ cells in atherosclerosis. Nat Clin Pract Cardiovasc Med, v. 5, n. 9, p. 531-40, Sep 2008. ISSN 1743-4300 (Electronic)

1743-4297 (Linking). Disponível em: < https://www.ncbi.nlm.nih.gov/pubmed/18607396 $>$.

GIANNELOU, M.; MAVRAGANI, C. P. Cardiovascular disease in systemic lupus erythematosus: A comprehensive update. J Autoimmun, v. 82, p. 1-12, Aug 2017. ISSN 1095-9157 (Electronic)

0896-8411 (Linking). Disponível em: < https://www.ncbi.nlm.nih.gov/pubmed/28606749 $>$.

GISTERA, A.; HANSSON, G. K. The immunology of atherosclerosis. Nat Rev Nephrol, v. 13, n. 6, p. 368-380, Jun 2017. ISSN 1759-507X (Electronic)

1759-5061 (Linking). Disponível em: < https://www.ncbi.nlm.nih.gov/pubmed/28392564 $>$.

GLADMAN, D. et al. The development and initial validation of the Systemic Lupus International Collaborating Clinics/American College of Rheumatology damage index for systemic lupus erythematosus. Arthritis Rheum, v. 39, n. 3, p. 363-9, Mar 1996. ISSN 0004-3591 (Print)

0004-3591 (Linking). Disponível em: < https://www.ncbi.nlm.nih.gov/pubmed/8607884 >.

GLADMAN, D. D.; IBANEZ, D.; UROWITZ, M. B. Systemic lupus erythematosus disease activity index 2000. J Rheumatol, v. 29, n. 2, p. 288-91, Feb 2002. ISSN 0315-162X (Print)

0315-162X (Linking). Disponível em: < https://www.ncbi.nlm.nih.gov/pubmed/11838846 $>$.

GLADMAN, D. D.; UROWITZ, M. B. Morbidity in systemic lupus erythematosus. J Rheumatol Suppl, v. 14 Suppl 13, p. 223-6, Jun 1987. ISSN 0380-0903 (Print) 0380-0903 (Linking). Disponível em: < https://www.ncbi.nlm.nih.gov/pubmed/3612650 >.

GOOSSENS, P. et al. Myeloid type I interferon signaling promotes atherosclerosis by stimulating macrophage recruitment to lesions. Cell Metab, v. 12, n. 2, p. 142-53, Aug 04 2010. ISSN 1932-7420 (Electronic)

1550-4131 (Linking). Disponível em: < https://www.ncbi.nlm.nih.gov/pubmed/20674859 $>$.

GROBE, J. L. et al. The brain Renin-angiotensin system controls divergent efferent mechanisms to regulate fluid and energy balance. Cell Metab, v. 12, n. 5, p. 431-42, Nov 03 2010. ISSN 1932-7420 (Electronic)

1550-4131 (Linking). Disponível em: < https://www.ncbi.nlm.nih.gov/pubmed/21035755 $>$. 
GUSTAFSSON, J. T. et al. Risk factors for cardiovascular mortality in patients with systemic lupus erythematosus, a prospective cohort study. Arthritis Res Ther, v. 14, n. 2, p. R46, 2012. ISSN 1478-6362 (Electronic)

1478-6354 (Linking). Disponível em: < https://www.ncbi.nlm.nih.gov/pubmed/22390680 $>$.

HANN, C. S. et al. Validation of the Healthy Eating Index with use of plasma biomarkers in a clinical sample of women. Am J Clin Nutr, v. 74, n. 4, p. 479-86, Oct 2001. ISSN 0002-9165 (Print)

0002-9165 (Linking). Disponível em: < https://www.ncbi.nlm.nih.gov/pubmed/11566646 $>$.

HANSSON, G. K. Inflammation, atherosclerosis, and coronary artery disease. N Engl J Med, v. 352, n. 16, p. 1685-95, Apr 21 2005. ISSN 1533-4406 (Electronic)

0028-4793 (Linking). Disponível em: < https://www.ncbi.nlm.nih.gov/pubmed/15843671 $>$.

HEYMSFIELD, S. B.; TIGHE, A.; WANG, Z. M. Nutricional assessment by anthopometric and biochemical methods. In: SHILS, M. E.;OLSON, J. A., et al (Ed.). Modern nutrition in health and disease: Malvem: Lea Febiger, 1994. p.812-841.

HUANG, Y. L. et al. Lymphopenia is a risk factor in the progression of carotid intimamedia thickness in juvenile-onset systemic lupus erythematosus. Arthritis Rheum, v. 60 , n. 12, p. 3766-75, Dec 2009. ISSN 0004-3591 (Print)

0004-3591 (Linking). Disponível em: < https://www.ncbi.nlm.nih.gov/pubmed/19950269 $>$.

HWANG, S. J. et al. Circulating adhesion molecules VCAM-1, ICAM-1, and Eselectin in carotid atherosclerosis and incident coronary heart disease cases: the Atherosclerosis Risk In Communities (ARIC) study. Circulation, v. 96, n. 12, p. 4219-25, Dec 16 1997. ISSN 0009-7322 (Print)

0009-7322 (Linking). Disponível em: < https://www.ncbi.nlm.nih.gov/pubmed/9416885 >.

JOURDAN, C. et al. Normative values for intima-media thickness and distensibility of large arteries in healthy adolescents. J Hypertens, v. 23, n. 9, p. 1707-15, Sep 2005. ISSN 0263-6352 (Print)

0263-6352 (Linking). Disponível em: < https://www.ncbi.nlm.nih.gov/pubmed/16093916 $>$.

JUONALA, M. et al. Influence of age on associations between childhood risk factors and carotid intima-media thickness in adulthood: the Cardiovascular Risk in Young Finns Study, the Childhood Determinants of Adult Health Study, the Bogalusa Heart Study, and the Muscatine Study for the International Childhood Cardiovascular Cohort (i3C) Consortium. Circulation, v. 122, n. 24, p. 2514-20, Dec 14 2010. ISSN 1524-4539 (Electronic)

0009-7322 (Linking). Disponível em: < http://www.ncbi.nlm.nih.gov/pubmed/21126976 >. 
KNIGHT, J. S.; KAPLAN, M. J. Lupus neutrophils: 'NET' gain in understanding lupus pathogenesis. Curr Opin Rheumatol, v. 24, n. 5, p. 441-50, Sep 2012. ISSN 15316963 (Electronic)

1040-8711 (Linking). Disponível em: < https://www.ncbi.nlm.nih.gov/pubmed/22617827 $>$.

Cardiovascular disease in lupus: insights and updates. Curr Opin Rheumatol, v. 25, n. 5, p. 597-605, Sep 2013. ISSN 1531-6963 (Electronic) 1040-8711 (Linking). Disponível em: < http://www.ncbi.nlm.nih.gov/pubmed/23846339 >

LAHOUTE, C. et al. Adaptive immunity in atherosclerosis: mechanisms and future therapeutic targets. Nat Rev Cardiol, v. 8, n. 6, p. 348-58, Jun 2011. ISSN 17595010 (Electronic)

1759-5002 (Linking). Disponível em: < https://www.ncbi.nlm.nih.gov/pubmed/21502963 $>$.

LAURENT, S. et al. Expert consensus document on arterial stiffness: methodological issues and clinical applications. Eur Heart J, v. 27, n. 21, p. 2588-605, Nov 2006. ISSN 0195-668X (Print)

0195-668X (Linking). Disponível em: < https://www.ncbi.nlm.nih.gov/pubmed/17000623 $>$.

LEE, Y. H. et al. Overall and cause-specific mortality in systemic lupus erythematosus: an updated meta-analysis. Lupus, v. 25, n. 7, p. 727-34, Jun 2016. ISSN 1477-0962 (Electronic)

0961-2033 (Linking). Disponível em: < https://www.ncbi.nlm.nih.gov/pubmed/26811368 $>$.

LEWANDOWSKI, L. B.; KAPLAN, M. J. Update on cardiovascular disease in lupus. Curr Opin Rheumatol, v. 28, n. 5, p. 468-76, Sep 2016. ISSN 1531-6963 (Electronic)

1040-8711 (Linking). Disponível em: < https://www.ncbi.nlm.nih.gov/pubmed/27227346 $>$.

LEWIS, M. J. et al. Improved monitoring of clinical response in Systemic Lupus Erythematosus by longitudinal trend in soluble vascular cell adhesion molecule-1. Arthritis Res Ther, v. 18, p. 5, Jan 8 2016. ISSN 1478-6362 (Electronic)

1478-6354 (Linking). Disponível em: < https://www.ncbi.nlm.nih.gov/pubmed/26746423 $>$.

LI, J. et al. Interferon-alpha priming promotes lipid uptake and macrophage-derived foam cell formation: a novel link between interferon-alpha and atherosclerosis in lupus. Arthritis Rheum, v. 63, n. 2, p. 492-502, Feb 2011. ISSN 1529-0131 (Electronic)

0004-3591 (Linking). Disponível em: < https://www.ncbi.nlm.nih.gov/pubmed/21280004 $>$.

LIBBY, P. Mechanisms of acute coronary syndromes and their implications for therapy. N Engl J Med, v. 368, n. 21, p. 2004-13, May 23 2013. ISSN 1533-4406 (Electronic) 
0028-4793 (Linking). Disponível em: < https://www.ncbi.nlm.nih.gov/pubmed/23697515 $>$.

LIBBY, P. et al. Report of the National Heart, Lung, and Blood Institute-National Institute of Diabetes and Digestive and Kidney Diseases Working Group on Cardiovascular Complications of Type 1 Diabetes Mellitus. Circulation, v. 111, n. 25, p. 3489-93, Jun 28 2005. ISSN 1524-4539 (Electronic)

0009-7322 (Linking). Disponível em: < https://www.ncbi.nlm.nih.gov/pubmed/15983263 $>$.

LIBBY, P.; THEROUX, P. Pathophysiology of coronary artery disease. Circulation, v. 111, n. 25, p. 3481-8, Jun 28 2005. ISSN 1524-4539 (Electronic)

0009-7322 (Linking). Disponível em: < https://www.ncbi.nlm.nih.gov/pubmed/15983262 $>$.

LLOYD-JONES, D. M. et al. Defining and setting national goals for cardiovascular health promotion and disease reduction: the American Heart Association's strategic Impact Goal through 2020 and beyond. Circulation, v. 121, n. 4, p. 586-613, Feb 2 2010. ISSN 1524-4539 (Electronic)

0009-7322 (Linking). Disponível em: < http://www.ncbi.nlm.nih.gov/pubmed/20089546 >.

LLOYD-JONES, D. M. et al. Prediction of lifetime risk for cardiovascular disease by risk factor burden at 50 years of age. Circulation, v. 113, n. 6, p. 791-8, Feb 14 2006. ISSN 1524-4539 (Electronic)

0009-7322 (Linking). Disponível em: < http://www.ncbi.nlm.nih.gov/pubmed/16461820 >

LOOD, C. et al. Platelet transcriptional profile and protein expression in patients with systemic lupus erythematosus: up-regulation of the type I interferon system is strongly associated with vascular disease. Blood, v. 116, n. 11, p. 1951-7, Sep 16 2010. ISSN 1528-0020 (Electronic)

0006-4971 (Linking). Disponível em: < https://www.ncbi.nlm.nih.gov/pubmed/20538795 $>$.

LOPEZ-PEDRERA, C. et al. Accelerated atherosclerosis in systemic lupus erythematosus: role of proinflammatory cytokines and therapeutic approaches. $\mathbf{J}$ Biomed Biotechnol, v. 2010, 2010. ISSN 1110-7251 (Electronic)

1110-7243 (Linking). Disponível em: < https://www.ncbi.nlm.nih.gov/pubmed/20936125 $>$.

MACHADO, D. et al. Lipid profile among girls with systemic lupus erythematosus. Rheumatol Int, v. 37, n. 1, p. 43-48, Jan 2017. ISSN 1437-160X (Electronic)

0172-8172 (Linking). Disponível em: < https://www.ncbi.nlm.nih.gov/pubmed/26573664 $>$.

MACKMAN, N. Triggers, targets and treatments for thrombosis. Nature, v. 451, n. 7181, p. 914-8, Feb 21 2008. ISSN 1476-4687 (Electronic)

0028-0836 (Linking). Disponível em: < https://www.ncbi.nlm.nih.gov/pubmed/18288180 $>$. 
MAGNUSSEN, C. G. et al. The association of pediatric low- and high-density lipoprotein cholesterol dyslipidemia classifications and change in dyslipidemia status with carotid intima-media thickness in adulthood evidence from the cardiovascular risk in Young Finns study, the Bogalusa Heart study, and the CDAH (Childhood Determinants of Adult Health) study. J Am Coll Cardiol, v. 53, n. 10, p. 860-9, Mar 10 2009. ISSN 1558-3597 (Electronic)

0735-1097 (Linking). Disponível em: < https://www.ncbi.nlm.nih.gov/pubmed/19264243 $>$.

MANZI, S. et al. Prevalence and risk factors of carotid plaque in women with systemic lupus erythematosus. Arthritis Rheum, v. 42, n. 1, p. 51-60, Jan 1999. ISSN 0004-3591 (Print)

0004-3591 (Linking). Disponível em: < http://www.ncbi.nlm.nih.gov/pubmed/9920014 >.

MCCARTHY, H. D. et al. Body fat reference curves for children. Int J Obes (Lond), v. 30, n. 4, p. 598-602, Apr 2006. ISSN 0307-0565 (Print)

0307-0565 (Linking). Disponível em: < https://www.ncbi.nlm.nih.gov/pubmed/16570089 $>$.

MCCARTHY, H. D.; JARRETT, K. V.; CRAWLEY, H. F. The development of waist circumference percentiles in British children aged 5.0-16.9 y. Eur J Clin Nutr, v. 55, n. 10, p. 902-7, Oct 2001. ISSN 0954-3007 (Print)

0954-3007 (Linking). Disponível em: < https://www.ncbi.nlm.nih.gov/pubmed/11593353 $>$.

MCGILL, H. C., JR. et al. Effects of serum lipoproteins and smoking on atherosclerosis in young men and women. The PDAY Research Group. Pathobiological Determinants of Atherosclerosis in Youth. Arterioscler Thromb Vasc Biol, v. 17, n. 1, p. 95-106, Jan 1997. ISSN 1079-5642 (Print) 1079-5642 (Linking). Disponível em: < http://www.ncbi.nlm.nih.gov/pubmed/9012643 >.

MCLAREN, J. E.; RAMJI, D. P. Interferon gamma: a master regulator of atherosclerosis. Cytokine Growth Factor Rev, v. 20, n. 2, p. 125-35, Apr 2009. ISSN 1879-0305 (Electronic)

1359-6101 (Linking). Disponível em: < https://www.ncbi.nlm.nih.gov/pubmed/19041276 $>$.

MENDE, R. et al. Analysis of Serum Interleukin (IL)-1beta and IL-18 in Systemic Lupus Erythematosus. Front Immunol, v. 9, p. 1250, 2018. ISSN 1664-3224 (Print) 1664-3224 (Linking). Disponível em: < https://www.ncbi.nlm.nih.gov/pubmed/29930551 $>$.

MIURA, M. et al. Association of Severity of Coronary Artery Aneurysms in Patients With Kawasaki Disease and Risk of Later Coronary Events. JAMA Pediatr, p. e180030, Mar 5 2018. ISSN 2168-6211 (Electronic)

2168-6203 (Linking). Disponível em: < https://www.ncbi.nlm.nih.gov/pubmed/29507955 $>$.

MONTEIRO, J. P. Consumo Alimentar - Visualizando porções. 1st 2007. 
MOZZINI, C. et al. An exploratory look at NETosis in atherosclerosis. Intern Emerg Med, v. 12, n. 1, p. 13-22, Feb 2017. ISSN 1970-9366 (Electronic)

1828-0447 (Linking). Disponível em: < https://www.ncbi.nlm.nih.gov/pubmed/27655025 $>$.

MUHL, H.; PFEILSCHIFTER, J. Anti-inflammatory properties of pro-inflammatory interferon-gamma. Int Immunopharmacol, v. 3, n. 9, p. 1247-55, Sep 2003. ISSN 1567-5769 (Print)

1567-5769 (Linking). Disponível em: < https://www.ncbi.nlm.nih.gov/pubmed/12890422 $>$.

NAGAHAMA, M. et al. Platelet activation markers and soluble adhesion molecules in patients with systemic lupus erythematosus. Autoimmunity, v. 33, n. 2, p. 85-94, 2001. ISSN 0891-6934 (Print)

0891-6934 (Linking). Disponível em: < https://www.ncbi.nlm.nih.gov/pubmed/11264787 $>$.

NIESSNER, A. et al. Pathogen-sensing plasmacytoid dendritic cells stimulate cytotoxic T-cell function in the atherosclerotic plaque through interferon-alpha. Circulation, v. 114, n. 23, p. 2482-9, Dec 05 2006. ISSN 1524-4539 (Electronic) 0009-7322 (Linking). Disponível em: < https://www.ncbi.nlm.nih.gov/pubmed/17116765 $>$.

NIKPOUR, M. et al. High-sensitivity C-reactive protein as a marker of cardiovascular risk in systemic lupus erythematosus. Arthritis Rheum, v. 64, n. 9, p. 3052-3, Sep 2012. ISSN 1529-0131 (Electronic)

0004-3591 (Linking). Disponível em: < http://www.ncbi.nlm.nih.gov/pubmed/22614710 >

OCAMPO-PIRAQUIVE, V. et al. Mortality in systemic lupus erythematosus: causes, predictors and interventions. Expert Rev Clin Immunol, v. 14, n. 12, p. 1043-1053, Dec 2018. ISSN 1744-8409 (Electronic)

1744-666X (Linking). Disponível em: < https://www.ncbi.nlm.nih.gov/pubmed/30338717 $>$.

PERRINS, C. J.; BOBRYSHEV, Y. V. Current advances in understanding of immunopathology of atherosclerosis. Virchows Arch, v. 458, n. 2, p. 117-23, Feb 2011. ISSN 1432-2307 (Electronic)

0945-6317 (Linking). Disponível em: < https://www.ncbi.nlm.nih.gov/pubmed/21069384 $>$.

PETERS, S. A.; DEN RUIJTER, H. M.; BOTS, M. L. Ultrasound protocols to measure carotid intima-media thickness: one size does not fit all. J Am Soc Echocardiogr, v. 25 , n. 10, p. 1135-7, Oct 2012. ISSN 1097-6795 (Electronic)

0894-7317 (Linking). Disponível em: < http://www.ncbi.nlm.nih.gov/pubmed/22948017 >.

PETRI, M.; MAGDER, L. Classification criteria for systemic lupus erythematosus: a review. Lupus, v. 13, n. 11, p. 829-37, 2004. ISSN 0961-2033 (Print)

0961-2033 (Linking). Disponível em: < http://www.ncbi.nlm.nih.gov/pubmed/15580978 >. 
PETRI, M. et al. Risk factors for coronary artery disease in patients with systemic lupus erythematosus. Am J Med, v. 93, n. 5, p. 513-9, Nov 1992. ISSN 0002-9343 (Print)

0002-9343 (Linking). Disponível em: < https://www.ncbi.nlm.nih.gov/pubmed/1442853 >.

PREVIDELLI, A. N. et al. A revised version of the Healthy Eating Index for the Brazilian population. Rev Saude Publica, v. 45, n. 4, p. 794-8, Aug 2011. ISSN 1518-8787 (Electronic)

0034-8910 (Linking). Disponível em: < https://www.ncbi.nlm.nih.gov/pubmed/21655703 $>$.

QUEVEDO-ABELEDO, J. C. et al. Disease Damage Influences Cardiovascular Risk Reclassification Based on Carotid Ultrasound in Patients with Systemic Lupus Erythematosus. J Rheumatol, Jan 15 2019. ISSN 0315-162X (Print)

0315-162X (Linking). Disponível em: < https://www.ncbi.nlm.nih.gov/pubmed/30647175 $>$.

QUILLARD, T. et al. TLR2 and neutrophils potentiate endothelial stress, apoptosis and detachment: implications for superficial erosion. Eur Heart J, v. 36, n. 22, p. 1394-404, Jun 07 2015. ISSN 1522-9645 (Electronic)

0195-668X (Linking). Disponível em: < https://www.ncbi.nlm.nih.gov/pubmed/25755115 $>$.

$\mathrm{RHO}, \mathrm{Y} . \mathrm{H}$. et al. Novel cardiovascular risk factors in premature coronary atherosclerosis associated with systemic lupus erythematosus. J Rheumatol, v. 35, n. 9, p. 1789-94, Sep 2008. ISSN 0315-162X (Print)

0315-162X (Linking). Disponível em: < https://www.ncbi.nlm.nih.gov/pubmed/18634156 $>$.

RIDKER, P. M. From C-Reactive Protein to Interleukin-6 to Interleukin-1: Moving Upstream To Identify Novel Targets for Atheroprotection. Circ Res, v. 118, n. 1, p. 145-56, Jan 08 2016. ISSN 1524-4571 (Electronic)

0009-7330 (Linking). Disponível em: < https://www.ncbi.nlm.nih.gov/pubmed/26837745 $>$.

ROCKVILLE, M., : U.S, DEPARTMENT, OF, HEALTH, AND, HUMAN, SERVICES,. How tobacco smoke causes disease: the biology and behavioral basis for smoking-attributable disease : a report of the Surgeon General: 704 p. 2010.

ROSS, R. Atherosclerosis--an inflammatory disease. N Engl J Med, v. 340, n. 2, p. 115-26, Jan 14 1999. ISSN 0028-4793 (Print)

0028-4793 (Linking). Disponível em: < https://www.ncbi.nlm.nih.gov/pubmed/9887164 >.

SACRE, K. et al. Overweight Is a Major Contributor to Atherosclerosis in Systemic Lupus Erythematosus Patients at Apparent Low Risk for Cardiovascular Disease: A Cross-Sectional Controlled Study. Medicine (Baltimore), v. 94, n. 48, p. e2177, Dec 2015. ISSN 1536-5964 (Electronic)

0025-7974 (Linking). Disponível em: < https://www.ncbi.nlm.nih.gov/pubmed/26632902 $>$. 
SALMON, J. E.; ROMAN, M. J. Subclinical atherosclerosis in rheumatoid arthritis and systemic lupus erythematosus. Am J Med, v. 121, n. 10 Suppl 1, p. S3-8, Oct 2008. ISSN 1555-7162 (Electronic)

0002-9343 (Linking). Disponível em: < https://www.ncbi.nlm.nih.gov/pubmed/18926167 $>$.

SALOMAO, R. G. et al. Homocysteine, folate, hs-C-reactive protein, tumor necrosis factor alpha and inflammatory proteins: are these biomarkers related to nutritional status and cardiovascular risk in childhood-onset systemic lupus erythematosus? Pediatr Rheumatol Online J, v. 16, n. 1, p. 4, Jan 9 2018. ISSN 1546-0096 (Electronic)

1546-0096 (Linking). Disponível em: < https://www.ncbi.nlm.nih.gov/pubmed/29316941 $>$.

SCHANBERG, L. E. et al. Premature atherosclerosis in pediatric systemic lupus erythematosus: risk factors for increased carotid intima-media thickness in the atherosclerosis prevention in pediatric lupus erythematosus cohort. Arthritis Rheum, v. 60 , n. 5, p. 1496-507, May 2009. ISSN 0004-3591 (Print)

0004-3591 (Linking). Disponível em: < http://www.ncbi.nlm.nih.gov/pubmed/19404953 >.

SILVERMAN, E.; ALLISON, E. Systemic Lupus Erythematosus. In: CASSIDY JT, P. R., LAXER RM, LINDSLEY CB. (Ed.). Textbook of Pediatric Rheumatology. sixth. Philadelphia Saunders Elsevier, 2010. cap. section 3, p.315-343. ISBN 978-1-41606581-4.

SKAGGS, B. J.; HAHN, B. H.; MCMAHON, M. Accelerated atherosclerosis in patients with SLE--mechanisms and management. Nat Rev Rheumatol, v. 8, n. 4, p. 214-23, Feb 14 2012. ISSN 1759-4804 (Electronic)

1759-4790 (Linking). Disponível em: < https://www.ncbi.nlm.nih.gov/pubmed/22331061 $>$.

SKEOCH, S. et al. Cell adhesion molecules as potential biomarkers of nephritis, damage and accelerated atherosclerosis in patients with SLE. Lupus, v. 23, n. 8, p. 819-24, Jul 2014. ISSN 1477-0962 (Electronic)

0961-2033 (Linking). Disponível em: < https://www.ncbi.nlm.nih.gov/pubmed/24647443 $>$.

SKOV, T. et al. Prevalence proportion ratios: estimation and hypothesis testing. Int $\mathbf{J}$ Epidemiol, v. 27, n. 1, p. 91-5, Feb 1998. ISSN 0300-5771 (Print)

0300-5771 (Linking). Disponível em: < https://www.ncbi.nlm.nih.gov/pubmed/9563700 >.

SOCIEDADE BRASILEIRA DE, $\mathrm{H}$. et al. [I Brazilian guidelines on diagnosis and treatment of metabolic syndrome]. Arq Bras Cardiol, v. 84 Suppl 1, p. 1-28, Apr 2005. ISSN 0066-782X (Print)

0066-782X (Linking). Disponível em: < http://www.ncbi.nlm.nih.gov/pubmed/16095065 $>$. 
SOUZA, A. W. et al. Atherosclerotic plaque in carotid arteries in systemic lupus erythematosus: frequency and associated risk factors. Sao Paulo Med J, v. 123, n. 3, p. 137-42, May 2 2005. ISSN 1516-3180 (Print)

1516-3180 (Linking). Disponível em: < https://www.ncbi.nlm.nih.gov/pubmed/16021278 $>$.

SOUZA, D. C.; SANTO, A. H.; SATO, E. I. Mortality profile related to systemic lupus erythematosus: a multiple cause-of-death analysis. J Rheumatol, v. 39, n. 3, p. 496503, Mar 2012. ISSN 0315-162X (Print)

0315-162X (Linking). Disponível em: < https://www.ncbi.nlm.nih.gov/pubmed/22247362 $>$.

SPRINGER, T. A. Traffic signals for lymphocyte recirculation and leukocyte emigration: the multistep paradigm. Cell, v. 76, n. 2, p. 301-14, Jan 28 1994. ISSN 0092-8674 (Print)

0092-8674 (Linking). Disponível em: < https://www.ncbi.nlm.nih.gov/pubmed/7507411 >.

SU-ANGKA, N. et al. Carotid intima-media thickness and arterial stiffness in pediatric systemic lupus erythematosus. Lupus, v. 26, n. 9, p. 989-995, Aug 2017. ISSN 1477-0962 (Electronic)

0961-2033 (Linking). Disponível em: < https://www.ncbi.nlm.nih.gov/pubmed/28420050 $>$.

SVENUNGSSON, E. et al. TNF-alpha: a link between hypertriglyceridaemia and inflammation in SLE patients with cardiovascular disease. Lupus, v. 12, n. 6, p. 45461, 2003. ISSN 0961-2033 (Print)

0961-2033 (Linking). Disponível em: < https://www.ncbi.nlm.nih.gov/pubmed/12873047 $>$.

TALEB, S. et al. Loss of SOCS3 expression in T cells reveals a regulatory role for interleukin-17 in atherosclerosis. J Exp Med, v. 206, n. 10, p. 2067-77, Sep 282009. ISSN 1540-9538 (Electronic)

0022-1007 (Linking). Disponível em: < https://www.ncbi.nlm.nih.gov/pubmed/19737863 $>$.

TALEB, S.; TEDGUI, A.; MALLAT, Z. Interleukin-17: friend or foe in atherosclerosis? Curr Opin Lipidol, v. 21, n. 5, p. 404-8, Oct 2010. ISSN 1473-6535 (Electronic) 0957-9672 (Linking). Disponível em: < https://www.ncbi.nlm.nih.gov/pubmed/20683328 $>$.

TAM, L. S. et al. Patients with systemic lupus erythematosus show increased platelet activation and endothelial dysfunction induced by acute hyperhomocysteinemia. J Rheumatol, v. 30, n. 7, p. 1479-84, Jul 2003. ISSN 0315162X (Print)

0315-162X (Linking). Disponível em: < https://www.ncbi.nlm.nih.gov/pubmed/12858444 $>$.

TELLES, R. W. et al. Progression of carotid atherosclerosis in patients with systemic lupus erythematosus. Clin Rheumatol, v. 32, n. 9, p. 1293-300, Sep 2013. ISSN 1434-9949 (Electronic) 
0770-3198 (Linking). Disponível em: < https://www.ncbi.nlm.nih.gov/pubmed/23620348 $>$.

THACKER, S. G. et al. The detrimental effects of IFN-alpha on vasculogenesis in lupus are mediated by repression of IL-1 pathways: potential role in atherogenesis and renal vascular rarefaction. J Immunol, v. 185, n. 7, p. 4457-69, Oct 012010. ISSN 1550-6606 (Electronic)

0022-1767 (Linking). Disponível em: < https://www.ncbi.nlm.nih.gov/pubmed/20805419 $>$.

THIJSSEN, D. $\mathrm{H}$. et al. Assessment of flow-mediated dilation in humans: a methodological and physiological guideline. Am J Physiol Heart Circ Physiol, v. 300 , n. 1, p. H2-12, Jan 2011. ISSN 1522-1539 (Electronic)

0363-6135 (Linking). Disponível em: < https://www.ncbi.nlm.nih.gov/pubmed/20952670 $>$.

THOMAS, G. et al. Mortality associated with systemic lupus erythematosus in France assessed by multiple-cause-of-death analysis. Arthritis Rheumatol, v. 66, n. 9, p. 2503-11, Sep 2014. ISSN 2326-5205 (Electronic)

2326-5191 (Linking). Disponível em: < https://www.ncbi.nlm.nih.gov/pubmed/24910304 $>$.

TOFFANO, R. B. D. et al. Validation of the Brazilian Healthy Eating Index-Revised Using Biomarkers in Children and Adolescents. Nutrients, v. 10, n. 2, Jan 302018. ISSN 2072-6643 (Electronic)

2072-6643 (Linking). Disponível em: < https://www.ncbi.nlm.nih.gov/pubmed/29385742 $>$.

TSELIOS, K. et al. Optimal Monitoring For Coronary Heart Disease Risk in Patients with Systemic Lupus Erythematosus: A Systematic Review. J Rheumatol, v. 43, n. 1, p. 54-65, Jan 2016. ISSN 0315-162X (Print)

0315-162X (Linking). Disponível em: < https://www.ncbi.nlm.nih.gov/pubmed/26568591 $>$.

URBINA, E. M. et al. Noninvasive assessment of subclinical atherosclerosis in children and adolescents: recommendations for standard assessment for clinical research: a scientific statement from the American Heart Association. Hypertension, v. 54, n. 5, p. 919-50, Nov 2009. ISSN 1524-4563 (Electronic)

0194-911X (Linking). Disponível em: < https://www.ncbi.nlm.nih.gov/pubmed/19729599 $>$.

VAN VOLLENHOVEN, R. F. et al. Efficacy and safety of ustekinumab, an IL-12 and IL-23 inhibitor, in patients with active systemic lupus erythematosus: results of a multicentre, double-blind, phase 2, randomised, controlled study. Lancet, v. 392, n. 10155, p. 1330-1339, Oct 13 2018. ISSN 1474-547X (Electronic)

0140-6736 (Linking). Disponível em: < https://www.ncbi.nlm.nih.gov/pubmed/30249507 $>$. 
VIEIRA-DE-ABREU, $A$. et al. Platelets: versatile effector cells in hemostasis, inflammation, and the immune continuum. Semin Immunopathol, v. 34, n. 1, p. 530, Jan 2012. ISSN 1863-2300 (Electronic)

1863-2297 (Linking). Disponível em: < https://www.ncbi.nlm.nih.gov/pubmed/21818701 $>$.

WEBER, C. et al. CCL17-expressing dendritic cells drive atherosclerosis by restraining regulatory $T$ cell homeostasis in mice. J Clin Invest, v. 121, n. 7, p. 2898910, Jul 2011. ISSN 1558-8238 (Electronic)

0021-9738 (Linking). Disponível em: < https://www.ncbi.nlm.nih.gov/pubmed/21633167 $>$.

WEENING, J. J. et al. The classification of glomerulonephritis in systemic lupus erythematosus revisited. J Am Soc Nephrol, v. 15, n. 2, p. 241-50, Feb 2004. ISSN 1046-6673 (Print)

1046-6673 (Linking). Disponível em: < https://www.ncbi.nlm.nih.gov/pubmed/14747370 $>$.

WILSON, P. W. et al. Prediction of coronary heart disease using risk factor categories. Circulation, v. 97, n. 18, p. 1837-47, May 12 1998. ISSN 0009-7322 (Print)

0009-7322 (Linking). Disponível em: < https://www.ncbi.nlm.nih.gov/pubmed/9603539 >

WONG, C. K. et al. Hyperproduction of IL-23 and IL-17 in patients with systemic lupus erythematosus: implications for Th17-mediated inflammation in auto-immunity. Clin Immunol, v. 127, n. 3, p. 385-93, Jun 2008. ISSN 1521-7035 (Electronic) 1521-6616 (Linking). Disponível em: < https://www.ncbi.nlm.nih.gov/pubmed/18373953 $>$.

WU, G. C. et al. Subclinical atherosclerosis in patients with systemic lupus erythematosus: A systemic review and meta-analysis. Autoimmun Rev, v. 15, n. 1, p. 22-37, Jan 2016. ISSN 1873-0183 (Electronic)

1568-9972 (Linking). Disponível em: < https://www.ncbi.nlm.nih.gov/pubmed/26455562 $>$.

ZHU, J.; PAUL, W. E. Peripheral CD4+ T-cell differentiation regulated by networks of cytokines and transcription factors. Immunol Rev, v. 238, n. 1, p. 247-62, Nov 2010. ISSN 1600-065X (Electronic)

0105-2896 (Linking). Disponível em: < https://www.ncbi.nlm.nih.gov/pubmed/20969597 $>$. 
Anexos

ANEXO 1:

\section{FICHA DE ACOMPANHAMENTO DOS PACIENTES}

Data da coleta:

Data do caso novo:

Data do início dos sintomas:

1) Nome do Paciente:

Data de nascimento:

Idade:

Sexo:

Raça:

2) Registro do HCFMRP:

3) Nome do responsável:

Endereço:

Telefone:

E-mail:

4) Critérios diagnósticos para o LES:

Rash malar

Rash discóide

Fotossensibilidade

úlceras orais

Artrite

Serosite

Alteração renal

Alteração neurológica

Alteração hematológica

Alteração imunológica:

FAN

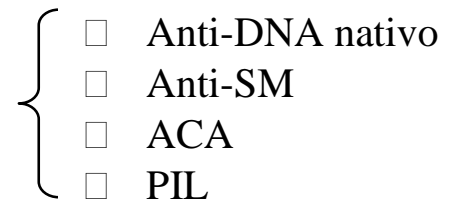

5) Comorbidades associadas ao LES (atual ou prévia):

HAS controlada

HAS não controlada

Dislipidemia em tratamento dietético 
Dislipidemia em tratamento medicamentoso

Dislipidemia não tratada

Presença de anticorpo antifosfolípide

Síndrome do anticorpo antifosfolípide

Obesidade

Fumo(tempo;cigarros/dia)

Outros

6) Índice de dano cumulativo (SLICC/ACR-DI) Após o 6ำ mês de diagnóstico de LES - Protocolo em anexo 3:

7) Índice de atividade da doença (SLEDAI) - Protocolo do SLEDAI 2K está em anexo 2:

8) Estadiamento Puberal e Menarca:

9) Medicamentos utilizados no momento:

\begin{tabular}{|l|l|l|}
\hline MEDICAMENTO & DOSE/DOSE ACUMULADA & TEMPO DE USO \\
\hline Prednisona & & \\
\hline Pulso de Metilprednisolona & & \\
\hline Azatioprina & & \\
\hline Micofenolato & & \\
\hline Metotretaxate & & \\
\hline Leflunomide & & \\
\hline Hidroxicloroquina & & \\
\hline Ciclofosfamida & & \\
\hline Anti-hipertensivos & & \\
\hline AAS & & \\
\hline Anticoagulante & & \\
\hline Estatina & & \\
\hline Ácido Fólico & & \\
\hline Cálcio & & \\
\hline Vitamina D & & \\
\hline
\end{tabular}


Outros medicamentos:

10) Dados Antropométicos:

\begin{tabular}{|l|l|l|l|l|l|}
\hline Dados & Peso & Estatura & IMC & $\begin{array}{l}\text { Classificação } \\
\text { IMC } \\
\text { (WHO 2007) }\end{array}$ & $\begin{array}{l}\text { Circuferência } \\
\text { da Cintura }\end{array}$ \\
\hline Valores & & & & & \\
\hline Unidades & $\mathrm{Kg}$ & metros & $\mathrm{kg} / \mathrm{m} 2$ & Percentil & $\mathrm{Cm}$ \\
\hline
\end{tabular}

11) Pressão arterial:

12) Atividade física

13) Infecção atual

14) Gestação

15) Dados laboratoriais:

\begin{tabular}{|l|l|l|l|}
\hline Análises & Unidade & Resultados & Valores de Referência \\
\hline Homocisteína & $\mu \mathrm{mol} / \mathrm{L}$ & & $<12$ \\
\hline Vitamina B12 & $\mathrm{pmol} / \mathrm{L}$ & & $128-648$ \\
\hline Folato & $\mathrm{ng} / \mathrm{mL}$ & & $3-17$ \\
\hline PCR & $\mathrm{mg} / \mathrm{L}$ & & 0,14 (mediana) \\
\hline TNF-a & $\mathrm{pg} / \mathrm{mL}$ & & 8,1 \\
\hline Colesterol total & $\mathrm{mg} / \mathrm{dL}$ & & $150-169$ (limítrofe) \\
\hline HDL & $\mathrm{mg} / \mathrm{dL}$ & & $100-129$ (limítrofe) \\
\hline LDL & $\mathrm{mg} / \mathrm{dL}$ & & $100-129$ (limítrofe) \\
\hline Triglicérides & $\mathrm{mg} / \mathrm{dL}$ & & \\
\hline Anti-DNA nativo & & & \\
\hline C-3 & & & \\
\hline C-4 & & & \\
\hline Cilindrúria & & & \\
\hline
\end{tabular}




\begin{tabular}{|l|l|l|l|}
\hline Hematúria & & & \\
\hline Proteinúria & & & \\
\hline Piúria & & & \\
\hline Hemoglobina & & & \\
\hline Hematócrito & & & \\
\hline Plaquetas & & & \\
\hline Leucócitos & & & \\
\hline
\end{tabular}

16) CIMT (medidas complexo intimo-média)

Data realização exame:

Responsável pela realização do exame

- carótida comum distal , 1-2 cm proximal à bifurcação carotídea: (três medidas com espessamento mínimo, médio e máximo)

- direita:

- esquerda: 
ANEXO 2:

Termo de Consentimento Livre e Esclarecido

$\begin{array}{ll}\text { Pesquisadores: } & \text { Priscila Beatriz de Souza Medeiros: Médica } \\ & \text { Luciana Martins de Carvalho: Médica } \\ & \text { Virgínia Paes Leme Ferriani: Médica }\end{array}$

Informações ao pais

Seu filho (a) está sendo convidado (a) a participar de uma pesquisa, ela se chama: "Avaliação de Aterosclerose Subclínica em Pacientes com Lúpus Eritematoso Sistêmico Juvenil"

O lúpus eritematoso sistêmico (LES) é uma doença autoimune crônica caracterizada por inflamação generalizada de vasos e tecido conjuntivo. Afeta principalmente indivíduos do sexo feminino em idade reprodutiva, e, em cerca de $15 \%$ dos casos, o diagnóstico é feito antes dos 18 anos de idade.

Nas últimas décadas, tem-se observado aumento na sobrevida dos pacientes com LES, decorrente principalmente do diagnóstico precoce e avanços no tratamento, predispondo esses pacientes a efeitos adversos a medicamentos e problemas futuros como as doenças cardiovasculares que se correlacionam com aterosclerose (placas de gordura nos vasos sanguíneos).

Por que este estudo está sendo feito?

Sendo o lúpus eritematoso sistêmico uma doença crônica, com alta taxa de morbimortalidade, em especial por doenças cardiovasculares, é de extrema importância o conhecimento e identificação dos fatores de risco para doença aterosclerótica em pacientes pediátricos brasileiros com lúpus objetivando a prevenção e tratamento precoces desse problema.

\section{Como será feito o estudo?}

Se vocês concordarem em participar do estudo, vamos perguntar, nos retornos de rotina, sobre o que aconteceu com seu filho (a), sua doença, e acompanharemos os exames de laboratório. Todas as informações clínicas e dos exames dos pacientes são em geral registradas no prontuário médico, e neste caso além do prontuário, como de rotina, o que vocês responderem, colocaremos também no computador dos pesquisadores.

Realizaremos a medida da pressão arterial, medidas de peso e altura, perguntas sobre hábitos de vida de seu filho (a) e faremos um ultrassom de carótida ( vaso do pescoço) e para ver sinais de aterosclerose em seu filho (a).

Existem riscos para participar do estudo?

Pode ser que consulta de seu filho (a) demore um pouco mais para o preenchimento dos questionários e talvez vocês precisem vir em um dia que não tem consulta, sendo previamente combinado com vocês.

Quais são os benefícios do estudo?

Se tivermos informações precoces sobre a aterosclerose de crianças e adolescentes que apresentam a mesma doença que seu filho (a), podemos atuar na prevenção e tratar precocemente esse problema, propiciando melhor qualidade de vida aos pacientes

Quem terá acesso aos dados da pesquisa?

O que seu filho (a) informar sobre a sua doença e seu exame físico, será registrado no Prontuário Médico e mantidos em segredo como rotina do Hospital das Clinicas da Faculdade de Medicina de Ribeirão Preto. As únicas pessoas que terão acesso às informações serão os médicos responsáveis por seu filho (a) e os pesquisadores que fazem parte deste projeto de pesquisa. Em nenhum momento durante a realização desse estudo a identidade de seu filho (a) será revelada. 
Quais serão as recompensas para a participação?

Seu filho (a) não terá nenhuma recompensa.

É obrigatória a minha participação?

Não. Se vocês decidirem agora ou mais tarde que não querem participar do projeto, estarão no seu pleno direito e não haverá nenhum prejuízo no tratamento atual ou futuro de seu flho (a) neste hospital.

Com quem devo falar se houver algum problema?

Se houver alguma queixa, você deve falar com a médica (Pesquisadora Responsável), ou se tiver queixa ou opinião sobre a pesquisa pode dirigir-se ao Comitê de Ética em Pesquisa (CEP) listado abaixo:

Profa Dra Luciana Martins de Carvalho

Profa Dra Virginia Paes Leme Ferriani

Dra Priscila Beatriz de Souza Medeiros

Hospital das Clínicas da Faculdade de Medicina de Ribeirão Preto

Departamento de Puericultura e Pediatria. Avenida Bandeirantes $3900,7^{\circ}$ andar, telefone (16)

36022476 e (16) 36022579 Ribeirão Preto -SP

e-mail: lucianamc2503@gmail.com.br

virginia.ferriani@gmail.com

priscy 01@hotmail.com.br

CEP: $\bowtie$ Comitê de Ética em Pesquisa do Hospital das Clínicas da FMRP-USP, Campus

Universitário; telefone (16) 3602 2228, Fax: (16) 36331144 e e.mail: cep@hcrp.fmrp.usp.br

1- Você foi convidado a fazer parte desta pesquisa. A pessoa encarregada do estudo vai explicar o projeto e após você poderá decidir se quer ou não participar.

2- Por favor, faça todas as perguntas que quiser, antes de decidir se seu filho (a) irá participar da pesquisa.

3- Se você decidir que seu filho (a) irá participar agora, mas depois decidir que você não quer mais participar, apenas diga ao responsável e isto não prejudicará de nenhuma forma o tratamento de seu filho (a).

4- Você receberá a folha de informações sobre a pesquisa para ler, guardar para se precisar ler novamente as informações em qualquer momento.

5- Em qualquer momento que houver queixas sobre a participação de seu filho (a) neste projeto, comunique-se com o responsável.

Você..

responsável por

pai, mãe ou

Após receber informações necessárias, concorda em participar do Projeto de Pesquisa "Avaliação de Aterosclerose Subclínica em Pacientes com Lúpus Eritematoso Sistêmico Juvenil", após receber as explicações necessárias. Afirma que leu e entendeu as explicações sobre a pesquisa.

Assinatura dos pais ou responsável:

Data: 
Assinatura do Paciente.

Data...

Assinatura do Pesquisador..

Data....... 
ANEXO 3:

Termo de Consentimento Livre e Esclarecido - ASSENTIMENTO

Pesquisadores: $\quad$ Priscila Beatriz de Souza Medeiros: Médica

Luciana Martins de Carvalho: Médica

Virgínia Paes Leme Ferriani: Médica

\begin{abstract}
Você está sendo convidado (a) a participar de uma pesquisa, ela se chama: "Avaliação de Aterosclerose Subclínica em Pacientes com Lúpus Eritematoso Sistêmico Juvenil"
\end{abstract}

O lúpus eritematoso sistêmico (LES) é uma doença autoimune crônica caracterizada por inflamação generalizada de vasos e tecido conjuntivo. Afeta principalmente indivíduos do sexo feminino em idade reprodutiva, e, em cerca de $15 \%$ dos casos, o diagnóstico é feito antes dos 18 anos de idade.

Nas últimas décadas, tem-se observado aumento na sobrevida dos pacientes com LES, decorrente principalmente do diagnóstico precoce e avanços no tratamento, predispondo esses pacientes a efeitos adversos a medicamentos e problemas futuros como as doenças cardiovasculares que se correlacionam com aterosclerose (placas de gordura nos vasos sanguíneos).

Por que este estudo está sendo feito?

Sendo o lúpus eritematoso sistêmico uma doença crônica, com alta taxa de morbimortalidade, em especial por doenças cardiovasculares, é de extrema importância o conhecimento e identificação dos fatores de risco para doença aterosclerótica em pacientes pediátricos brasileiros com lúpus objetivando a prevenção e tratamento precoces desse problema.

Como será feito o estudo?

Se você e seus pais concordarem em participar do estudo, vamos perguntar, nos seus retornos de rotina, sobre o que aconteceu com você, sua doença, e acompanharemos seus exames de laboratório. Todas as informações clínicas e dos exames dos pacientes são em geral registradas no prontuário médico, e neste caso além do prontuário, como de rotina, o que você responder, colocaremos também no computador dos pesquisadores.

Realizaremos a medida da pressão arterial, medidas de peso e altura, perguntas sobre seus hábitos de vida e faremos um ultrassom de carótida (vaso do pescoço) e para ver sinais de aterosclerose.

\title{
Existem riscos para participar do estudo?
}

Pode ser que a sua consulta demore um pouco mais para o preenchimento dos questionários e talvez você precise vir em um dia que não tem consulta, sendo previamente combinado com você e seus pais.

\section{Quais são os benefícios do estudo?}

Se tivermos informações precoces sobre a aterosclerose de crianças e adolescentes que apresentam a mesma doença que você, podemos atuar na prevenção e tratar precocemente esse problema, propiciando melhor qualidade de vida aos pacientes

\section{Quem terá acesso aos dados da pesquisa?}

O que você informar sobre a sua doença e seu exame físico, será registrado no Prontuário Médico e mantidos em segredo como rotina do Hospital das Clinicas da Faculdade de Medicina de Ribeirão Preto. As únicas pessoas que terão acesso às informações serão os médicos responsáveis por você e os pesquisadores que fazem parte deste projeto de pesquisa. Em nenhum momento durante a realização desse estudo a sua identidade será revelada.

Quais serão as recompensas para a participação?

Você não terá nenhuma recompensa. 
É obrigatória a minha participação?

Você tem direito de não participar do estudo. Se você decidir agora ou mais tarde que não quer participar do projeto, estará no seu pleno direito e não haverá nenhum prejuízo no seu tratamento atual ou futuro neste hospital.

Com quem devo falar se houver algum problema?

Se houver alguma queixa, você deve falar com a médica (Pesquisadora Responsável), ou se tiver queixa ou opinião sobre a pesquisa pode dirigir-se ao Comitê de Ética em Pesquisa (CEP) listado abaixo:

Profa Dra Luciana Martins de Carvalho

Profa Dra Virginia Paes Leme Ferriani

Dra Priscila Beatriz de Souza Medeiros

$\triangle$ Hospital das Clínicas da Faculdade de Medicina de Ribeirão Preto

Departamento de Puericultura e Pediatria. Avenida Bandeirantes $3900,7^{\circ}$ andar, telefone (16)

36022476 e (16) 36022579 Ribeirão Preto -SP

e-mail: lucianamc2503@gmail.com.br

virginia.ferriani@gmail.com

priscy 01@hotmail.com.br

CEP: $\bowtie$ Comitê de Ética em Pesquisa do Hospital das Clínicas da FMRP-USP, Campus

Universitário; telefone (16) 3602 2228, Fax: (16) 36331144 e e.mail: cep@hcrp.fmrp.usp.br

1- Você foi convidado a fazer parte desta pesquisa. A pessoa encarregada do estudo vai explicar o projeto e após você poderá decidir se quer ou não participar.

2- Por favor, faça todas as perguntas que quiser, antes de decidir se irá participar da pesquisa.

3- Se você decidir que irá participar agora, mas depois decidir que você não quer mais participar, apenas diga ao responsável e isto não prejudicará de nenhuma forma o seu tratamento.

4- Você receberá a folha de informações sobre a pesquisa para ler, guardar para se precisar ler novamente as informações em qualquer momento.

5- Em qualquer momento que houver queixas sobre a sua participação neste projeto, comunique-se com o responsável.

Você.

concorda em

participar do Projeto de Pesquisa "Avaliação de Aterosclerose Subclínica em Pacientes com Lúpus Eritematoso Sistêmico Juvenil", após receber as explicações necessárias. Afirma que leu e entendeu as explicações sobre a pesquisa.

Assinatura do Paciente.

Data.......

Assinatura do Pesquisador

Data... 
ANEXO 4: SLEDAI - 2k

SISTÊMICO 2000 (SLEDAI-2K) ${ }^{20}$.

\begin{tabular}{|c|c|c|}
\hline MANIFESTAÇÃO & DEFINIÇĀO & PESO \\
\hline CONVULSÃO & EXCLURR CAUSAS METABÓLICAS, NNECCIOSAS OU DROGAS. & 8 \\
\hline PSICOSE & 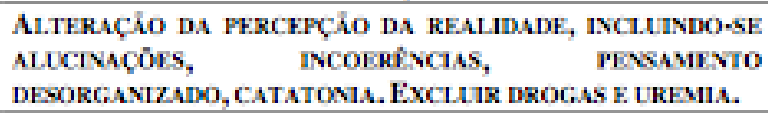 & 8 \\
\hline $\begin{array}{l}\text { SINDROME } \\
\text { ORGÃNICO-CEREBRAL }\end{array}$ & 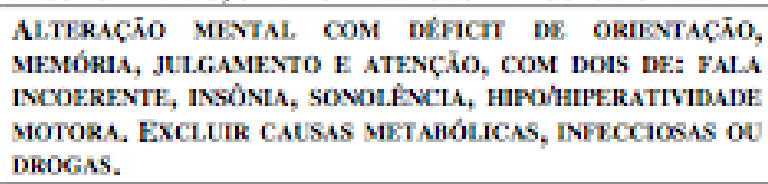 & 8 \\
\hline ALTERACOOES VISUAIS & $\begin{array}{l}\text { CORPOS CETOIDES OU HEMORRAGLAS RETINLANAS, } \\
\text { EXSLDATOS OU HFMARROGIAS DE CORÓDE, NFL RITE OPTICA. } \\
\text { EXCLUIR CALSAS INFECCIOSAS, DROGAS OU HIPERTENSÃO. }\end{array}$ & 8 \\
\hline $\begin{array}{l}\text { ALTERACOES DE NERVOS } \\
\text { CRANIANOS }\end{array}$ & NELROPATLA MOTORA OU SFNSORLAL. & 8 \\
\hline CEFALELIA & $\begin{array}{l}\text { PERSISTR.NTE, INTENSA, THPO ENXNQUECA, Nĩo RESPONSIVA } \\
\text { AOS ANALCÉ́SICOS NARCótICOS. }\end{array}$ & 8 \\
\hline $\begin{array}{l}\text { ACIDENTE } \\
\text { CEREBRAL }\end{array}$ & EXCLUIR ATEROSCLEROSE. & 8 \\
\hline VASCULITES & $\begin{array}{l}\text { ULLCERAS, GANGRENA, NODULOS DOLOROSOS, INFARTO SUB } \\
\text { OU PFRIUNGUEAL, BIÓPSLA OU ANGIOGRAFLA COMPATIVEL. }\end{array}$ & 8 \\
\hline ARTRITES & DUAS OU MAIS ARTICULAÇÕES. & 4 \\
\hline MIOSITES & $\begin{array}{l}\text { FRAQUEZA OU DOR MUSCULAR PROXIMAL COM: ELEVAC̄̃O } \\
\text { DE ENZMMAS MUSCULARES, ELTROMHOGRANA OU RIÓSIA } \\
\text { COMPATIVEIS. }\end{array}$ & 4 \\
\hline CILINDROS URINÄRIOS & GRANULOSOS OU HEMATICOS. & 4 \\
\hline HEMATÚRIA & $\begin{array}{l}\text { MANOR QUE } 5 \text { IEMACIAS POR CAMTO. EXCLUTR CÁLCULOS } \\
\text { OU INRECCOOES. }\end{array}$ & 4 \\
\hline PROTEINÚRIA & $\begin{array}{l}\text { MANOR QUE 0,5G/DLA DE NICIO RECENTE OU AUMENTO } \\
\text { MALOR QUE 0,5G/DA EM RELACAO AOS VALORES } \\
\text { ANTERLORES. }\end{array}$ & 4 \\
\hline LEUCOCITÚRIA & $\begin{array}{l}\text { MAIOR QUE } 5 \text { LEUCOCTTOS POR CAMTO. EXCUUTR } \\
\text { INFECCOOEF. }\end{array}$ & 4 \\
\hline ERITEMA MALAR & $\begin{array}{l}\text { ERTTEMA SOBRE AS FMINÉNCIAS MALARES POUPANDO OS } \\
\text { SULCOS NASOLABLAS }\end{array}$ & 2 \\
\hline ALOPÉCIA & $\begin{array}{l}\text { PFrod ANORMAI. DE CABFI.OS, DE. FORMA LOCALIZADA OU } \\
\text { DIFUSA. }\end{array}$ & 2 \\
\hline ÚLCERAS DE MUCOSAS & ÚLCERAS ORAIS OU NASAIS. & 2 \\
\hline PLEURITE & $\begin{array}{l}\text { DOR PLLURITICA, COM ATRTTO OU DERRAME PLEURAL, OU } \\
\text { ESPESSAMENTO PIEURAL. }\end{array}$ & 2 \\
\hline PERICARDITE & $\begin{array}{l}\text { DOR PERICARDACA COM ATRTTO, DERRAME OU } \\
\text { EL.RTROCARDIOGRAMA OU ECOCARDOGRAMA COMPATIVEAS. }\end{array}$ & 2 \\
\hline $\begin{array}{l}\text { DIMINUICÃO } \\
\text { COMPLEMENTO }\end{array}$ & DIMINUÇ̄̃o DE C3, C4 OU CH50. & 2 \\
\hline ANTI-DNA & PRESENÇ. & 2 \\
\hline FEBRE & TEMPFRATURA MAIOR OUE 38'C. EXCL.UIR INFECÇÕFS. & 1 \\
\hline PLAQUETOPENIA & MFNOR QUE 100 D00 PLAOUETAS POR MM⒊ & 1 \\
\hline LEUCOPENLA & MENOR QUE 3.000 LEUCOCITOS POR MM'. EXCUUR DROGAS. & 1 \\
\hline TOTAL & & \\
\hline
\end{tabular}

Obs: valido para manifestą̧̋̌es de início recente (até dez dias anteriores à avaliaçăo) 
ANEXO 5: SLICC/ACR-DI

DeFINIC̨Ão doS ESCORES DO SLICC/ACR-DI $1{ }^{(16,17)}$

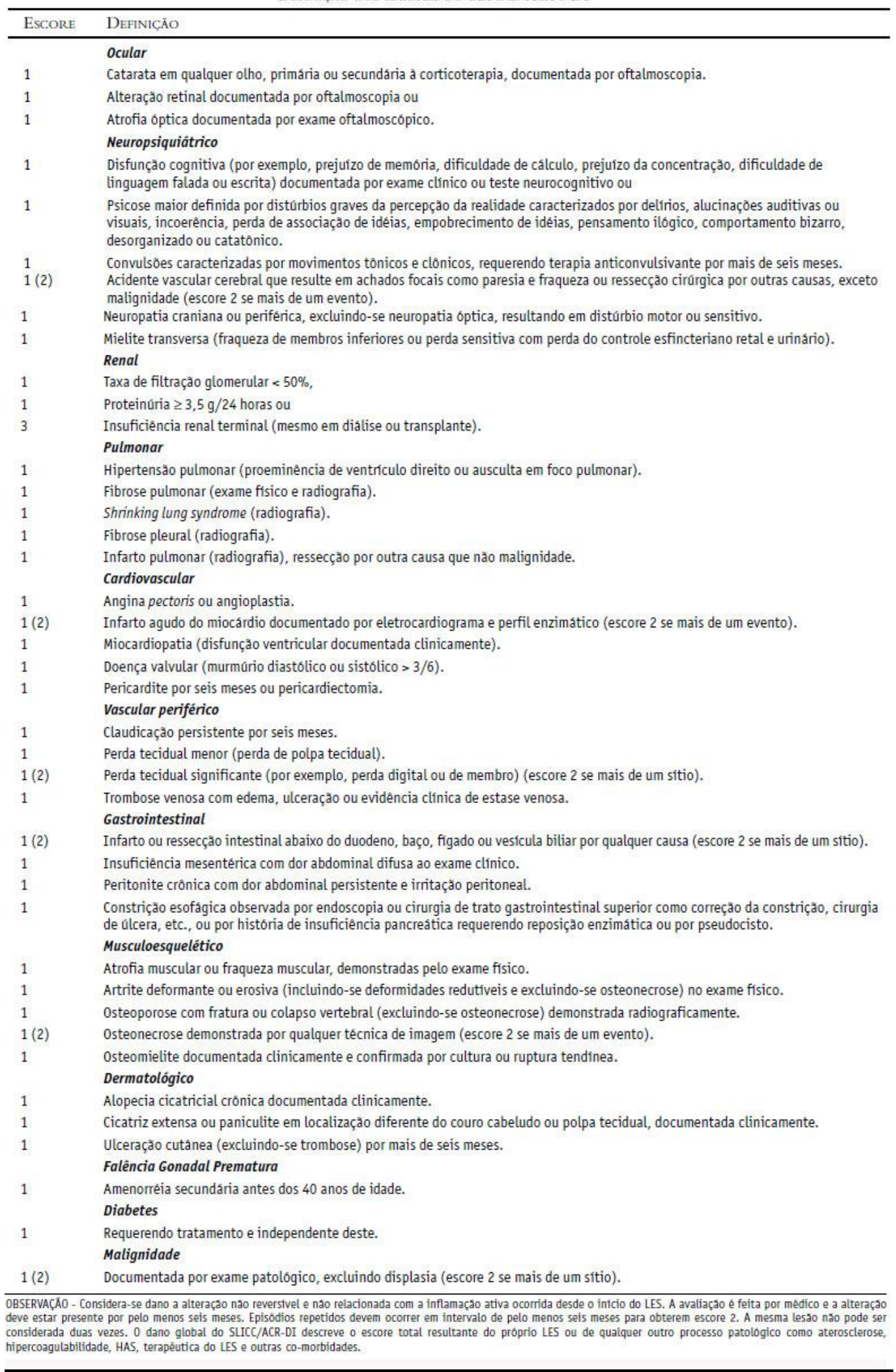

